\title{
Medical Worker Migration and Origin-Country Human Capital: Evidence from
} U.S. Visa Policy

\author{
Paolo Abarcar, Mathematica* \\ Caroline Theoharides, Amherst College ${ }^{\dagger}$
}

September 2021

We exploit changes in U.S. visa policies for nurses to measure the origin-country human capital response to international migration opportunities. Combining data on all migrant departures and postsecondary institutions in the Philippines, we show that nursing enrollment and graduation increased substantially in response to greater U.S. demand for nurses. The supply of nursing programs expanded. Nurse quality, measured by licensure exam pass rates, declined. Despite this, for each nurse migrant, 9 additional nurses were licensed. New nurses switched from other degree types, but graduated at higher rates than they would have otherwise, increasing the human capital stock in the Philippines. JEL: O15, F22, J61.

We are extremely grateful to the Commission on Filipinos Overseas (CFO) and the Commission on Higher Education (CHED) for access to the data. We thank Achyuta Adhvaryhu, Kate Ambler, Brian Baisa, Emily Beam, John Bound, Eric Edmonds, Susan Godlonton, Jamie Gracie, Joshua Hyman, Brian Jacob, Seema Jayachandran, Kartini Shastry, Katharine Sims, Jeffrey Smith, and Dean Yang for their comments, and conference and seminar participants at 2021 NBER SI Development, NEUDC 2017, Barcelona Summer Forum Migration 2017, Pac-Dev 2017, Migration and Development Conference 2018, APPAM 2018, Australian National University, Boston University, Clark University, IFPRI, NOVAFRICA, RPI, Tufts, University of Connecticut, University of Michigan, University of Notre Dame, and Williams. Alejandra Castro, Juanita Jaramillo, Cristine Ong, and Emily Young provided excellent research assistance. 


\section{Introduction}

Many developed countries, including the United States, face a shortage of health care workers, particularly nurses. To fill these gaps, these countries often recruit foreign-born nurses (Cortes and Pan, 2014). Despite the many benefits of migration for human capital formation (Yang, 2008; Dinkelman and Mariotti, 2016; Theoharides, 2018; Khanna et al., 2021), a long theoretical literature in economics asserts that recruitment of high-skilled workers leads to a scarcity, or brain drain, of these professionals in the country of origin (Bhagwati and Hamada, 1974; Bhagwati and Rodriguez, 1975; Docquier et al., 2008). In the case of health care workers, their departure may contribute to poor health outcomes for the local population (Bhargava and Docquier, 2008). In contrast, alternative models of human capital formation propose that emigration and high prospective returns to skill in foreign countries lead to skill acquisition, or brain gain, at home (Stark et al., 1997; Mountford, 1997; Beine et al., 2001). Despite the theoretical prevalence of the brain drain and brain gain debate, little causal evidence exists, particularly in the context of health care professionals.

In this paper, we exploit a pair of plausibly exogenous migration policy changes to examine the effect of demand for foreign-born health care workers on the stock of health care workers and educated labor in the country of origin. In 2000, the U.S. dramatically expanded the availability of visas for foreign nurses and their families, but in 2007, suddenly reduced visa availability back to pre-2000 levels. The 2000 expansion altered the migration prospects of many nurses, especially those from the Philippines, which is the world's largest supplier of foreign nurses and supplies approximately $40 \%$ of foreign-born nurses in the U.S. (Cortes and Pan, 2015; Huang, 2020). We examine the effects of the abrupt expansion and subsequent contraction of nursing visas to the U.S. on postsecondary education decisions in the Philippines. We measure 
effects on both the demand for and supply of education, by looking at changes in postsecondary enrollment and graduation, the number of postsecondary nursing programs, and nursing licensure exam pass rates.

We use an event study methodology to compare educational outcomes in historically high versus low nurse migrant-origin provinces in the Philippines before and after the policy changes. This approach leverages migrant networks as an important determinant of where and in what occupation migrants work (Munshi, 2003; Theoharides, 2018). Due to these networks, not all geographic areas of the Philippines were affected equally by the policy changes, and the changes in nursing visa availability had a larger effect in provinces that historically specialized in nurse migration. To help address the concern that historically high and low nurse migration provinces may differ in important ways, such as access to health care or nursing education, we include a set of baseline controls, most notably domestic nurses per capita in the province, interacted with year fixed effects. This control allows us to isolate the impact of foreign, as opposed to domestic, demand for nurses. We find no evidence that educational attainment was trending differentially in high relative to low nurse migration provinces before the policy changes. We use a new administrative dataset that includes the province of origin and country of destination for all nurse migrants. We match these province-year-level migration data with administrative records on enrollment, graduation, and nurse licensure exam pass rates for the universe of postsecondary institutions in the Philippines.

We show that nurse migration to the U.S. rose substantially in high relative to low nurse migration provinces following the visa expansion in 2000, and then fell suddenly in 2007 when visa availability contracted. Postsecondary enrollment and graduation in nursing programs increased dramatically in response to greater opportunities to work in the U.S, and then returned 
to near pre-2000 levels following the visa contraction. While women account for $76 \%$ of nursing students in the Philippines, the enrollment and graduation responses were only somewhat smaller for men, and thus in percent terms, substantially larger than for women. Leveraging the two opposite-signed policy shocks improves identification beyond a standard differences-indifferences analysis by allowing for a falsification check of alternative hypotheses for the increases in education post-2000. The inverted u-shaped pattern of results that we find is challenging to attribute to concerns about differential province-specific trending by high versus low nurse migration areas.

The supply of nursing programs quickly expanded to accommodate the increase in demand for nursing education. The supply response was concentrated among private schools, largely through nursing programs opening at existing private institutions, rather than the opening of new nursing institutions. The enrollment response was driven by provinces with a greater elasticity of the supply of schooling, as measured by the fraction of private institutions without nursing programs. Marginal nursing graduates passed the Philippine Nursing Licensure Exam at a lower rate, but despite this lower pass rate, the increase in licensed nurses far exceeded the number of departing nurses: for each additional nurse who went abroad, approximately 9 new nurses were licensed in the Philippines. Our results imply that increases in nurse migration from the Philippines actually increased the number of nurses in the country, indicating a brain gain of health care workers.

We examine the effects of the policy changes on enrollment and graduation in other degree programs to determine whether increased migration prospects for nurses spurred new students to obtain postsecondary education or, instead, caused students to shift from other fields of study. While these results are relatively imprecise, they suggest that nursing enrollees 
primarily switched to nursing from other fields. This result helps to explain our large enrollment effects by clarifying that we are not estimating the elasticity of overall education to migration opportunities. Rather, the policy changes examined here were occupation-specific, and individuals might be more elastic in switching between fields of study than making the extensive margin decision to enroll in higher education. Further, while the probability of securing a visa is low, the returns to U.S. nurse migration are substantial: nurses in the U.S. earn approximately 13 times more than college-educated workers in the Philippines and receive legal status for their families in the U.S. ${ }^{1}$

While the enrollment effects were driven primarily by students switching from other degree types, students persisted to graduation at higher rates, leading to an overall increase in college graduates in the Philippines. We show that most nursing graduates who never migrated on a U.S. nursing visa did not find other migration opportunities, though many appeared to find nursing jobs in the Philippines. For other nursing graduates, these nursing jobs were not an option because they did not pass the licensure exam. If individuals acted rationally when making their education decision, then they were ex ante better off regardless of their labor market outcomes. However, their choice may not have been rational if they were, for instance, misinformed about the probability of migration. Additionally, individuals switching degree type could have created negative externalities for the Philippines if this led to labor market shortages in other important fields. While understanding the potential welfare implications is beyond the scope of this paper, we aim to provide a well-identified and convincing estimate of the partial

\footnotetext{
${ }^{1}$ Mean annual wages during the expansion period for a nurse in the U.S. were USD $\$ 56,940$ (U.S. Bureau of Labor Statistics), while mean purchasing-power parity adjusted wages of college-educated labor in the Philippines were USD \$4,339 (Philippine Labor Force Survey).
} 
equilibrium effect of the U.S. visa policy changes.

We contribute to the literature on the brain drain and brain gain debate by providing the first causal microeconomic estimates of the effect of medical worker migration on educational attainment in migrant-origin countries. Our results provide further support for models of human capital formation where emigration and high prospective returns to skill in foreign countries lead to skill acquisition at home (Stark et al., 1997; Mountford, 1997; Beine et al., 2001) rather than human capital depletion (Bhagwati and Hamada, 1974; Bhagwati and Rodriguez, 1975).

Previous empirical evidence is mixed. ${ }^{2}$ On the macro side, some studies analyzing cross-country data find overall evidence of brain drain across the developing world (Docquier et al., 2008), while others find evidence of brain gain (Beine et al., 2008), including for medical workers (Clemens, 2007). On the micro side, several natural experiments provide evidence of brain gain in both low-skilled (Batista et al., 2012; Dinkelman and Mariotti, 2016; Shrestha, 2017; Theoharides, 2018) and high-skilled (Chand and Clemens, 2019; Khanna and Morales, 2021) settings.

These studies focus on the overall enrollment response across all fields in primary, secondary, or postsecondary education. Two notable exceptions are Chand and Clemens (2019), who find differential impacts on enrollment in fields awarded visa points to Australia versus not, and Khanna and Morales (2021), who examine skill-specific migration by looking at the Indian and U.S. IT sectors and demand for computer science degrees. When migration opportunities are for highly specialized migrants, the supply of postsecondary education may not be able to respond as readily due to the skill-specific nature of the training. Similar to Khanna and Morales (2021), we document that brain gain is possible in a specialized field, but we focus on health

\footnotetext{
${ }^{2}$ See review articles: Gibson and McKenzie (2011) and Docquier and Rapoport (2012).
} 
care, where the supply of training is thought to be particularly sticky (Docquier and Marfouk, 2006; Gibson and McKenzie, 2011). Beyond documenting an increase in educational attainment, we provide the first explicit evidence of increases in the supply of postsecondary education in the brain drain versus gain literature.

More broadly, our estimates provide an empirical test of human capital theory (Becker, 1962; Schultz, 1961) by examining the response of educational investment to an exogenous increase in the returns to education. Large, plausibly exogenous changes to the returns to education are rare, and our paper adds evidence to the literature of well-identified tests of human capital theory, such as Jensen (2010), Shastry (2012), Abramitzky and Lavy (2014), and Kuka et al. (2020), in a migration setting.

Our contributions are in large part due to the unique nature of our administrative data. In addition to facilitating an analysis of the supply of postsecondary schooling and nurse quality, our data measure skilled migrant flows more accurately than most previous studies, which typically measure changes in the stock of educated individuals in the destination country to estimate skilled migration from a given origin country. Such calculations may overstate brain drain if many individuals acquire education after they migrate. For example, Özden and Philipps (2015) show that almost half of African-born doctors were trained outside of their birth country. Further, studies that use origin-country survey data will miss the migration of entire households, which is common for skilled migrants. Our data overcome both of these concerns because they include the universe of all permanent migrant departures as well as each migrant's field of work and educational attainment.

The migration policy changes we examine in this paper provide a unique opportunity to examine the debate about brain drain versus brain gain among health care professionals. Key to 
our findings of brain gain is that the supply of schooling was able to respond to accommodate increased demand. Such a response may not be possible in all contexts, for example in subSaharan Africa, where the postsecondary education system may not expand as readily in response to increased demand (Bhargava and Docquier, 2008; Gibson and McKenzie, 2011). Yet, our finding that the supply response was primarily due to existing institutions adding nursing programs suggests that countries with an established system of postsecondary institutions may find it possible to meet foreign demand by adding new programs, which may require less new infrastructure and present fewer hurdles than opening new institutions. While our results may not generalize to all cases, they provide some evidence that for low- to middleincome countries seeking to use skilled migration as a development tool, the human capital stock and the domestic supply of health care workers will not be depleted.

\section{Background}

With over $11 \%$ of its population living abroad, the Philippines is one of the top migrant-origin countries globally, in large part due to the facilitation of migration as a development strategy. ${ }^{3}$ It

\footnotetext{
${ }^{3}$ Numerous other developing countries in Asia facilitate labor migration as a development strategy. In 1977, the government of Kerala, India set up the Overseas Development and Employment Promotion Consultants (ODEPC) to facilitate overseas migration; it continues to operate today. India is the second-highest migrant origin country for nurses globally (Oda et al., 2018). Bangladesh formed the Bureau of Manpower, Employment and Training in 1976 to help workers migrate as part of its development plan. Sri Lanka developed the Bureau of Foreign Employment in 1985, and asked ILO in 2008 to formulate a National Labour Migration Policy for Sri Lanka with revisions in 2015 (ILO, 2020). The 2008 International Migration Outlook Sri Lanka highlights the recruitment of nurses.
} 
is the world's top origin country for foreign nurses (Huang, 2020), including to OECD countries (OECD, 2007). The U.S. is the most common destination for Filipino migrant nurses, and departures to the U.S. were a major driver of changes in Filipino nurse migration between 1990 and 2014 (Figure 1a). Relative to working in the Philippines, salaries are almost 13 times higher in the U.S. Family members of nurse migrants receive legal status, which is not the case for many of the other countries to which Filipino nurses migrate or for most lower-skilled migration opportunities. The origins of Filipino nurse migration can be traced to the U.S. colonial period in the Philippines (1898-1946), as detailed in Choy (2006). During this period, the U.S. established an Americanized training hospital system, with emphasis on nursing education. Nursing schools resembled institutions in the U.S. in terms of curriculum, training, and culture.

Migrant networks are an important determinant of migration patterns in the Philippines (Theoharides, 2018), and such networks appear even more critical for nurse migration (Choy, 2006). As a result of these migrant networks, certain provinces are more likely to send nurses to the U.S. Appendix Table 1 lists the 20 provinces with the highest rates of nurse migration to the U.S. in 1990, the first year of our data. The inclusion of several provinces in this list is unsurprising, given the history of Filipino migration to the U.S. Today these provinces remain more connected to the U.S. as a destination for migrants. More details about the background of Filipino nurse migration and these networks can be found in Online Appendix A.

Filipino nurses most commonly enter the U.S. market through employment-based (EB) visas, which allow individuals and their family members to permanently reside in the U.S. Opportunities to migrate under temporary work permits for nurses are generally limited (DHS, 2008). For an EB visa, a worker must be sponsored by an employer but is not obligated to remain with the employer. U.S. immigration law provides 140,000 EB visas annually for workers, plus 
additional visas for spouses and children (Jasso et al., 2010). Nurses belong to the thirdpreference category for EB visas, but since the U.S. Department of Labor designates nursing as a "Schedule A" occupation, meaning that there is a shortage of U.S. workers, they typically experience a shorter visa processing time than other skilled professionals in this category.

Despite this special preference category, it is difficult to migrate to the U.S. as a nurse from the Philippines. Immigration rules stipulate that no country may be allocated more than $7 \%$ of the total number of immigrant visas per fiscal year. Since visa applications from the Philippines far exceed the $7 \%$ per-country limit each year, wait times are often several years. Foreign nurses must also pass the National Council Licensure Examination (NCLEX) and an English proficiency test (TOEFL), as well as their home country's licensure examination to practice as registered nurses in the U.S. (Aiken, 2007). In the Philippines, nurses must have a four-year bachelor's degree in nursing to take the local licensure exam.

Several changes in U.S. immigration policy affected nurse migration from the Philippines in the 2000s. The American Competitiveness in the $21^{\text {st }}$ Century Act of 2000 (AC21) loosened per country limits in visa allocations when part of the 140,000 annual employment-based visas would otherwise go unused. This immediately allowed the issuance of visas to oversubscribed countries like China, Mexico, India, and the Philippines. AC21 also made immediately available 130,137 visas that had gone unused in 1999 and 2000 to EB visa applicants (Jasso et al., 2010). In addition, the Real ID Act of 2005 allocated 50,000 unused visas from 2001-2004 to Schedule A occupations. These policies caused nurse migration from the Philippines to the U.S. to rise from fewer than 2,000 nurse migrants in 2000 to approximately 7,000 in 2006 (Figure 1a).

Then, in February 2007, the 180,137 unused visas had all been claimed, and processing of Schedule A visas suddenly stopped. The number of visas processed for Filipino nurses fell to 
approximately 2,000 and never returned to the level it reached during the expansion. This sudden decline was unanticipated, and even U.S. immigration officials reported to Congress that they could not have predicted this abrupt change (USCIS, 2007). These visa policy changes did not affect non-nurses attempting to migrate from the Philippines. Nurse migration to other destinations remained essentially unchanged during the expansion period (Figure 1a).

With such high rates of nurse migration, the Philippines provides a compelling example of where one might anticipate a shortage of domestic nurses. Indeed, Filipino policymakers expected as much when nurse migration increased in response to the U.S. visa expansion in 2000. "Sadly, this is no longer brain drain, but more appropriately, brain hemorrhage of our nurses," remarked the former Secretary of the Department of Health, Dr. Jaime Galvez-Tan. "Very soon, the Philippines will be bled dry of nurses." (Asia Times, 2003).

Despite this concern, postsecondary enrollment and graduation data from the Philippine Commission on Higher Education (CHED) suggest an opposite outcome. Following the increase in U.S. visa availability, total four-year enrollment in nursing programs rose from 90,000 in 2000 to over 400,000 in 2006, before declining again in 2007 (Figure 1b). The number of new nursing graduates shows a similar pattern, though with a four-year lag due to the time it takes to complete a nursing degree. ${ }^{4}$ The number of graduates grew slowly during 2003 and 2004 before rapidly increasing until 2009. In 2010, 4 years after the contraction of visas, graduates declined. (Figure 1c). Nurse migrants to the U.S. are a small fraction of the number of new nursing graduates. This suggests that increased demand for nurses from abroad may not have caused a drain on human resources, but rather increased the supply of nurses remaining in the Philippines.

\footnotetext{
${ }^{4}$ Note that even with a $100 \%$ graduation rate, graduation should be one quarter the size of enrollment, because enrollment includes all four years of postsecondary education.
} 


\section{Data}

We use a new administrative dataset from the Commission on Filipinos Overseas (CFO) on all permanent migrant departures from the Philippines from 1990 to 2013. CFO is a government agency responsible for registering all permanent emigrants before they depart and strengthening ties with the diaspora. Our dataset includes demographics, place of birth, usual address, country of destination, education, course of study, and profession for all individuals who migrated on a permanent visa. As a result, we can accurately measure the number of skilled professionals, including nurses, leaving each Philippine province annually. To calculate province-year level nurse migration rates, we divide the number of nurses by the working-aged (18-60) population in each province-year. We define nurses as those who have obtained a nursing degree or whose usual work is as a professional nurse.

We obtained administrative data on postsecondary enrollment, graduation, and number of nursing programs from 1991 to 2013 from the Commission on Higher Education (CHED). The data include annual school-level counts of enrollees and graduates, disaggregated by program of study. The enrollment counts include students in all four years of college. ${ }^{5} \mathrm{We}$ aggregate these data at the province-level and calculate rates of enrollment and graduation for nurses and other disciplines by dividing by the college-aged population (18-22) in each province. We also calculate the number of nursing programs in each province-year.

We collected data on the number of examinees and passers on the Philippine Nursing Licensure Exam (NLE) by institution between 1990 and 2016 from the Philippine Professional Regulation Commission (PRC). A nursing graduate must pass the NLE in order to practice nursing in the Philippines or to apply for jobs abroad, and individuals must have a bachelor's in

\footnotetext{
${ }^{5}$ Unfortunately, enrollment counts by grade of study are not available in most years.
} 
nursing to take the exam. The exam is offered two times per year. We aggregate institution-level data on examinees and passers to create province-year-level examination and pass rates. More detail on all datasets are in Online Appendix B.

Appendix Table 2 presents summary statistics overall and by high and low nurse migration provinces. We identify high (low) nurse migration provinces as those with above (below) median U.S. nurse migration rates at baseline (1990). Our sample includes 74 provinces, which are defined to use consistent geographic boundaries over the sample period. ${ }^{6}$ Panel A shows summary statistics for the full sample period. The average province has 75 total migrants and 3.9 nurse migrants per 100,000 working-aged individuals. The average province-level postsecondary enrollment rate out of the college-aged population is $25.02 \%$, while the enrollment rate in nursing programs is $1.80 \%$. Total and nurse graduation rates are on average $4.43 \%$ and $0.42 \%$ of the province's college-aged population, respectively. Provinces have an average of 4.39 institutions offering nursing degrees, the majority being private institutions. On average, $0.53 \%$ of the college-aged population takes the NLE each year, while $0.24 \%$ passes the exam. Panel B shows means for our outcomes of interest prior to the U.S. visa policy changes. High nurse migration provinces have higher rates of migration, postsecondary enrollment, graduation, and nursing programs in the pre-period. Our analysis includes province fixed effects to account for fixed differences between high and low nurse migration provinces. We address other possible concerns about endogeneity stemming from these differences in Section 4.

\footnotetext{
${ }^{6}$ We treat the four districts of Metro Manila as one province since students commonly travel within the metro area for postsecondary education.
} 


\section{Empirical Strategy}

To identify the causal effect of U.S. demand for Filipino nurses on human capital accumulation in the Philippines, we exploit the two sudden and opposite-signed shocks to visa policy that expanded and then restricted nurse migration to the U.S. While the aggregate national changes over time in nurse migration, nursing degree enrollment, and graduation presented in Section 2 provide suggestive evidence about the impacts of the U.S. visa policy changes, we isolate the causal impacts of the policy changes from other factors changing over time by exploiting the importance of migrant networks as determinants of international migration patterns (Munshi, 2003; Theoharides, 2018). This is based on the idea that provinces that historically had a larger flow of nurse migrants to the U.S. should be disproportionately exposed to the policy changes compared to provinces that had a smaller flow of nurse migrants at baseline. Our empirical strategy designates provinces with high baseline nurse migration rates as the treatment group and provinces with low baseline nurse migration rates as the control group. ${ }^{7}$

We estimate the following event study equation:

$$
Y_{p t}=\sum_{\tau \neq 1999} \beta_{\tau} H i g h_{p, 1990} D_{t}^{\tau}+X_{p 0} \gamma_{t}+\alpha_{p}+\gamma_{t}+\varepsilon_{p t}
$$

where $Y_{p t}$ is a measure of nurse migration or education in province $p$, year $t . \operatorname{High}_{p, 1990}$ is a binary variable equal to one for provinces with above median nurse migration in 1990. $D_{t}^{\tau}$ is a binary variable equal to one if the year of observation $t$ equals the specific year, $\tau$. We omit the

\footnotetext{
${ }^{7}$ Appendix Figure 1 shows the baseline U.S. nurse migration rates. All results are robust to using the continuous baseline U.S. nurse migration rate as the treatment intensity variable (Appendix Table 7 and Appendix Figure 2). We prefer the binary specification since the non-linearities shown in Appendix Figure 1 place more weight on outliers with the continuous treatment.
} 
interaction term in 1999 (the year prior to the visa expansion). $X_{p 0} \gamma_{t}$ are baseline province characteristics interacted with year fixed effects, $\gamma_{t}$. These allow for time-varying effects of prepolicy characteristics that are correlated with both the variable High and our outcomes over the sample period. In particular, to isolate variation in the responsiveness of nursing education to U.S. demand shocks, we control for baseline province-level domestic nurses per capita interacted with year fixed effects. ${ }^{8}$ This control alleviates concerns that differential impacts of changes in domestic demand for nurses could bias our results. Province fixed effects, $\alpha_{p}$, and year fixed effects, $\gamma_{t}$, account for province-specific and year-specific omitted variables, respectively. Standard errors are clustered at the province level.

The $\beta_{\tau}$ 's capture the differential changes in outcomes by year for high versus low nurse migration provinces relative to the omitted year, 1999. The $\beta_{\tau}$ 's after 2000 measure the effect of visa expansion, while the $\beta_{\tau}$ 's after 2007 measure the effect of visa contraction, allowing the effect of each policy on our outcomes of interest to evolve flexibly. The $\beta_{\tau}$ 's prior to 2000 provide evidence on whether our outcomes were changing differentially in high versus low nurse migration provinces prior to the policy change. In order to interpret our estimates as causal, these coefficients should be small and statistically insignificant.

Our identification strategy is similar in spirit to a shift-share design. A recent literature has directed scrutiny at the necessary assumptions for causal identification using such strategies (Adao et al., 2019; Borusyak et al., 2020; Goldsmith-Pinkham et al., 2020). In our case, given

\footnotetext{
${ }^{8}$ Additionally, $X_{p 0} \gamma_{t}$ includes baseline values for the average female employment rate, the average male employment rate, the average age in the province, and the fraction female. We calculate all controls from the 1990 Philippine Census.
} 
the use of shares from a single industry (nursing) and the presence of a pre-period, the empirical strategy reduces to conventional difference-in-differences, and we can test the plausibility of the identifying assumption in the standard ways (Borusyak et al., 2020, pg. 23; Goldsmith-Pinkham et al., 2020). We discuss falsification exercises below to argue for the validity of the identifying assumption. Further, we use a two-way fixed effects design (TWFE), and while treatment timing is simultaneous in our case rather than staggered, the inclusion of province-specific covariates times year fixed effects means that the properties of conventional difference-in-differences break down (Borusyak et al., 2021). To address this, we estimate all of our main results using the imputation estimator by Borusyak et al. (2021). All results are robust to the use of this estimator, and the event study figures are included in Appendix Figure 3.

We also estimate a pooled event study model, which reduces the number of estimated parameters and thus allows for easier interpretability and increased statistical precision:

$$
\begin{aligned}
& Y_{p t}=\beta^{\text {postexp }} \mathrm{High}_{p, 1990} 1\left(t \geq t_{2000}^{*}\right)+\beta^{\text {trendexp }} \mathrm{High}_{p, 1990} 1\left(t>t_{2000}^{*}\right)\left(t-t_{2000}^{*}\right) \\
& +\beta^{\text {postcon }} \mathrm{High}_{p, 1990} 1\left(t \geq t_{2007}^{*}\right)+\beta^{\text {trendcon }} \mathrm{High}_{p, 1990} 1\left(t>t_{2007}^{*}\right)\left(t-t_{2007}^{*}\right) \\
& +\beta^{\text {trend }} \mathrm{High}_{p, 1990}\left(t-t_{1999}^{*}\right)+\alpha_{p}+\gamma_{t}+X_{p 0} \gamma_{t}+\varepsilon_{p t}
\end{aligned}
$$

where $t_{2000}^{*}$ and $t^{*} 2007$ represent the years of the expansion and contraction of visas, respectively. The coefficients $\beta^{\text {postexp }}$ and $\beta^{\text {postcon }}$ represent the change in outcomes in high relative to low nurse migration provinces in the years of the visa expansion and visa contraction, respectively. $\beta^{\text {trendexp }}$ and $\beta^{\text {trendcon }}$ capture delayed effects and can be interpreted as annual changes in outcomes in high relative to low nurse migration provinces after the initial year of the policy. $\beta^{\text {trend }}$ estimates the changes in outcome variables in high relative to low nurse migration provinces prior to the policy change in 2000 , and $\beta^{\text {trend }} \neq 0$ would suggest differential trending in high versus low nurse provinces prior to the policy change. All other variables are defined as 
in equation 1. All of our event-study figures show the event-study coefficients and standard errors from equation 1 with the results from equation 2 overlaid.

The key identifying assumption for both models is that, in the absence of the visa expansion and contraction, high nurse migration provinces would not have experienced differential changes in outcomes compared to low nurse migration provinces. We find no evidence of differential pre-trends for any of our outcomes. Additionally, the visa expansion and subsequent contraction yield an inverted u-shaped pattern of coefficients which is unlikely to be explained by a spurious correlation with underlying differences between high and low nurse migration areas. Finally, we find that non-nursing disciplines decline in enrollment during the period of nursing enrollment expansion. If the nursing enrollment results were driven by differential trends in overall education for high and low nurse migration provinces, then we would expect enrollment in other fields to follow a similar pattern to nursing enrollment.

One potential source of bias is cross-province migration within the Philippines for postsecondary nursing education. Upward bias could arise if students move from low nurse migration provinces to attend school in high nurse migration provinces. In Appendix Table 3, we use Census data to show that this is only the case for about $1.5 \%$ of all postsecondary students on average. Despite this low rate, in Appendix C we conduct bounding exercises to address potential bias in our estimates that could arise due to migration for education, finding that such bias explains only a trivial portion of our effects under reasonable, but conservative assumptions.

A remaining threat to the validity of our estimates is a simultaneous policy change that differentially affected high relative to low nurse migration provinces. For instance, if the health care system expanded in high nurse migration provinces at the same time as the policy expansion, we might attribute the effects on nurse enrollment and graduation to U.S. visa policy, 
when it was actually due to changes in demand in the Philippines. Appendix Table 4 shows the numbers of hospitals and community clinics, in the Philippines from the early 1990s through 2010. These are the main employers of nurses, and their numbers appear to be relatively stable during the period of the U.S. visa policy changes. This suggests that there were no major changes to the health care system that might bias our results. Further, we collected data on all health policy legislation in the Philippines since 1954, and find no policy changes that would differentially impact high and low nurse migration provinces and occurred at the same time as the U.S. visa policy changes (WHO, 2011; WHO, 2018). Finally, our results could be biased by simultaneous changes in migration policy or demand for non-nurse migrants that differentially affected high versus low nurse migration provinces. In Section 5.4, we add controls for demand for non-nurse migrants and show that our results are robust to including them.

\section{Results}

\subsection{Effects on Nurse Migration and Nursing Education}

We first estimate the effect of the visa expansion and contraction on the migration rate of nurses to the U.S. Figure 2a presents the results: the solid line represents the $\beta_{\tau}{ }^{\prime}$ s from the event study, with $95 \%$ confidence intervals shown by dotted lines. The dashed line shows the results of the pooled event study. The two grey vertical lines represent the 2000 and 2007 policy changes.

Following the policy change in 2000 , nurse migration started to increase in high nurse migration provinces relative to low nurse migration provinces. Consequently, in 2007 when visas were restricted, the nurse migration rate dropped suddenly. These results confirm that changes in U.S. visa policy had a larger impact in provinces with historically high nurse migration to the U.S. ${ }^{9}$ We report the coefficients from the pooled specification in Column 1 of Table 1. In 2000,

\footnotetext{
${ }^{9}$ The larger standard errors post-2000 are due to increased variance in the outcome variables.
} 
nurse migration jumped by 1.21 migrants per 100,000 working-aged individuals in high relative to low nurse migration provinces, resulting in an over 39\% increase based on the pre-policy nurse migration sample mean of 3.07 nurses per 100,000. In addition to this initial jump, the trend in nurse migration increased by approximately 0.76 nurses per 100,000 each year in high relative to low nursing provinces until 2007. In 2007, nurse migration dropped by 4.20 nurses per 100,000 , and continued to fall in the period after 2007 by 0.44 nurses per year.

Nurse migration had a slight downward trend before the 2000 policy change in high relative to low nurse migration provinces. This pre-trend is relatively stable over the decade before the policy change, and it is of the opposite sign and much smaller in magnitude than the sudden and large positive effects following the visa expansion. This suggests that it is not likely that the sudden changes in nurse migration to the U.S. following the visa expansion and contraction were due to differential trending by high and low nurse migration provinces.

We now turn to the effects on nursing school enrollment. We find that enrollment rates in nursing programs in high relative to low nurse migration provinces increased, and then decreased, following the policy changes in 2000 and 2007, respectively (Figure 2b). Similar to aggregate nursing enrollment in the Philippines (Figure 1b), nursing enrollment started to increase in 2000 in high relative to low nurse migration provinces. At its peak in 2006, the effect of the visa expansion on nursing enrollment is approximately 3.5 percentage points (off a preperiod mean of 1.35 percent), before gradually declining to zero after the onset of visa restrictions in $2007 .{ }^{10}$ This inverted $u$-shaped pattern of results is difficult to explain as due to differential trending across high and low nurse migration provinces.

10 This gradual decline is consistent with current nursing students continuing toward their degree, while new potential nursing students enroll in other degree types. 
The pooled event study follows the same pattern (Table 1). The trend in nursing enrollment increased by 0.69 percentage points per year following the initial (statistically insignificant) jump of 0.045 percentage points in 2000. To interpret the magnitude of the effect, consider that the average increase in the enrollment rate during the seven-year visa expansion period was 1.74 percentage points per year. ${ }^{11}$ Given an average pre-period enrollment rate of $1.35 \%$, nurse enrollment increased by $129 \%$ in high relative to low nurse migration provinces. This is a large effect, though not surprising given the aggregate enrollment numbers in Figure $1 \mathrm{~b}$. The visa contraction in 2007 led to an immediate drop in nurse enrollment of 0.85 percentage points. Enrollment continued to decline by 1.14 percentage points per year through 2013, until the increase in enrollment in high relative to low nurse migration provinces disappeared. The coefficient on the pre-trend is small and statistically insignificant.

We next explore the effects of the policy changes on enrollment by gender. The results are shown graphically in Appendix Figures 4a and b. Both male and female enrollment exhibit a similar inverted $\mathrm{u}$-shaped pattern as in Figure $2 \mathrm{~b}$. While the raw effect is larger for women, because male enrollment rates in nursing were considerably lower prior to the visa expansion $(0.32 \%$ of the college-aged population compared to $1.09 \%$ for women), the magnitude of the results in percent terms is larger for men. Men experienced a 1.83\% increase in nursing

\footnotetext{
${ }^{11}$ We calculate this by adding up the effect in each year from 2000 to 2006 and dividing by 7 . As an example of how we calculate the effect for each year, the effect in 2001 is: $0.045+0.685 *(2001-2000)+(-0.091) *(2001-1999)=0.548$ percentage points. Alternatively, one could use the specification in equation 1 and add up the coefficients for 2000 to 2006 and divide by 7 . The effect sizes are very similar in magnitude.
} 
enrollment while women experienced a $1.06 \%$ increase (Appendix Table 5). ${ }^{12}$ This difference is statistically significant at the $1 \%$ level.

Although the visa expansion dramatically increased enrollment, the marginal enrollees will not contribute to the supply of nurses if they do not persist to graduation. Figure $2 \mathrm{c}$ shows the corresponding event study analysis for graduation rates, and the results reflect the same pattern as the enrollment rates. We find that there were large increases in nurse graduation after visas for nurses increased, but that the effect manifests approximately four years after visas were made available, consistent with the four years it takes to finish postsecondary nursing school. Nurse graduations decreased after the contraction, again with a four-year lag. ${ }^{13}$ Because it takes four years to persist to graduation, we estimate the pooled event study assuming the expansion and contraction each occurred four years later (2003 and 2010, respectively, rather than 2000 and 2007). We find no evidence of a statistically significant pre-trend in nursing graduation.

Were there enough additional nursing graduates due to the visa expansion to replenish the supply of nurses who migrated to the U.S.? In the seven-year period from 2003 through 2009, the average effect on nurse graduation was 0.39 percentage points. ${ }^{14}$ Given an average pre-period nursing graduation rate of $0.16 \%$, the visa expansion led to a $247 \%$ increase in nurse graduates

${ }^{12}$ These are calculated as in footnote 18, but using the coefficients from Appendix Table 5.

${ }^{13}$ One reason nursing students might persist to graduation despite the reduction in migration opportunities is due to the low return of completing only part of a college degree, as shown in Beam et al.'s (2020) audit study of employers in the Philippines.

${ }^{14}$ The average annual effect is calculated as described in footnote 11. In this case, for 2005 , the effect is: $-0.067+0.148 *(2005-2003)+(0.002) *(2005-2002)=0.235$ percentage points. We calculate these effects for 2003 to 2009 and average them. 
following the policy change. The average high nurse migration province had 270 nursing graduates per year before the expansion, so the visa expansion led to an increase of 666 new nursing graduates in high relative to low nurse migration provinces. With an average of 32 new nurse departures in high relative to low nurse migration provinces during the post-expansion period, this suggests that, for each additional nurse who goes abroad to the U.S., 21 additional students graduate from nursing school.

While this is a huge effect, consider the aggregate nurse migration and nurse graduation data shown in Figure 1. For the Philippines overall, nurse migration increased from 1,207 in 1999 to 7,323 in 2006, while nursing graduates increased from approximately 11,313 in 2002 to 113,484 at the peak in 2009 . These nationwide increases are not necessarily causal, but they can help put into perspective the huge scale of increases in nursing enrollment and graduation during this period relative to the still dramatic, but much smaller-scale, increases in nurse migration. Further, in Appendix D, we conduct a back-of-the-envelope calibration of a standard utility function, showing that under reasonable levels of risk aversion, many individuals would choose to enroll in a nursing degree rather than an alternative degree type despite the low migration probability due to the high returns to nurse migration.

In terms of gender composition, both men and women increased graduation from nursing programs four years after the expansion, and decreased following the contraction (Appendix Figures $4 \mathrm{c}$ and $\mathrm{d})$. The effects are again larger in percent terms for males $(4.47 \%)$ than females $(1.99 \%)$, and this difference is statistically significant at the $1 \%$ level (Appendix Table 5). For each new nurse migrant that goes abroad, 13 additional females and 8 additional males graduate in high relative to low nurse migration provinces. The high returns to nursing as a result of the expansion appear to have shifted the gender composition of both enrollees and graduates. 


\subsection{Effects on the Supply of Nursing Programs}

Although the potential for brain gain has long been touted as a possibility, one concern for specialized occupations like nursing is that even if individuals aspire to obtain nursing education due to increased returns to human capital, they may not be able to do so if the supply of schooling does not respond in specialized occupations (Docquier and Marfouk, 2006). We explore whether the supply of nursing programs in the Philippines responded to accommodate the increased demand for nursing education. Following the 2000 visa expansion, we find that the number of nursing programs increased substantially in high relative to low nursing provinces (Figure 3a). ${ }^{15}$ The increase occurred gradually, with 0.4 new programs per year through 2007 (Table 1), or 9.7\% per year based on a pre-period sample mean of 4.13 programs. Again, we see no evidence of differential pre-trends in the number of nursing programs.

$85 \%$ of nursing programs in the Philippines are privately operated. As such, we find that the large expansion of nursing programs is driven by increases in private institutions (Table 1 and Figure 3c). However, there is also a marginally statistically significant increase in the number of public programs. While the effect on public institutions is smaller in magnitude, in percentage terms this represents a $17 \%$ increase in the number of public nursing programs compared to a $8.7 \%$ increase in private programs. These results suggest that nursing enrollment and graduation were able to increase in response to U.S. visa policy because the supply of nursing programs, both public and private, were nimble enough to respond to increased demand.

Was the increased supply of nursing programs due to new nursing institutions opening or due to existing institutions adding nursing programs? This question has implications for external

\footnotetext{
${ }^{15}$ Unfortunately, the CHED data do not include information on program capacity, so we cannot examine if existing programs expanded.
} 
validity, as it may be easier for low-income countries to expand program offerings at existing postsecondary institutions than open entirely new institutions. We explore this in Appendix Figure 5 for private institutions, since the majority of the supply increases were due to increases in private programs. The effects appear to be driven by existing institutions adding nursing programs, with essentially no response in terms of new nursing institutions. This result is important when considering the conditions under which such brain gain effects are possible: the Philippines did not respond through the creation of entirely new nursing schools, but rather through adding new programs in institutions that previously did not engage in nursing education.

The ability of the Philippines to increase the supply of nursing programs in order to accommodate increased demand suggests that the postsecondary schooling supply elasticity is a key contextual factor that allowed for the brain gain effects that we find. To explore the extent to which our effects vary by the supply elasticity, we next examine heterogeneity in our results by the province-level postsecondary schooling supply elasticity. Since the expansion of programs occurred primarily in institutions without existing nursing programs (as opposed to in entirely new institutions), we create a measure of elasticity that is the share of private institutions without nursing programs out of the total number of private institutions in the pre-period. A larger share should indicate that the supply is more elastic, since there are more institutions where nursing programs can be added. We then examine effects on nursing enrollment separately for those provinces above and below the median value of this share $(0.80)$.

The results are shown in Appendix Figure 6. The results appear to be driven by places with a more elastic supply. In less elastic places, there is little to no enrollment response. This reinforces the notion that an elastic postsecondary schooling supply is key to the brain gain effects that we find. However, it is worth noting again that the supply response does not require 
the creation of entirely new institutions, but rather the ability of countries to expand their existing institutions to include new in-demand programs.

\subsection{Effects on the Number of Licensed Nurses and Nursing Exam Pass Rates}

In order to work as a nurse in the Philippines or to migrate abroad, all nursing graduates must pass the Philippine Nursing Licensure Examination (NLE). While the U.S. expansion of visas led to a large increase in the number of nursing graduates, these new graduates will only contribute to the nursing labor force if they are able to pass the NLE exam. We examine the effect of the policy changes on province-level NLE pass rates using our event study framework (equation 1). ${ }^{16}$ Figure $3 \mathrm{~d}$ shows the effect on the number of NLE passers out of the college age population (blue circles), indicating that in high relative to low nurse migration provinces, the number of passers out of the college aged population increased. Similar to the graduation results, the effects occur with a lag since it takes four years for students induced to attend nursing school by the policy changes to obtain their degree and take the exam, though earlier nursing graduates who previously did not take or did not pass the exam may respond immediately. There is no evidence of differential trending prior to the visa expansion.

To assess the magnitude of this response, we estimate the effect of the policy expansion by regressing passers out of the population on the interaction of an indicator for high nurse

\footnotetext{
${ }^{16}$ One possible response to the huge influx of nursing graduates would be to make the test easier. Because nurses migrating to the United States must also pass the National Council Licensure Examination (NCLEX), little incentive exists for the Philippines to make it easier to pass the local exam. If the test did become easier (or harder) over time, this will not bias the differencein-differences estimates since the NLE is a national exam.
} 
migration provinces and an indicator for the post-period (2000 and onward). ${ }^{17}$ On average, high migration provinces compared to low nurse migration provinces experienced an annual increase in licensed nurses out of the college-aged population of 0.174 percentage points, which is significant at the $1 \%$ level (Appendix Table 6, row 1). ${ }^{18}$ With a pre-period rate of $0.216 \%$, this effect is equivalent to an $80 \%$ increase in the number of licensed nurses in high relative to low provinces, or 293.6 newly licensed nurses per year on average. With 32 new nurse migrants on average in these provinces, there are 9 newly licensed nurses for each new nurse migrant. This substantial gain in the number of licensed nurses as a result of the visa expansion suggests a brain gain of health care professionals.

\subsubsection{Effects on Nurse Quality}

While the Philippines gained licensed nurses, not all new graduates induced by the visa expansion passed the exam. Given the large increases in both new nursing graduates and nursing programs, one important question is whether the marginal nursing graduate is less likely to pass the exam. New graduates may be less-skilled, either because the new nursing programs are less rigorous or because the students themselves are weaker. While ideally we would estimate the effect of the policy changes on the pass rate (number of passers/number of examinees), this analysis is complicated by the fact that not all provinces have examinees in every year. For these province-year observations, the pass rate is undefined. Dropping these provinces from the analysis alters the composition of the treatment and control groups relative to our previous

${ }^{17}$ This is a simpler difference-in-differences estimator than the pooled event study model, as we want to capture the effects on pass rates in a single parameter. All previous controls are included. ${ }^{18}$ We also report coefficients of the effect of the policy changes on passers out of the population using our event study framework. 
analysis, primarily by removing province-year observations from the control group. In order to include all provinces in the sample, we estimate two regressions: 1) the number of passers out of the population regressed on the interaction of an indicator for high nurse migration provinces and an indicator for the post-period (2000 and onward) and 2) the number of examinees out of the population regressed on the same interaction term. The event study estimates shown in Figure $3 \mathrm{~d}$ indicate the lack of pre-trends for both outcome variables. We then divide the estimated coefficient for passers out of the population $(0.174)$ by the estimated coefficient for examinees out of the population (0.453), both of which are statistically significant at the $1 \%$ level (Appendix Table 6, row 1). This quotient backs out the implied pass rate in the post-period for those induced to take the exam by the policy change: $38.4 \%$ (Column 3 ). We then test the null hypothesis that the implied pass rate is equal to the pass rate in the pre-period (58\%). We reject the null hypothesis at the $1 \%$ level that these pass rates are equal, indicating that pass rates declined following the expansion in U.S. nursing visas. ${ }^{19}$

We cannot determine whether this decline is because the new nursing programs are lower quality or because the marginal student induced to attend nursing school is weaker. ${ }^{20} \mathrm{We}$ discuss potential labor market outcomes for unlicensed nursing graduates in Section 5.6.

${ }^{19}$ Appendix Table 6 also uses the event study estimates to calculate the implied pass rate in each year in the post-period by dividing the coefficient on the interaction of High and a given year fixed effect in the passers/population regression by the same coefficient for the examinees/population regression. Beginning in 2006, the pass rates among the marginal test takers are statistically significantly lower than the pre-period pass rate.

${ }^{20}$ Additionally, individuals with nursing degrees who previously failed or did not take the exam may now choose to take the exam at a higher rate, potentially lowering the pass rate. 


\subsection{Robustness}

We show the robustness of our results to a number of potential concerns in Appendix Table 7. We first explore whether changes in demand for non-nurse migrants that differentially affected high versus low nurse migration provinces could bias the results. To address this, we control for the non-nurse migration rate at baseline interacted with year fixed effects. This accounts for changes in migration policy or demand in other migrant networks. The results are robust, though the effects on the number of nursing programs is no longer statistically significant (Panel B). Our second concern is if our results are driven by the inclusion of Metro Manila, which is one of the 74 provinces in our sample, and an outlier in terms of migration rates and postsecondary enrollment. The results are nearly identical when we exclude it (Panel C).

Third, we add baseline average years of schooling for 25- to 64-year-olds and baseline fraction of households that live in urban areas in the province, both interacted with year fixed effects (Panel D). All results except nursing programs are robust. For the nurse program results, the coefficient is still positive, but far smaller in magnitude and no longer statistically significant. Panel E includes these controls but drops Metro Manila. All results are robust, indicating that the attenuation of the nursing program result is driven by Metro Manila. ${ }^{21}$ Next we examine whether high and low nurse migration provinces experience differences in economic growth during the sample period, due to varying industrial composition across geographic areas of the Philippines. We group the Philippines into three major island groups: Luzon (where Manila is located), Visayas, and Mindanao, and include island times year fixed effects as controls. All of our estimates are robust (Panel F), though the nurse program results are no longer significant.

${ }^{21}$ We discuss the reasons for this, as well as other details on these robustness checks, in Appendix E. The results are also robust to the inclusion of population weights. 
Finally, we report our results using a continuous measure of the baseline nurse migration rate as our second difference, rather than the binary treatment variable, High. In Panel G, we scale the coefficients so they can be interpreted as the impact of a one standard deviation increase in the baseline nurse migration rate and show the results are similar in significance and magnitude. Event study figures are shown in Appendix Figure 2.

\subsection{Effects on Enrollment and Graduation in Other Fields}

A natural question is whether the visa expansion increased the overall human capital stock in the Philippines by inducing more individuals to attend and persist through college, or if it simply altered the choice of degree type for students who would have enrolled and persisted through college in the absence of the policy changes. We examine this by looking at non-nursing enrollment and graduation rates. We note that when looking at aggregate enrollment across the Philippines, non-nursing enrollment declined after the visa expansion and increased after the contraction (Figure 1b). This pattern is the opposite of nursing enrollment and suggests that individuals may have switched from other disciplines to nursing in response to the visa expansion. Turning to our event study framework, this potential switching behavior is evident (Figure 4a), though the results are statistically imprecise. A simple difference-in-differences analysis, presented in Table 2 , shows a statistically significant decline in enrollment in nonnursing fields in the expansion period (column 1). Consistent with students switching to nursing from other fields of study, the results for total enrollment (nurse plus non-nurse) are flat and near zero during the visa expansion period (Figure $4 b$ ). There is little evidence of differential pretrends in either non-nursing or total enrollment.

We next examine both non-nursing and total graduation. While there were no overall increases in postsecondary enrollment due to the visa expansion, the policy could have affected 
the persistence rate of the marginal enrollee through college and therefore graduation. As with enrollment, aggregate graduation across the Philippines in non-nursing disciplines illustrates a ushaped pattern, declining following the expansion and then increasing following the contraction (Figure 1c). Turning to the event study framework, this u-shaped pattern in non-nurse graduation is no longer evident. Non-nurse graduation rates, while noisy, appear flat and close to zero during the sample period (Figure 4c). The coefficients in Table 2, Column 3 are also small in magnitude and not statistically significant. Total graduation rates, however, appear to increase due to the visa expansion (Figure $4 \mathrm{~d}$ and Table 2). This increase is driven by the period when nursing graduation can respond, which is four years after the initial expansion (2003-2009) due to the time necessary to complete a degree. We test the joint significance of the event study coefficients for 2003 through 2009 and reject the null hypothesis that they are jointly equal to zero ( $\mathrm{p}$-value $=0.0497$ ). The total graduation rate results are robust across the specifications discussed in Section 5.4 (Appendix Table 7, Column 5). Given an average pre-period total graduation rate of $4.67 \%$, the visa expansion led to an $11.9 \%$ increase in the graduation rate, or 560.5 new graduates per year in the average province.

The null effect on total enrollment but increase in total graduation suggests that those in nursing degrees were more likely to persist to graduation. This could be because those switching to a nursing degree were more likely to persist to graduation than if they had enrolled in their counterfactual program or because those previously enrolled in nursing programs persisted at a higher rate due to the higher returns. In Appendix F, we show that graduation rates were low enough to accommodate increased persistence leading to increased graduation.

Was this increase of 560.5 graduates enough to increase the human capital stock in the Philippines, given that some new nursing graduates migrated to the U.S.? Recall that the visa 
expansion caused an increase of 32 new nurse migrants per year in the average province. This implies that rather than depleting the Philippines of college graduates as the brain drain hypothesis would suggest, the number of college graduates, and thus the human capital stock of college-educated labor in the Philippines, in fact increased. ${ }^{22}$

\subsection{What happens to nursing graduates who do not get a visa?}

A remaining question is what happens to individuals who obtain a nursing degree but do not migrate to the U.S.? Given the large increase in nursing graduates, the answer is important for understanding the overall effects of the policy changes on Filipino workers.

We first examine whether demand for nurses from other destinations absorbed some of the newly licensed nurses. Appendix Figure 7 shows that non-U.S. nurse migration is largely unaffected by the expansion and contraction of U.S. nurse visas. Non-U.S. destinations provided jobs for only a very small share of the newly graduated nurses. Recently graduated nurses may also migrate in lower-skilled positions, such as caregivers or domestic helpers, that leverage some skills learned in nursing programs (DeParle, 2019). To gain some insight into this question, we look at the total annual flows of domestic helpers and caregivers during our sample period. Neither occupation experienced a substantial increase in outflows during the period when nurses graduated at high rates. It seems unlikely that a large share of the new nurses migrated to work in these other occupations. That said, this exercise is merely suggestive given that it is based on

\footnotetext{
${ }^{22}$ We also examine the effect of the visa expansion and contraction on child and maternal mortality rates. We do not find statistically significant effects on either outcome. The lack of negative effects on health during the early expansion years helps to alleviate concern of transitory brain drain during the four years when the U.S. hired more nurses but new enrollees had not yet graduated (2000-2003). These health results, however, are noisy and not definitive.
} 
aggregate time series evidence and that even if domestic helper and caregiver migration did not increase, new nurses may have crowded out other potential migrants for these positions.

If the bulk of the additional nursing graduates were not migrating to other destinations as nurses or in lower-skilled occupations, a remaining question is: What are the occupational outcomes of nursing degree recipients who stay in the Philippines? We use the 1990, 2000, and 2010 Philippine Census to estimate a basic difference-in-differences analysis of the effect of the visa expansion on domestic nurse employment. We discuss this exercise in detail in Appendix G. We find an $83 \%$ increase in domestic nurse employment, or 1,830 nurses. Where did these domestic nurses work? No substantial expansions to the health system occurred during this time, so it is unlikely that growth in the health system accounts for this increase. To deal with nursing shortages in low nurse migration areas and help unemployed nurses, the Philippines began the Registered Nurse for Health Enhancement and Local Service (RN HEALS) program during the late 2000s (WHO, 2018). Nurses worked for six months for rural health units and another six months in hospital service. The 20,000 nurses hired by this program account for almost $30 \%$ of the increase in nurses found using the Census data. Many other nurses work as "Professional Volunteer Nurses" (Rudin, 2013), paying a fee to hospitals in the Philippines under an official training program.

Finally, what happened to individuals who never worked as nurses but completed a nursing degree? Ideally, we would examine the occupations and employment status of nursing degree recipients, but such data do not exist. Anecdotally, nursing degree recipients who never passed the licensure exam were hired by the Department of Health as Universal Health Care Implementers, Public Health Associates, and Family Health Associates (WHO, 2018). Others 
worked in Business Process Outsourcing (BPO) and call centers (Marcus et al., 2014), where a college degree is generally required and compensation is higher than nursing (Uy, 2019).

What are the welfare implications of the surge in nursing degrees due to the U.S. policy changes? If these students acted rationally in their decision to invest in nursing education, then even if the vast majority ended up unemployed domestically, they are still better off ex-ante. However, individuals may be acting irrationally, for example, if they overestimate the probability of migrating as a nurse to the U.S (Arends-Kuening et al., 2015). In addition, shortages in fields students switched away from could lead to negative externalities. In terms of benefits, the Philippines gained nurses, many of whom worked in underserved areas. Those who migrated experienced huge gains in wages, and households in the Philippines benefited from remittances. For those who did not migrate, many found employment as nurses or in other highpaying jobs. In terms of costs, many nurses remained unemployed or in volunteer positions. They primarily switched to nursing from other fields, and while the total number of postsecondary graduates increased, it is unclear whether remaining in other fields would have resulted in better outcomes for their households or greater development impacts for the Philippines. While understanding the potential implications for welfare is beyond the scope of this paper, ultimately we aim to provide a well-identified estimate of the partial equilibrium effect of the U.S. visa policy changes.

\section{Conclusion}

The debate surrounding the migration of medical workers from developing countries is highly controversial, particularly due to concerns about resulting adverse health outcomes in the country of origin (WHO, 2010; Bradby, 2014; Lema and Baldwin, 2020; Skladany, 2020). Yet, little causal evidence exists measuring the impacts of such migration on the origin-country 
human capital stock. In this paper, we exploit two migration policy experiments to provide evidence on the brain drain versus brain gain debate for health care professionals. We examine the effects of an abrupt expansion and subsequent contraction of visas for nurses migrating to the United States on postsecondary education decisions in the Philippines. We find that both enrollment in and graduation from nursing programs increased dramatically in response to increased U.S. demand for nurses and then fell when visas were restricted. The number of nursing programs rapidly expanded to accommodate the increased demand for nursing education, mainly through expansions in existing postsecondary institutions. Although students induced into nursing education passed the licensure exam at lower rates, the increase in licensed nurses overall was much larger than the increase in nurse migration: for each additional nurse who went abroad, 9 more nursing graduates passed the licensure exam.

Our results suggest that expanded migration opportunities did not deplete the stock of nurses in the Philippines, and in fact, the supply of nurses, as well as the total human capital stock of college-educated labor in the Philippines, increased. Our results may not translate to all settings, such as the most underdeveloped countries where postsecondary infrastructure may be unable to expand to meet demand, and such setting should be the subject of future research. However, our results provide useful evidence for many low- to middle-income countries seeking to emulate the Philippines' facilitation of labor migration: brain gain effects can dominate brain drain effects in the context of medical worker migration. These results highlight the potential for well-designed partnerships between destination and origin countries. Such partnerships can, at least in principle, present an advantageous situation by allowing destination countries to subsidize training for workers in origin countries while facilitating the migration of skilled workers (Clemens, 2015). That said, while we are able to contribute to the partial equilibrium 
policy debate surrounding medical worker migration, we are unable to quantify the total welfare effects of such migration. These general equilibrium effects should be the subject of future research examining the impacts of migration opportunities on migrant-origin countries.

\section{References}

Abramitzky, Ran and Victor Lavy. 2014. "How Responsive is Investment in Schooling to Changes in Redistributive Policies and in Returns?" Econometrica, 82(4): 1241-1272.

Adao, Rodrigo, Michal Kolesar, and Eduardo Morales. 2019. "Shift-Share Designs: Theory and Inference.” Quarterly Journal of Economics, 134(4): 1949-2010.

Aiken, Linda. 2007. “US Nurse Labor Market Dynamics are Key to Global Nurse Sufficiency." Health Services Research, 42(3): 1299-1320.

Arends-Kuenning, Mary, Alvaro Calara, and Stella Go. 2015. "International Migration: Opportunities and Occupational Choice: A Case Study of Philippine Nurses 2002 to 2014.” IZA Discussion Paper No. 8881.

Asia Times. 2003. "Nurse Exodus Plagues Philippines." May 17.

Batista, Catia, Aitor Lacuesta, and Pedro C. Vicente. 2012. "Testing the 'Brain Gain' Hypothesis: Micro Evidence from Cape Verde.” Journal of Development Economics, 97(1): $32-45$.

Beam, Emily A., Joshua Hyman, and Caroline Theoharides. 2020. “The Relative Returns to Education, Experience, and Attractiveness for Young Workers." Economic Development and Cultural Change, 68(2): 391-428.

Becker, Gary. 1962. "Investment in human capital: A theoretical analysis." Journal of Political Economy, 70(5, Part 2): 9-49. 
Beine, Michel, Frederic Docquier, and Hillel Rapoport. 2001. "Brain Drain and Economic Growth: Theory and Evidence.” Journal of Development Economics, 64(1): 275-289.

Beine, Michel, Frederic Docquier, Hillel Rapoport. 2008. "Brain Drain and Human Capital Formation in Developing Countries: Winners and Losers.” Economic Journal, 118(528): 63152.

Bhagwati, Jagdish, and Koichi Hamada. 1974. "The Brain Drain, International Integration of Markets for Professionals and Unemployment: A Theoretical Analysis," Journal of Development Economics, 1(1): 19-42.

Bhagwati, Jagdish, and Carlos Rodriguez. 1975. "Welfare-Theoretical Analyses of the Brain Drain." Journal of Development Economics, 2(3): 195-221.

Bhargava, Alok, and Frederic Docquier. 2008. "HIV Pandemic, Medical Brain Drain, and Economic Development in Sub-Saharan Africa." World Bank Economic Review, 22(2): 345366.

Borusyak, Kirill, Peter Hull, and Xavier Jaravel. 2020. “Quasi-Experimental Shift-Share Research Designs." Review of Economic Studies, forthcoming.

Borusyak, Kirill, Xavier Jaravel, and Jann Spiess. 2021. "Revisiting Event Study Designs: Robust and Efficient Estimation.” Working Paper.

Bradby, Hannah. 2014. "International medical migration: A critical conceptual review of the global movements of doctors and nurses." Health, 18(6): pp.580-596.

Chand, Satish, and Michael Clemens. 2019. "Human Capital Investment under Exit Options: Evidence from a Natural Experiment.” Center for Global Development Working Paper 152. Choy, Catherine Ceniza. 2006. Empire of Care: Nursing and Migration in Filipino American History. Duke University Press. 
Clemens, Michael. 2007. “Do Visas Kill? Health Effects of African Health Professional Emigration.” Center for Global Development Working Paper Number 114.

Clemens, Michael. 2015. “Global Skill Partnerships: A Proposal for Technical Training in a Mobile World.” IZA Journal of Labor Policy, 4(1): 1-18.

Cortes, Patricia, and Jessica Pan. 2014. "Foreign Nurse Importation and the Supply of Native Nurses." Journal of Health Economics, 37: 164-180.

Cortes, Patricia, and Jessica Pan. 2015. “The Relative Quality of Foreign Nurses in the U.S." Journal of Human Resources, 50: 1009-1050.

DeParle, Jason. 2019. A Good Provider is One Who Leaves: One Family and Migration in the $21^{\text {st }}$ Century. Viking.

Department of Homeland Security. 2008. 'Improving the Processing of 'Schedule A' Nurse Visas.” U.S. Department of Homeland Security, https://www.dhs.gov/xlibrary/assets/cisomb_recommendation_36.pdf

Dinkelman, Taryn and Martine Mariotti. 2016. "The Long Run Effect of Labor Migration on Human Capital Formation in Communities of Origin," American Economic Journal: Applied Economics, 8(4): 1-35.

Docquier, Frederic, and Abdeslam Marfouk. 2006. "International Migration by Educational Attainment (1990-2000)—Release 1.1" in International Migration, Remittances and Development., ed. Caglar Özden and Maurice Schiff. Palgrave Macmillan: New York. Docquier, Frederic, Ousmane Faye, and Pierre Pestieau. 2008. "Is Migration a Good Substitute for Education Subsidies?” Journal of Development Economics, 86(2): 263-276.

Docquier, Frederic, and Hillel Rapoport. 2012. “Globalisation, Brain Drain, and Development." Journal of Economic Literature, 50(30): 681-730. 
Gibson, John, and David McKenzie. 2011. "Eight Questions about Brain Drain.” Journal of Economic Perspectives, 25(3): 107-128.

Goldsmith-Pinkham, Paul, Isaac Sorkin, and Henry Swift. 2020. "Bartik Instruments: What When, Why, and How." American Economic Review, 110(8): 2586-2624.

Huang, Josie. 2020. “A Fifth of California's Nurses are Filipino. Their Burden of the Coronavirus Pandemic is Fast Emerging." LAist, May 8.

International Labor Organization (2020). "Labour Migration in Sri Lanka and the Maldives." https://www.ilo.org/colombo/areasofwork/labour-migration/lang--en/index.htm.

Jasso, Guillermina, Vivek Wadhwa, Gary Gereffi, Ben Rissing, and Richard Freeman. 2010. "How Many Highly Skilled Foreign-Born are Waiting in Line for U.S. Legal Permanent Residence?" International Migration Review, 44(2): 477-498.

Jensen, Rob. 2010. "The (Perceived) Returns to Education and the Demand for Schooling. The Quarterly Journal of Economics, 125(2): 515-548.

Khanna, Gaurav, and Nicolas Morales. 2021. "The IT Boom and Other Unintended Consequences of Chasing the American Dream.” Working Paper.

Khanna, Gaurav, Emir Murathanoglu, Caroline Theoharides, and Dean Yang. 2021. “Abundance from Abroad: Migrant Income and Long-Run Development.” Working Paper. Kuka, Elira, Na'ama Shenhav, and Kevin Shin (2020). "Do Human Capital Decisions Respond to the Return to Education? Evidence from DACA.” American Economic Journal: Economic Policy, 12(1): 293-324.

Lema, Karen. And Clare Baldwin. 2020. “Pandemic 'hero' Filipino nurses struggle to leave home." Reuters, September 16. https://www.reuters.com/article/us-health-coronavirusphilippine-nurses/pandemic-hero-filipino-nurses-struggle-to-leave-home-idUSKBN2671Z2 
Marcus, Kanchan, Gabriella Quimson, and Stephanie Short. 2014. “Source Country

Perceptions, Experiences, and Recommendations Regarding Health Workforce Migration: A

Case Study from the Philippines.” Human Resources for Health, 12(62).

Mountford, Andrew. 1997. "Can a Brain Drain be Good for Growth in the Source Economy?" Journal of Development Economics, 53(2): 287-303.

Munshi, Kaivan. 2003. "Networks in the Modern Economy: Mexican Migrants in the U.S. Labor Market.” Quarterly Journal of Economics, 118(2): 549-599.

Nelson, Sioban, Sarita Verma, Linda McGillis Hall, Denise Gastaldo, and Martyna Janjua. 2011. "The Shifting Landscape of Immigration Policy in Canada: Implications for Health Human Resources." Healthcare Policy, 7(2): 60.

Oda, Hisaya, Yuko Tsujita Sebastian Nil, and Irudaya Rajan. 2018. "An Analysis of Factors Influencing the International Migration of Indian Nurses." Journal of International Migration and Integration, 19: 607-624.

Organization for Economic Cooperation and Development (OECD). 2007. "Immigrant Health Workers in OECD Countries in the Broader Context of Highly Skilled Migration." International Migration Outlook, SOPEMI 2007 Edition. OECD Publishing: Paris.

Özden, Caglar, and David Phillips. 2015. "What Really is Brain Drain? Location of Birth, Education, and Migration Dynamics of African Doctors.” KNOMAD Working Paper 4.

Rudin, Daniel. 2013. “Workers Find Ways: The Volunteer Nurse.” Rappler, September 15.

Schultz, Theodore. 1961. "Investment in Human Capital." American Economic Review, 51(1):1-17.

Shastry, Kartini. 2012. "Human Capital Responses to Globalization: Education and Information Technology in India.” Journal of Human Resources, 47(2): 287-330. 
Skladany, Martin. 2020. “Stop Stealing Doctors from Developing Countries.” Scientific American, September 2.

Shrestha, Slesh A. 2017. "No Man Left Behind: Effects of Emigration Prospects on Educational and Labor Outcomes of Non-migrants.” Economic Journal, 127(600): 495-521.

Stark, Oded, Christian Helmenstein, and Alexia Prskawetz. 1997. "A Brain Gain with a Brain Drain," Economic Letters, 55(3): 227-234.

Theoharides, Caroline. 2018. "Manila to Malaysia, Quezon to Qatar: International Migration and the Effects on Origin-Country Human Capital.” Journal of Human Resources, 53(4): 1022-1049.

Yang, Dean. 2008. 'International Migration, Remittances, and Household Investment: Evidence from Philippine Migrants’ Exchange Rate Shocks.” Economic Journal, 118: 591-630.

United States Citizenship and Immigration Services (USCIS) Ombudsman. 2007. Annual Report to Congress June 2007.

U.S. Bureau of Labor Statistics. "Occupational Employment Statistics" https://www.bls.gov/oes/data.htm

Uy, Ria Cacananta (Nursing school instructor). 2019. Personal Correspondence. Manila, Philippines.

World Health Organization. "WHO Global Code of Practice on the International Recruitment of Health Personnel.” Sixty-third World Health Assembly, May 2010.

World Health Organization. 2011. "The Philippine Health System Review.” Health Systems in Transition, 1(2).

World Health Organization. 2018. "The Philippine Health System Review." Health Systems in Transition, 8(2). 
Figure 1: Migration, Postsecondary Enrollment, and Graduation

(a) Number of Nurse Migrants and Non-Nurse Migrants

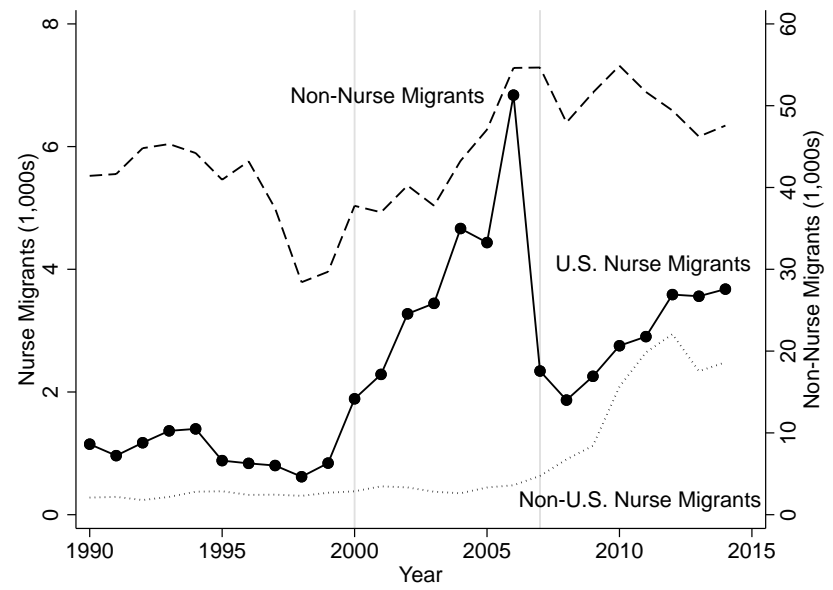

(b) Postsecondary Enrollment by Discipline

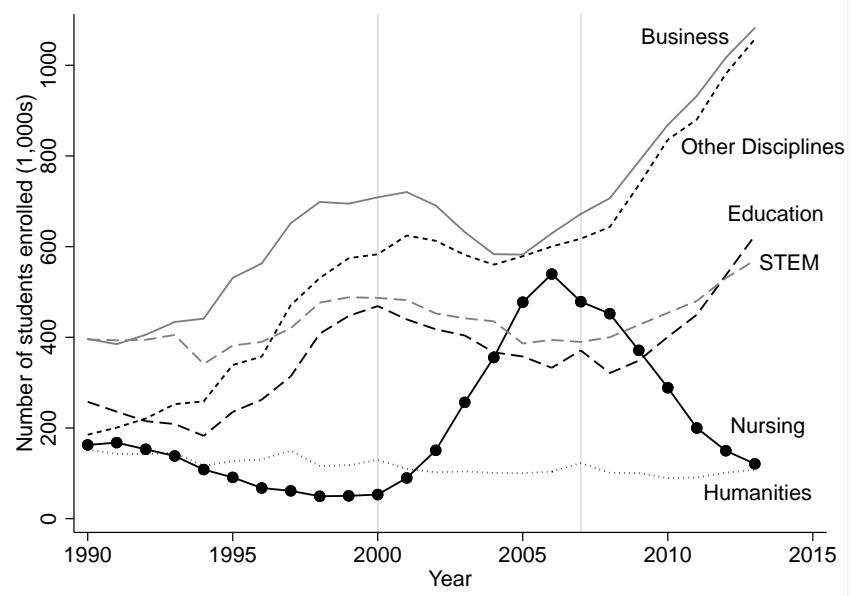

(c) Postsecondary Graduation by Discipline

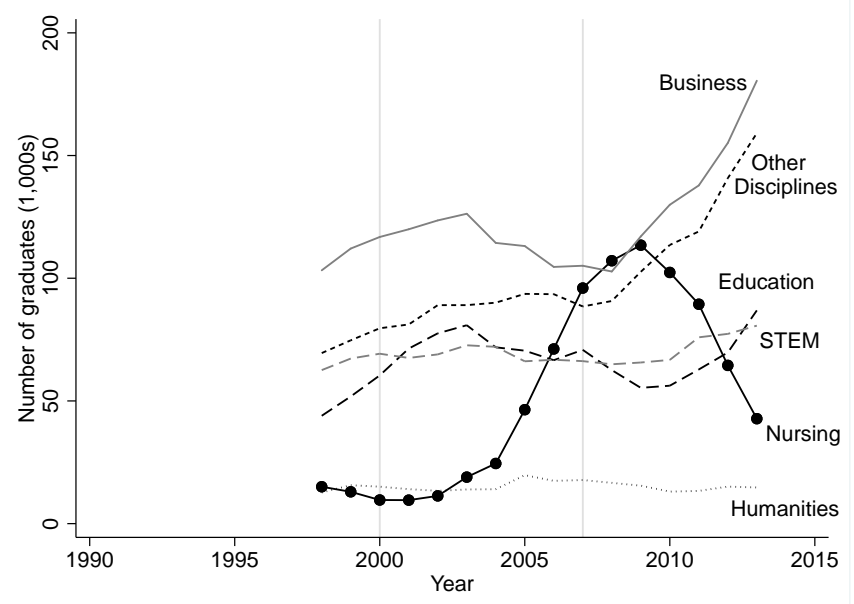

Notes: In panel a, the solid line with circle markers and the dotted line show total nurse migrants to the U.S. and other destinations (left vertical axis) while the dashed line shows total non-nurse migrants (right vertical axis). In panels b and c, enrollment includes all four years of postsecondary education. Graduation data are unavailable prior to 1998. The right axis shows the total number of enrollees and graduates across all fields, while the left axis shows the number disaggregated by field. S\$Qce: CFO, CHED, and authors' calculations. 


\section{Figure 2: Effect of Visa Expansion and Contraction on Nurse Migration and Education}

(a) U.S. Nurse Migration Rate

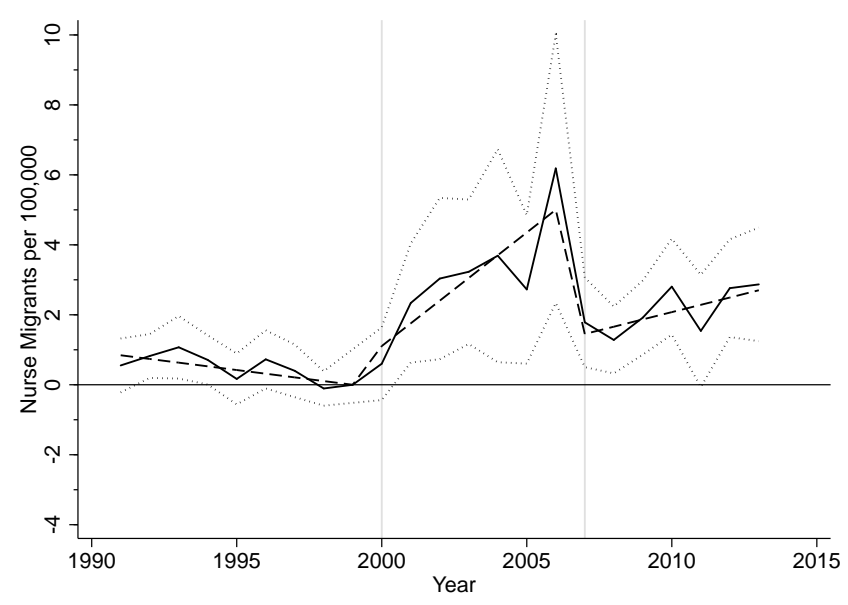

(b) Nursing Enrollment Rate

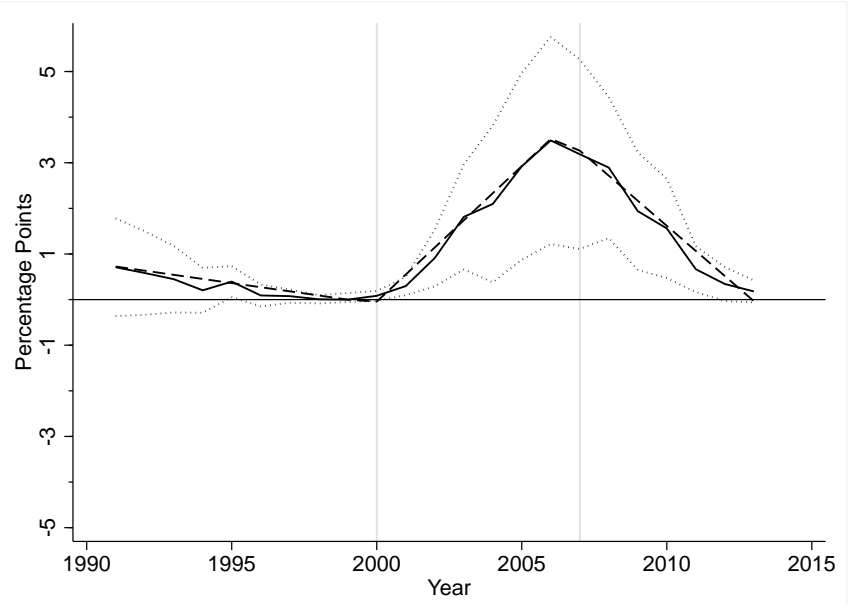

(c) Nursing Graduation Rate

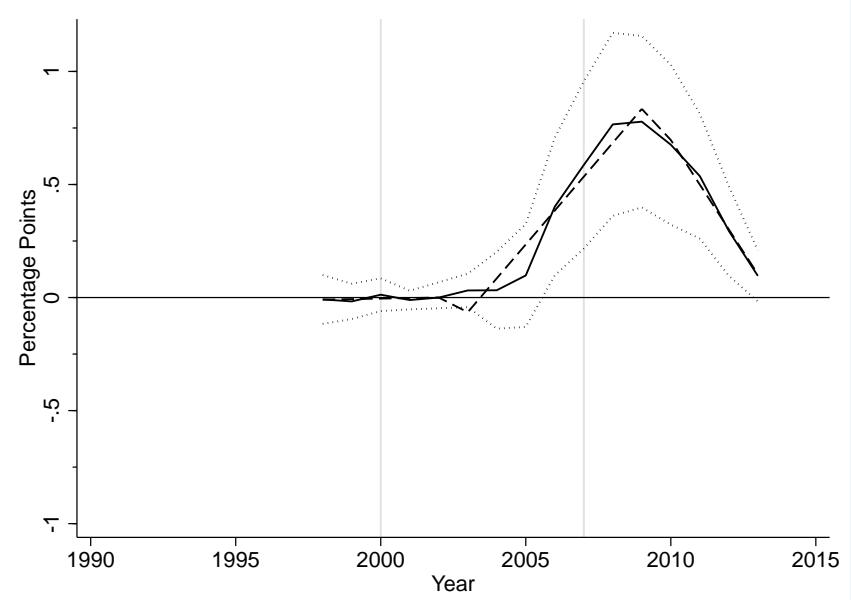

Notes: The solid line shows coefficients from the event study model (equation 1). The interaction with the indicator for 1999 is omitted to identify the model. 95\% confidence intervals are shown by dotted lines. Dashed lines show the pooled model (equation 2). All specifications include province and year fixed effects, and baseline controls interacted with year indicators. Province-level baseline controls include: domestic nurses per capita, male employment rate (aged 25-64), female employment rate (aged 25-64), share female, and average age in the province. The sample includes 74 provinces. Standard errors are clustered by province. The p-yalue on the test of joint significance of pre-trends equals 0.01 (panel a), 0.15 (panel b), and 0.87 (panel c). The light grey vertical lines represent the visa expansion in 2000 and subsequent contraction in 2007. Source: CHED, CFO, and authors' calculations. 
Figure 3: Effect of Visa Expansion and Contraction on Number of Nursing Programs and Licensure

\section{(a) Total Nursing Programs}

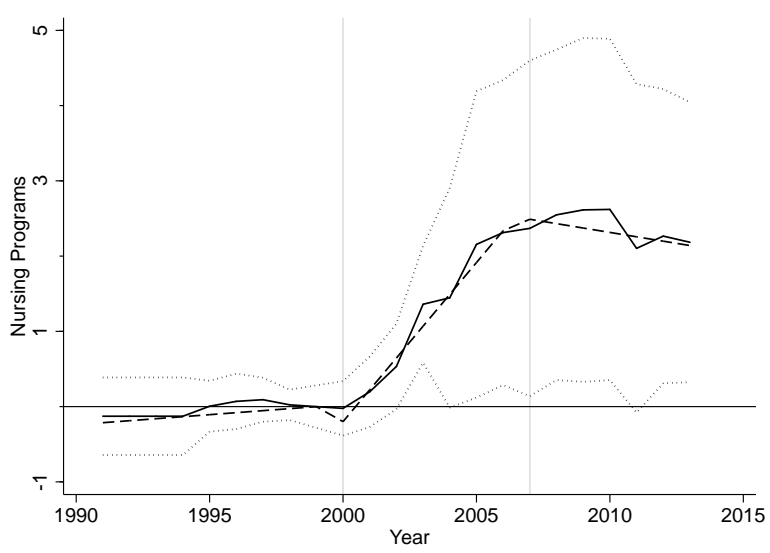

(b) Public Programs

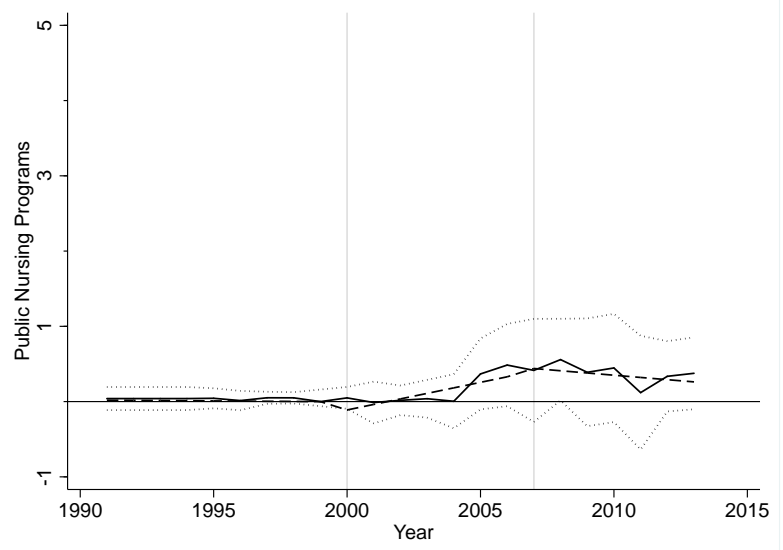

(c) Private Programs

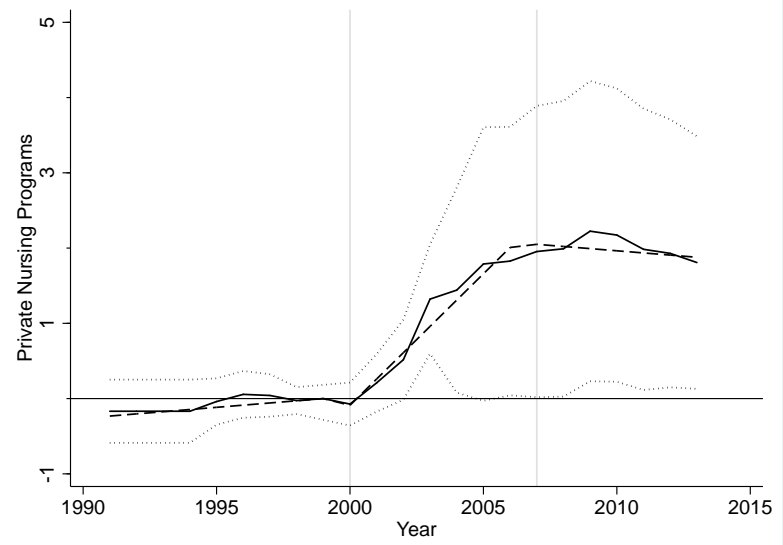

(d) Nursing Licensure Exam Pass Rates

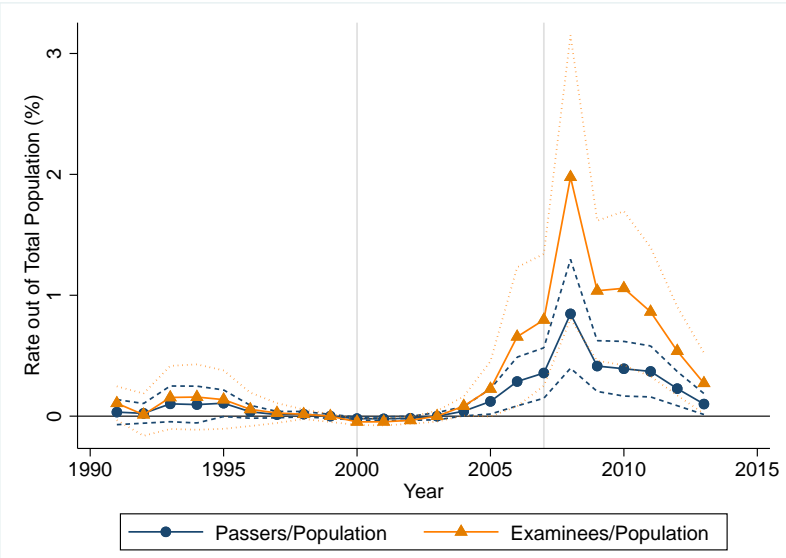

Notes: Panels a through c follow the same structure as Figure 2. In panel d, the orange line with triangle (blue with circle) markers plots event study coefficients where the outcome is the number of examinees (passers) out of the college-aged population at baseline. 95\% confidence intervals are shown by the dotted (dashed) line. The sample includes 74 provinces. Standard errors are clustered by province. The p-value on the test of joint significance of pre-trends equals 0.88 (panel a), 0.65 (panel b), 0.76 (panel c), 0.02 (pass rate) and 0.06 (examinee rate). The light grey vertical lines represent the visa expansion in 2000 and subsequent contraction in 2007.

Source: CHED, CFO, and authors' calculations. 
Figure 4: Effect of Visa Expansion and Contraction on Non-Nursing and Total Enrollment and Graduation Rates

(a) Non-Nursing Enrollment Rate

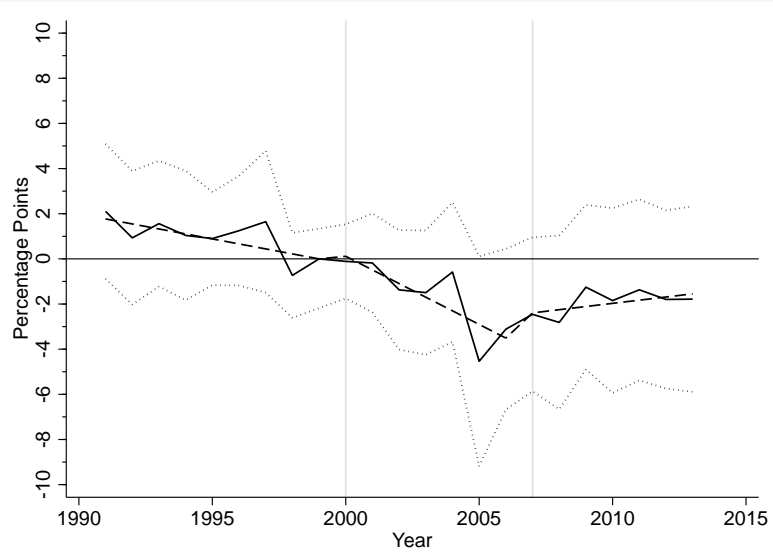

(c) Non-Nursing Graduation Rate

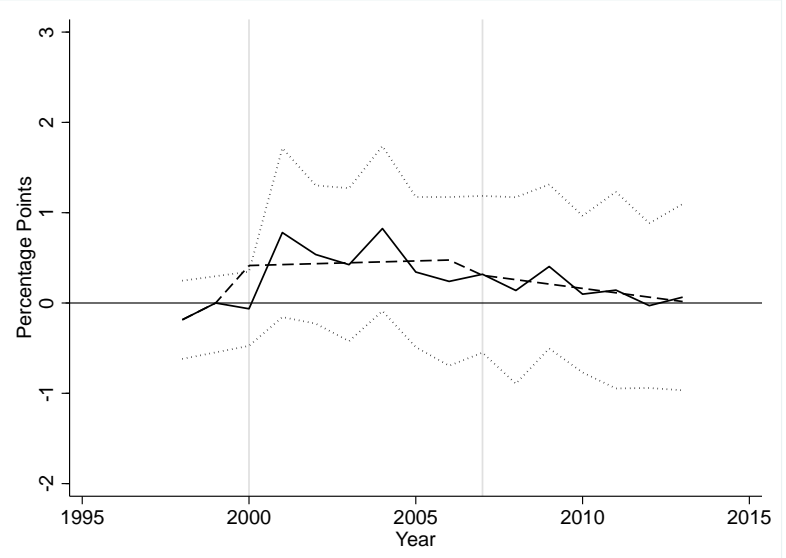

(b) Total Enrollment Rate

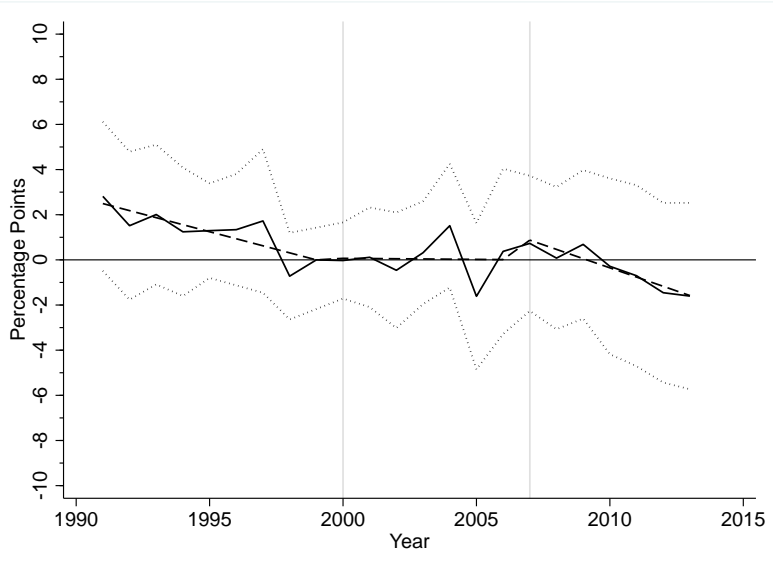

(d) Total Graduation Rate

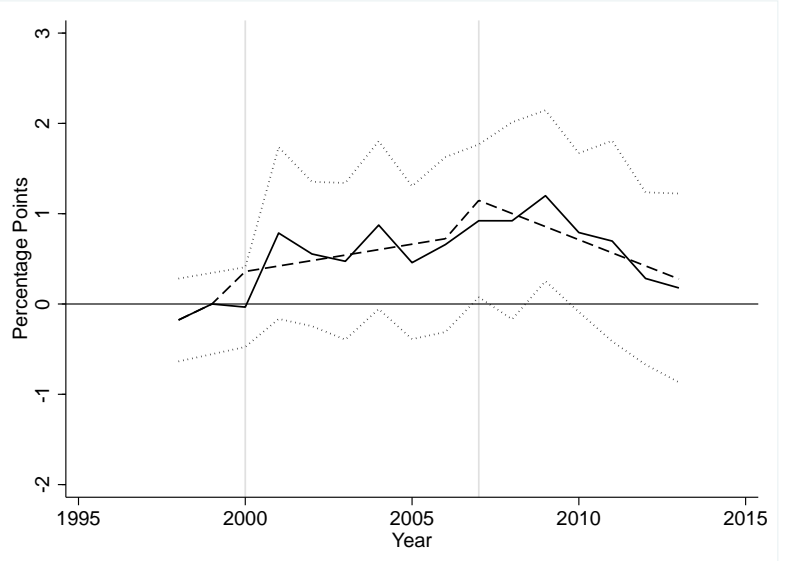

Notes: The solid line shows coefficients from the event study model (equation 1). The interaction with the indicator for 1999 is omitted to identify the model. 95\% confidence intervals are shown by dotted lines. Dashed lines show the pooled model (equation 2). All specifications include province and year fixed effects, and baseline controls interacted with year indicators as listed in Figure 2. The sample includes 74 provinces. Standard errors are clustered by province. The p-value on the test of joint significance of pre-trends equals 0.35 (panel a), 0.31 (panel b), 0.25 (panel c) and 0.29 (panel d). The light grey vertical lines represent the visa expansion in 2000 and subsequent contraction in 2007.

Source: CHED, CFO, Census, and authors' calculations. 
Table 1. Pooled Event Study Estimates of Effect of Visa Expansion and Contraction on Nursing Education Outcomes

\begin{tabular}{|c|c|c|c|c|c|c|}
\hline & $\begin{array}{c}\text { U.S. Nurse Migrants Per } \\
100,000 \\
(1) \\
\end{array}$ & $\begin{array}{l}\text { Nursing Enrollment } \\
\text { Rate } \\
(2) \\
\end{array}$ & $\begin{array}{c}\text { Nursing Graduation } \\
\text { Rate } \\
(3) \\
\end{array}$ & $\begin{array}{c}\text { Number of Nursing } \\
\text { Programs } \\
(4) \\
\end{array}$ & $\begin{array}{l}\text { Number of Private } \\
\text { Nursing Programs } \\
\text { (5) }\end{array}$ & $\begin{array}{c}\text { Number of Public } \\
\text { Nursing Programs } \\
\text { (6) } \\
\end{array}$ \\
\hline Post Expansion x High & $\begin{array}{l}1.211^{*} \\
(0.646)\end{array}$ & $\begin{array}{l}0.045 \\
(0.133)\end{array}$ & $\begin{array}{l}-0.067 \\
(0.074)\end{array}$ & $\begin{array}{l}-0.226 \\
(0.296)\end{array}$ & $\begin{array}{l}-0.118 \\
(0.255)\end{array}$ & $\begin{array}{l}-0.109 \\
(0.102)\end{array}$ \\
\hline Post Expansion x High x Trend & $\begin{array}{c}0.755^{* * *} \\
(0.267)\end{array}$ & $\begin{array}{r}0.685^{* *} \\
(0.261)\end{array}$ & $\begin{array}{c}0.148 * * * \\
(0.043)\end{array}$ & $\begin{array}{r}0.396 * * \\
(0.187)\end{array}$ & $\begin{array}{l}0.320^{*} \\
(0.172)\end{array}$ & $\begin{array}{l}0.076^{*} \\
(0.045)\end{array}$ \\
\hline Post Contraction x High & $\begin{array}{c}-4.200 * * \\
(1.760)\end{array}$ & $\begin{array}{l}-0.850^{*} \\
(0.497)\end{array}$ & $\begin{array}{l}-0.287 * * * \\
(0.108)\end{array}$ & $\begin{array}{l}-0.270 \\
(0.251)\end{array}$ & $\begin{array}{l}-0.307 \\
(0.219)\end{array}$ & $\begin{array}{l}0.037 \\
(0.135)\end{array}$ \\
\hline Post Contraction $\mathrm{x}$ High $\mathrm{x}$ Trend & $\begin{array}{c}-0.441^{* *} \\
(0.217)\end{array}$ & $\begin{array}{l}-1.144 * * * \\
(0.371)\end{array}$ & $\begin{array}{l}-0.348^{* * *} \\
(0.077)\end{array}$ & $\begin{array}{l}-0.481^{*} \\
(0.250)\end{array}$ & $\begin{array}{l}-0.378^{*} \\
(0.219)\end{array}$ & $\begin{array}{l}-0.103 \\
(0.064)\end{array}$ \\
\hline Trend $x$ High & $\begin{array}{c}-0.105^{* * *} \\
(0.039)\end{array}$ & $\begin{array}{l}-0.091 \\
(0.073) \\
\end{array}$ & $\begin{array}{c}0.002 \\
(0.014) \\
\end{array}$ & $\begin{array}{c}0.027 \\
(0.038) \\
\end{array}$ & $\begin{array}{c}0.029 \\
(0.031) \\
\end{array}$ & $\begin{array}{l}-0.002 \\
(0.011) \\
\end{array}$ \\
\hline Observations & 1702 & 1670 & 1169 & 1702 & 1702 & 1702 \\
\hline $\begin{array}{l}\text { Pre-period mean for high nurse } \\
\text { provinces }\end{array}$ & 3.068 & 1.348 & 0.156 & 4.126 & 3.685 & 0.441 \\
\hline
\end{tabular}

Notes: Table reports estimates of the pooled event study model (equation 2). Post Expansion is a binary variable equal to 1 if the year is 2000 or later and Post Contraction is a binary

variable equal to 1 if the year is 2007 or later for all outcomes except graduation. Because it takes four years to graduate from college, for nurse graduation (Column 4), Post Expansion is a binary variable equal to 1 if the year is 2003 or later, and Post Contraction is a binary variable equal to 1 if the year is 2010 or later. High is a binary variable for above median nurse

migration to the U.S. in the base year 1990. The sample period is from 1991-2013 in all columns except Column 3, which is 1998-2013. Province and year fixed effects, as well as baseline controls interacted with year dummies as outlined in Figure 2 notes, are included in all specifications unless otherwise indicated. Robust standard errors are clustered at the province level. ${ }^{* * *} \mathrm{p}<0.01,{ }^{* *} \mathrm{p}<0.05,{ }^{*} \mathrm{p}<0.10$.

Sources: CFO, CHED, Census, and authors' calculations. 
Table 2. Effects of Visa Expansion and Contraction on Non-Nursing Enrollment and Graduation

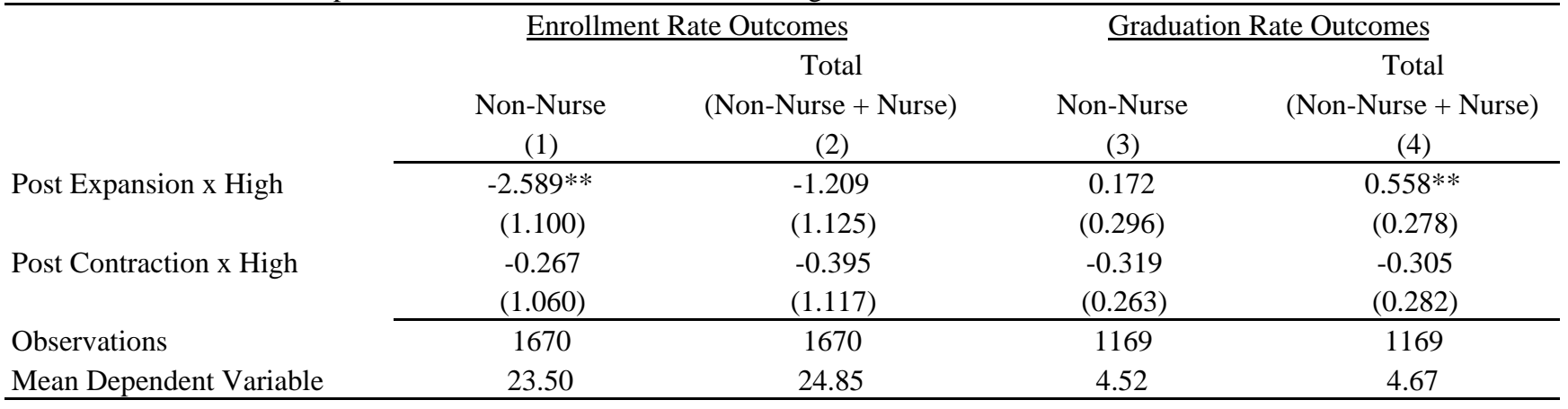

Notes: The table reports estimates from a basic DID model. Post Expansion is a binary variable equal to 1 if the year is 2000 or later for Columns 1 and 2 while Post Contraction is a variable equal to 1 if the year is 2007 or later. In Columns 3 and 4, because it takes four years to graduate from college, Post Expansion is a binary variable equal to 1 if the year is 2003 or later, and Post Contraction is a binary variable equal to 1 if the year is 2010 or greater. High is a binary variable equal to 1 for a high nurse migration province to the U.S. in the base year 1990. The sample period is from 1991-2013 in Columns 1 and 2 and $1998-2013$ in Columns 3 and 4. Province and year fixed effects, as well as baseline controls interacted with year dummies as outlined in Figure 2 notes, are included in all specifications. Robust standard errors clustered at the province level are in parentheses. ${ }^{* * *} \mathrm{p}<0.01,{ }^{* *} \mathrm{p}<0.05,{ }^{*} \mathrm{p}<0.10$.

Sources: CFO, CHED, Census, and authors' calculations. 


\title{
Online Appendix
}

\section{Medical Worker Migration and Origin-Country Human Capital: Evidence from U.S. Visa Policy}

\author{
Paolo Abarcar and Caroline Theoharides
}

\begin{abstract}
Appendix A: Background on Filipino Nurse Migration
In this section, we provide additional background details on Filipino nurse migration. In particular, we return to the importance of migrant networks for nurse migration. Choy (2006) outlines the importance of nursing school friends and classmates in determining migration patterns for Filipino nurses. Prospective migrant nurses often submitted visa applications as a batch with groups of friends. Certain historical migrant networks are also more likely to facilitate migration to the U.S. Turning to Appendix Table 1 and the top origin provinces for nurse migrants, Ilocos Norte, Ilocos Sur, Pangasinan, and La Union are places where mass emigration of Filipinos to the U.S. originated as a result of recruitment from Hawaiian sugar plantations in the early 1900s. In addition, Zambales, Pampanga, and Tarlac are where the U.S. established military bases at the end of World War II. ${ }^{1}$
\end{abstract}

A unique aspect of the Americanized nursing curriculum was the emphasis on both grammatical and colloquial English, even relative to other English-speaking colonies. ${ }^{2}$ During the colonial period, Filipino nurses came to the U.S. on short exchanges and training missions. These flows increased dramatically in the 1950s and 1960s with the formation of the Exchange Visitor Program (EVP) for nurses, a two-year training and cultural exchange program. Many Filipino EVP nurses desired to stay in the U.S. permanently, though few pathways existed at the time. Following the Immigration Act of 1965, permanent nurse migration to the U.S. became possible, and by 1967, the Philippines became the top origin country for nurses globally.

\section{Appendix B: Data Construction}

This data appendix outlines the technical details for the construction of the datasets used in this paper. Our final dataset includes province-year-level data on migration rates, postsecondary education, and nursing licensure exam pass rates.

In all datasets, we use consistent geographic boundaries based on 1990 province definitions. The sample excludes the provinces of Tawi-Tawi and Sulu due to low rates of reporting. The poor data quality from these provinces is typical in data from the Philippines, and is likely due to the decades old conflict between the Philippine government and local leaders in the two provinces. We treat Metro Manila as a single province. Metro Manila is composed of four administrative districts, which make up the National Capital Region (NCR). It is typical to either treat Metro Manila as a single province, as we do here, or as four separate provinces. We treat Manila as a single province because it is common for students to travel around the metro area for postsecondary education.

\footnotetext{
${ }^{1}$ For a full discussion of the history of these areas with respect to the U.S., see Scalabrini Migration Center (2011).

${ }^{2}$ In 1920, 5\% of the nursing licensure exam was devoted to testing English language skills.
} 


\section{A1. Migration Data}

The migration data are from the Commission on Filipinos Overseas (CFO), a government agency responsible for registering emigrants and strengthening the ties of the diaspora with the homeland. All emigrants who plan to move abroad on permanent immigrant visas are required to register with the CFO before leaving. We obtained administrative data on all permanent migrants who departed from the Philippines from 1990 to 2013. The data are recorded from a mandatory pre-departure form, and include information on demographics, birthplace, usual address, country of destination, education, course of study, and profession for each migrant. Migrants cannot obtain exit clearance without filling out this form in its entirety. 1,565,635 individual, permanent migration episodes occurred between 1990 and 2013.

We define nurse migrants as those who had obtained at least a bachelor's degree in nursing or whose usual work was as a professional nurse prior to migration. All other migrants were classified as non-nurse migrants. We then calculated province-level migration rates for nurses overall, nurses to the U.S., and non-nurses by counting individuals within each group who were of working age (18 to 60 years old), and dividing it by the working age population in each province-year. The working age population in each province-year was computed from the 1990, 1995, 2000, 2010, and 2015 Philippine Census data. We interpolated working-age population counts for years in between these censuses by using population growth rates for each province, which we also computed from the Census data.

\section{A2. Postsecondary Education Data}

The postsecondary education data are from the Commission on Higher Education (CHED), the government agency responsible for oversight of the postsecondary education system in the Philippines. We obtained institution-level administrative data on the number of enrollees and graduates in each academic year from 1991 to 2013, disaggregated by program of study.

To calculate rates of enrollment and graduation for nursing and other disciplines, we count the number of 1.) enrolled students taking these courses and 2.) graduates of these courses in each province-year. We identify the course using the program of study information in the data. We then divide these counts by the college-age population to calculate enrollment and graduation rates. We computed the college-age population in each province-year from the 1990, 1995, 2000, 2010, and 2015 Philippine Census data. We interpolated college-age population counts for years in between these censuses by using population growth rates for each province as computed from the Census data.

This dataset includes 1,702 province-year level observations. We drop 32 observations for the enrollment rate because of lack of reporting by institutions in the province. This yields a sample of 1,670 provinceyear enrollment rates, with $1.8 \%$ of the original sample missing. Graduation data are only available from 1998 onwards. 15 province-year level observations are missing due to lack of reporting by institutions (1.3\%). Institutions that offered other types of degrees but began offering nursing programs during our sample period are counted as new nursing programs in the year the nursing program began.

To determine the number of nursing programs in each year, we counted the number of schools offering nursing programs in each province and year. Schools were classified as offering a nursing program if they reported students enrolled in or graduating from such a program. If a school did not appear in the data for a single year, we assumed that this is because the school failed to submit their data for that year, and so we include the school in our final province-year count of programs. This affected less than $1 \%$ of observations. 


\section{A3. Nursing Licensure Exam Data}

The Philippine Nursing Licensure exam is administered by the Philippine Professional Regulation Commission (PRC). The PRC administers licensure exams in a wide variety of disciplines such as accounting, engineering, and nursing. The nursing licensure exam is offered in 12 locations around the Philippines two times per year. The results of the exam are published in the newspaper, and show the pass rates for each nursing school as well as individual scores on the exam. To qualify as a nurse, an individual must correctly answer $75 \%$ of questions.

We obtained reports from the PRC on the number of examinees and the number of passers of the exam by institution-month-year from 1990-2016. The month is when the exam was administered, usually June and November. The reports from 1990-2005 were only available in hard copy, while the reports from 2006 to 2016 were available as electronic PDFs. We then encoded these documents to create an institution-monthyear dataset. We cleaned the data so that institution names were consistent over time. This included both name changes of institutions over time as well as spelling errors in the reports.

Geographic information about each institution is not included in the PRC reports. Since our unit of analysis is the province-year, we assigned each institution to its province and aggregated the monthly data in order to calculate exam pass rates at the province-year level. To account for measurement error, we replaced the number of examinees and the number of passers with the average of the preceding and succeeding years if a given observation is three times above or below the preceding and succeeding years. $2.1 \%$ of the observations for number of examinees, and $2.9 \%$ of observations for the number passed are replaced with the average following this rule.

\section{A4. Calculating Wages and Probabilities for Utility Function Calibration}

To calculate the wages used in our back-of-the-envelope calibration, we use data from the 2004-2006 Philippine Labor Force Survey (LFS). We are limited to these years of the expansion period because they are the only years that include data on both wages in the Philippines and detailed occupation codes, such as nursing. Wage data are only available from 2001 onward, while detailed occupation codes are available from 2004 onward. We calculate the wages earned by nurses in the Philippines ( $\left.\mathrm{w}_{\mathrm{N}, \mathrm{PH}}\right)$ by averaging wages for all individuals working as nurses. To calculate the wages of individuals who have a nursing degree but do not work as nurses $\left(\mathrm{w}_{\mathrm{NO}, \mathrm{PH}}\right)$, we are limited by the fact that we only know the broad degree type which includes all individuals with bachelor's degrees in medical fields, engineering, and architecture. As such, we calculate wages for all individuals with this degree type who are not working in an occupation in these fields. This means that we include wages of, for instance, an engineer, who is not working in an engineering field. Note that individuals with degrees beyond a bachelor's (such as doctors) are excluded. We include wages equal to zero for anyone with this degree type who is not working. Finally, to obtain wages for individuals who do not enroll in a nursing degree $\left(\mathrm{w}_{\mathrm{O}, \mathrm{PH}}\right)$, we calculate the average wage for all workers with a bachelor's degree who are not working in nursing. We again include wages equal to zero for anyone with this degree type who is not working. All wages are converted from Philippine pesos to U.S. dollars using PPP exchange rates. Wages are reported as daily wages, and we convert these to annual wages by assuming individuals work 20 days per month for 12 months. We use wage data from the U.S. Bureau of Labor Statistics to determine average wages for nurses in the U.S. $\left(\mathrm{w}_{\mathrm{N}, \mathrm{US}}\right)$. We average these wages over 2004 to 2006 in order to match the time period of the LFS wages.

To calculate the relevant probabilities, we calculate $\mathrm{p}_{\mathrm{N}, \mathrm{us}}$ by first determining the number of nurses migrating from the Philippines to the U.S. during the expansion years (2000 to 2006), which is 26,835. We divide this by the total stock of individuals with nursing degrees in Philippines. To obtain the total stock, we average the total number of individuals with a nursing degree in each year from 1992-2000 LFS. In LFS waves prior to 2001, we have data on the detailed degree type (specifically nursing degree) 
which we do not have in the data from 2001 onward. Because there could be individuals with a nursing degree who are outside the age range for migration, we calculate the stock based on the $5^{\text {th }}$ to $95^{\text {th }}$ percentile of ages, or ages 26 to 58. This results in a stock of 420,732 people with a nursing degree. Dividing 26,835 by 420,732 yields $\mathrm{p}_{\mathrm{N}, \mathrm{US}}=0.06$. To determine $\mathrm{p}_{\mathrm{N}, \mathrm{PH}}$, we obtain the average number of individuals working as nurses in the Philippines from the 2000 and 2010 Philippine Censuses, or 186,012. We divide this by the total stock of individuals with nursing degrees, such that $\mathrm{p}_{\mathrm{N}, \mathrm{PH}}=0.442$.

\section{Appendix C: Bounding Exercises for Internal Migration for Education}

As we discussed in Section 4, one potential source of bias is cross-province migration for nursing education from low to high nurse migration provinces. For instance, if individuals from low nurse migration provinces enroll in nursing school in high nurse migration provinces, this will overstate the enrollment effects. Ideally, we would calculate province-level nursing enrollment rates based on the home province of the student, but the CHED data do not allow for this sort of calculation. Instead, we explore rates of cross-province migration for post-secondary education using the Philippine Census in Appendix Table 3. The timing of Census waves is particularly convenient: the 2000 data represent pre-expansion enrollment patterns, the 2007 data represent post expansion and pre-contraction enrollment patterns, and the 2010 data represent post contraction enrollment patterns. The Census does not include information on the type of degree a postsecondary student is obtaining, so we are unable to disaggregate cross-province migration for nursing degrees versus other types of degrees. Approximately $8 \%$ of all postsecondary students attend in a province other than the one in which they reside, and this appears stable across Census waves. Columns 2 through 5 decompose this national rate into rates of cross-province migration between low and high nurse migration provinces. Most migration for college is between high nurse migration provinces (Column 4), which is not a concern for our estimates.

While total rates of cross-province migration for postsecondary education from low to high provinces are small (Appendix Table 3), we bound our estimates to address this concern. To begin, consider that the impact of the visa expansion on nursing enrollment in high relative to low nurse migration provinces represents an additional 3,059 nursing students enrolled in the average province, or a $129 \%$ increase (Table 1). ${ }^{3}$ Based on the 2007 Census, which was fielded during the peak of the expansion period, the average high nurse migration province had 613 postsecondary students in any field of study who moved from low nurse migration provinces. For our initial bounds, we make two extreme assumptions: 1) that prior to the visa expansion, no students migrating from low to high provinces to attend college were enrolled in nursing programs; and 2) that after the expansion, all students migrating from low to high provinces to attend college were enrolled in nursing programs. Under these assumptions, all 613 of the 3,059 additional nursing students were misclassified as from high provinces instead of low, leading to an overestimate of the treatment effect. A conservative lower bound estimate for our effects would remove these students from the high provinces and include them in the low provinces. This suggests the average high nurse migration province experienced a $1,833(=3,059-1,226)$, or $77 \%$, student increase in response to the policy expansion, compared to the $129 \%$ increase that we report in Table 1 .

While this is still a sizeable effect, it relies on two extreme and unrealistic assumptions. To estimate a more realistic lower bound, we relax assumption 2 and instead assume that after the visa expansion, students migrating for postsecondary schooling enrolled in nursing programs at the same rate that all postsecondary students nationally enrolled in nursing programs. At the peak of nursing program enrollment (2006), $20.8 \%$ of postsecondary students were enrolled in nursing programs. If $20.8 \%$ of the

\footnotetext{
${ }^{3}$ We calculate this effect by adding up the effect of the policy change in each year from 2000 to 2006, and dividing by 7 , as in Section 5.1 .
} 
613 migrating students enrolled in nursing programs, this would represent 128 students on average moving from low to high nurse migration provinces. Reassigning these 128 students from high to low migration provinces would yield an increase of nurse enrollment in high relative to low provinces of $2,803(=3,059-256)$ students, or $118 \%$, compared to our estimate of $129 \%$ (Table 1$)$. Thus, under conservative but reasonable assumptions, we show that it is unlikely that migration for education between low and high provinces significantly biases our results.

\section{Appendix D: Risk Aversion and Major Choice}

We find sizeable enrollment, graduation, and licensure responses to the increased opportunities for nurse migration in spite of the fact that the probability of migrating to the U.S. is still quite low. Given the low probability of nurse migration to the U.S., is it reasonable that students would change their education decisions and switch degree types in response? To provide some intuition on this choice, we conduct a simple back-of-the-envelope calibration of a standard utility function under different levels of risk aversion.

We assume constant relative risk aversion (CRRA) CES utility, such that:

$$
U(c)=\frac{c^{1-\gamma}}{1-\gamma}
$$

Individuals have no savings, such that income and consumption are identical, and models of expected utility of consumption and income are identical. Individuals make the decision whether to enroll in a nursing program or stay enrolled in their counterfactual field of study. If they enroll in a nursing program, they have probability $p_{N, U S}$ of migrating to the U.S. as a nurse, probability $p_{N, P H}$ of working as a nurse in the Philippines, and probability $\left(1-p_{N, U S^{-}} p_{N, P H}\right)$ of not getting a job as a nurse either in the U.S. or the

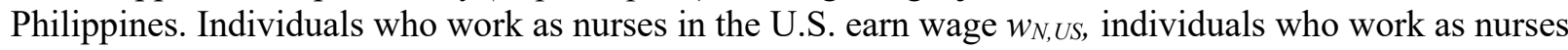
in the Philippines earn $w_{N, P H}$, and individuals who have a nursing degree but do not get a job as a nurse earn $w_{N O, P H}$. If the individual does not enroll in a nursing degree, they earn wage $w_{O, P H .}{ }^{4}$

Thus, the individual is indifferent between switching to a nursing degree if:

$$
\mathrm{p}_{\mathrm{N}, \mathrm{US}} \frac{w_{N, U S}{ }^{1-\gamma}}{1-\gamma}+\mathrm{p}_{\mathrm{N}, \mathrm{PH}} \frac{w_{N, P H}{ }^{1-\gamma}}{1-\gamma}+\left(1-\mathrm{p}_{\mathrm{N}, \mathrm{US}}-\mathrm{p}_{\mathrm{N}, \mathrm{PH}}\right) \frac{w_{N O, P H}{ }^{1-\gamma}}{1-\gamma}=\frac{w_{O, P H}{ }^{1-\gamma}}{1-\gamma}
$$

We calculate the probabilities and wages from our data in Appendix A4, and calibrate the model under varying levels of risk aversion. We calculate $p_{N, U S}$ by dividing the number of nurses migrating from the Philippines to the U.S. during the expansion years by the total stock of individuals with nursing degrees in the Philippines $\left(p_{N, U S}=0.06\right)$. To determine $p_{N, P H}$, we divide the number of individuals working as nurses in the Philippines by the total stock of individuals with nursing degrees $\left(p_{N, P H}=0.44\right)$. We use wage data from the U.S. Bureau of Labor Statistics to determine average annual wages for nurses in the U.S. $\left(w_{N, U S}=\right.$ USD 56,940). Using the Philippine LFS, we calculate average annual wages of nursing in the Philippines $\left(w_{N, P H}=\mathrm{USD} 6,571.2\right) .{ }^{5}$ The wages of those with a nursing degree working in an alternative field are $w_{N O, P H}=\mathrm{USD} 3,304$. Finally, individuals who do not switch degree types earn the average wage for all college educated workers who are not working as nurses ( $\left.w_{O, P H}=\mathrm{USD} 4,344\right)$.

We calculate the certainty equivalent wages, $\mathrm{w}_{\mathrm{CE}}$, under several reasonable levels of risk aversion. Following Morten (2019), who examines migration and risk sharing in India, we use values of $\gamma=0.5$,

${ }^{4}$ Tuition costs are similar across degree types. For nursing programs, tuition is approximately USD 1200 per year (Arends-Kuening et al., 2015). These costs are slightly higher than for liberal arts degrees, but similar to other, specialized programs such as engineering (authors' calculations).

${ }^{5}$ All Philippine wages are converted to U.S. dollars at PPP exchange rates. 
1.2, 1.6, 2.0, and 2.5. Appendix Table 9 shows the certainty equivalent for each value of the coefficient of relative risk aversion. Individuals are more risk averse as $\gamma$ increases. Under all levels of risk aversion used by Morten, individuals would choose to take the gamble and enroll in a nursing degree since $\mathrm{w}_{\mathrm{CE}}>\mathrm{W}_{\mathrm{O}, \mathrm{PH}}$. For instance, even when $\gamma=2.5$, we calculate that individuals would be indifferent between the gamble of switching to a nursing degree and earning USD 4,374 with certainty, which is greater than the average wages for college educated workers not working as nurses ( $\left.\mathrm{w}_{\mathrm{O}, \mathrm{PH}}=\mathrm{USD} 4,344\right)$.

This simple calibration suggests that individuals with reasonable levels of risk aversion would choose to enroll in a nursing degree program instead of an alternative degree program, even though the chance of migration to the U.S. is quite low. Note that this calculation ignores any non-pecuniary benefits to U.S. migration, such as potential citizenship for the migrant and their family, which has large benefits, and would increase the returns to migration.

\section{Appendix E: Robustness Checks}

We outline a series of robustness checks in Section 5.4, with results shown in Appendix Table 7. To conserve space and for ease of exposition, we estimate basic difference-in-differences specifications for our robustness checks, where Post Expansion is a dummy variable equal to 1 in the year 2000 and after, and Post Contraction is a dummy variable equal to 1 in the year 2007 and after. ${ }^{6}$ Panel A replicates the main results from Table 1 using this simpler difference-in-differences framework, revealing increases in all outcomes post-expansion in high relative to low nurse migration provinces. The coefficients on Post Contraction $x$ High give the difference between the post-expansion level and the post-contraction level. The smaller and statistically insignificant coefficients for all outcomes other than nursing programs are consistent with the symmetric increase and decrease shown in the event study figures. The postcontraction effect for nurse programs is positive and significant which is consistent with the event study.

In terms of the robustness of the nurse program results in Panels D and E, Manila is an extreme outlier in terms of both average years of schooling and urbanity, with approximately two more years of education at baseline than other high nurse migration provinces and $100 \%$ of households in urban areas. Manila is also an outlier in nursing programs, with a very high number of programs, but also a very low percent growth given the high initial level. When education and urbanity controls are added, the event study compares nurse program growth in high versus low nurse migration provinces with similar levels of baseline education and urbanity. The very low nursing program growth in Metro Manila contrasts with the positive relationship between education, urbanity, and nursing program growth in other provinces, thus pulling down the overall nursing program point estimate, and producing the apparent null result. We prefer to include Manila in our sample, yet do not want the results to be driven by a single, outlier province. Thus, we exclude these controls from our preferred specification. ${ }^{7}$

\section{Appendix F: Persistence Rates}

In Section 5.5, we show that total graduation increased in response to the visa policy changes. Given the lack of effects on enrollment, we argue that this is due to increased persistence for individuals switching

\footnotetext{
${ }^{6}$ The pooled estimates (equation 2) for all robustness checks are shown in Appendix Table 8.

${ }^{7}$ The results are also robust to the inclusion of population weights, with the one exception of the nursing program results. Similar to the results shown in Panel D, the attenuation of these results is driven by Metro Manila, which has a high number of baseline nursing programs and low nursing program growth. If we consider the population weighted results without Metro Manila, we cannot reject the null hypothesis that the effect on nursing programs is equivalent to the main results shown Appendix Table 7 (row 1), though the effect is not statistically significant.
} 
to nursing programs from other degree types. Were the graduation rates in the Philippines prior to the policy changes low enough to plausibly accommodate increased persistence rates as an explanation for the increase in total graduates? To explore this, we calculate the pre-period nationwide persistence rate as the number of graduates out of enrollees. Because we do not have enrollment data by class year, we divide the pre-period average number of graduates by one quarter of the pre-period average number of enrollees. ${ }^{8}$ Approximately $74 \%$ of enrollees graduate from college in the pre-period. Total graduation increased by 0.558 percentage points (Table 2, Column 4). Given an average pre-period total graduation rate of $4.67 \%$, the visa expansion led to an $11.9 \%$ increase in the graduation rate, or 560.5 new graduates per year in the average province. If the entire increase in total graduates was due to an increase in the persistence rate, then the $11.9 \%$ increase in total graduates in the expansion period would yield an 8.8 $(=74 \% * 0.119)$ percentage point increase in the share of enrollees that graduate, resulting in a persistence rate of $82.8 \%$. This suggests that there was room for an increase in persistence to explain the increase in total graduates.

\section{Appendix G: Domestic Nursing Employment}

In Section 5.6, we explore whether there are more domestically employed nurses in the Philippines following the visa expansion. Using the 1990, 2000, and 2010 Philippine Census, we examine if these individuals worked as nurses at home. Nationally, nurse and midwife employment increased slightly between 1990 and 2000 and substantially between 2000 and 2010 (Appendix Figure 8). ${ }^{9,10}$ Of course, such an increase is not necessarily due to changes in U.S. visa policy. To attempt to estimate the causal impact of the visa expansion on domestic nurse employment, we employ a basic difference-in-differences strategy and estimate the following equation:

$$
Y_{p t}=\beta_{0}+\beta_{1} \text { High }_{p, 1990} \text { Post }_{t}+\alpha_{p}+\gamma_{t}+X_{p 0} \gamma_{t}+\varepsilon_{p t}
$$

where $Y_{p t}$ is the number of nurses in province $p$, year $t$, divided by the 1990 province population, and Post is equal to 1 in 2010 and to 0 otherwise. ${ }^{11}$ All other variables are defined as in equation $1 .{ }^{12}$

The number of Filipinos employed as nurses increased by 1.04 percentage points $(\mathrm{SE}=0.281)$ in response to the visa policy changes. Given that $1.26 \%$ of the province working-aged population worked as a nurse in the pre-period, this is an $83 \%$ increase in nurse employment. Based on the pre-period province average of 2,205 nurses, this yields an increase of 1,830 nurses in high relative to low nurse migration provinces. We check for pre-trends by restricting our analysis to the pre-period years, with 2000 treated as the "post" period. The coefficient in the check for pre-trends is small and not statistically significant $(0.173$, $\mathrm{SE}=0.137$ ), indicating that this effect is not driven by differential trending in nurse employment in high nurse migration provinces. While this basic difference-in-differences analysis using only three census

\footnotetext{
${ }^{8}$ Taking a quarter of pre-period enrollment likely yields an overestimate since it assumes an equal number of enrollees across 4 years, but some enrollees will drop out as they progress.

${ }^{9}$ Unfortunately, the 2000 Census does not allow us to separately identify nurses and midwives. In the 2010 Census, $85 \%$ of individuals in the nurse/midwife category were nurses, so it is likely that the majority of workers in this category in 2000 are also nurses.

${ }^{10}$ In 2000, the Philippines had 4.3 nurses and midwives per 1,000 people, compared to 1.61 for middle income countries (World Development Indicators). In 2009, this had increased to 5.7 for the Philippines, versus 1.91 for middle income countries in 2010.

${ }^{11}$ While the U.S. visa policy expansion occurred in 2000, we saw in Section 5.1 that nurse graduation occurred with a lag, and so we treat 2000 as the pre-period.

${ }^{12}$ Baseline domestic nurses per capita x year fixed effects are now excluded as controls since baseline domestic nurses per capita is encompassed in the outcome variable.
} 
years is not ideal, it certainly suggests that, rather than a brain drain, the Philippines appears to have employed significantly more nurses in response to the policy changes.

\section{References}

Arends-Kuenning, Mary, Alvaro Calara, and Stella Go. 2015. "International Migration: Opportunities and Occupational Choice: A Case Study of Philippine Nurses 2002 to 2014.” IZA Discussion Paper No. 8881 .

Morten, Melanie. 2019. "Temporary Migration and Endogenous Risk Sharing in Village India.” Journal of Political Economy, 127(1): 1-46.

Scalabrini Migration Center. 2011. Minding the Gaps: Migration, Development and Governance in the Philippines. Manila, Philippines. 


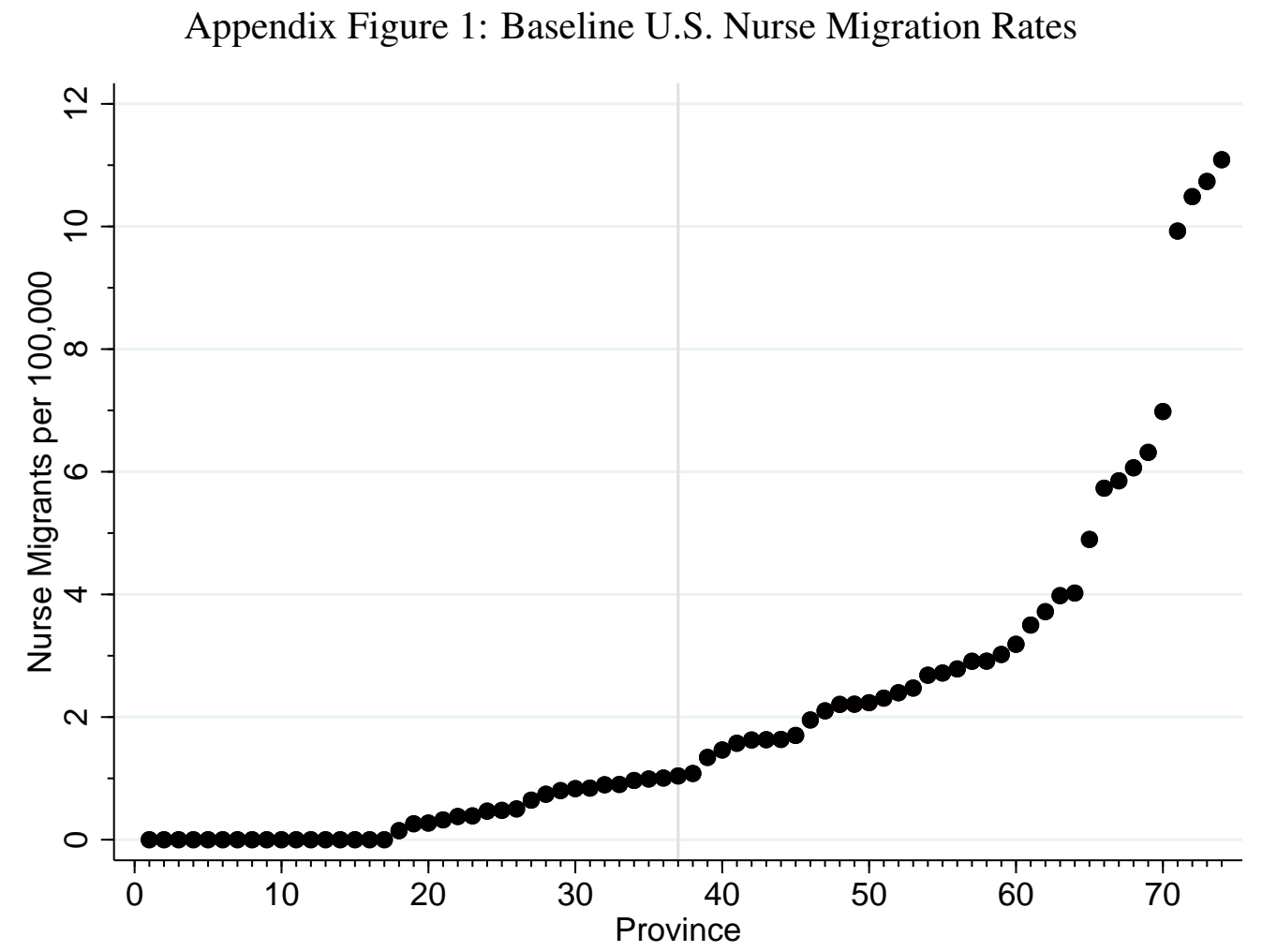

Notes: Baseline rates of nurse migrants to the U.S. per 100,000 are shown for each province. The grey line denotes the median. The baseline year is 1990.

Source: CFO, Census, and authors' calculations. 


\section{Appendix Figure 2: Effect of Policy Changes Using Continuous Treatment Measure}

(a) U.S. Nurse Migration Rate

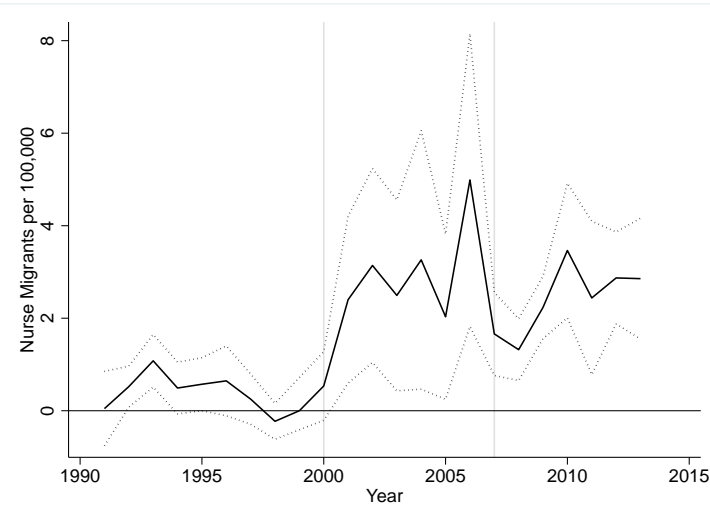

(c) Nursing Graduation Rate

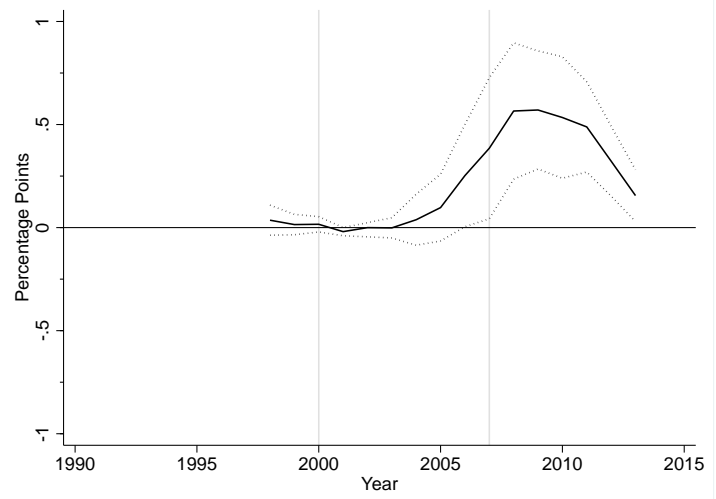

(e) Nursing Exam Pass Rate

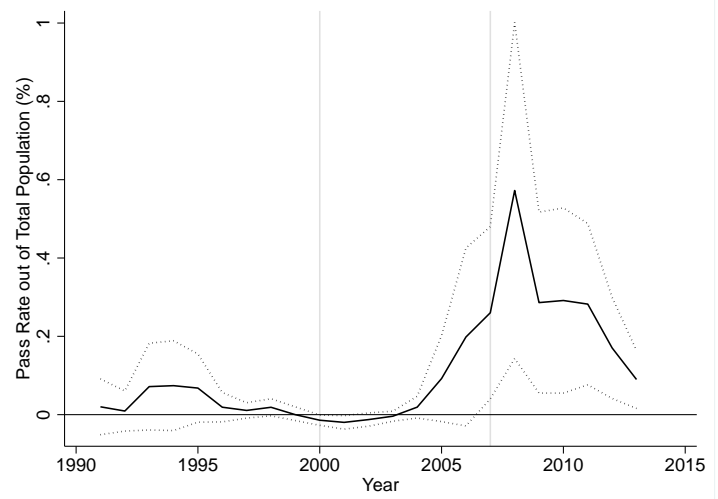

(b) Nursing Enrollment Rate

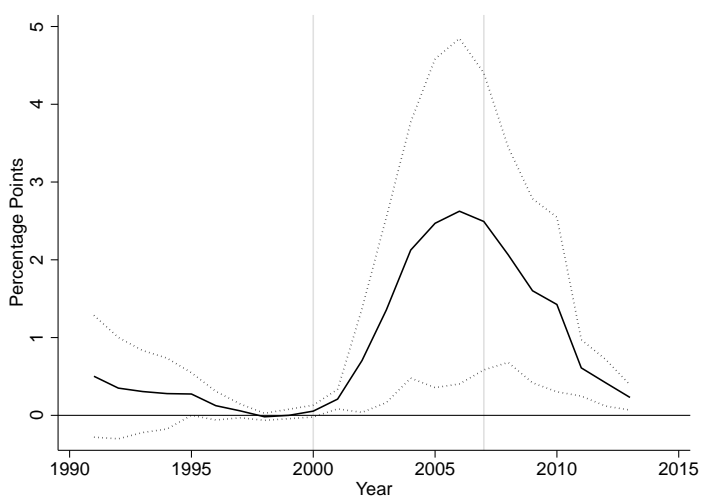

(d) Total Nursing Programs

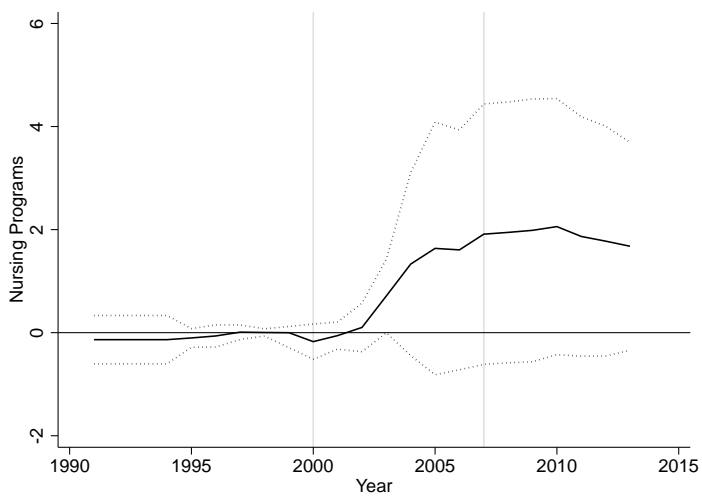

(f) Total Graduation Rate

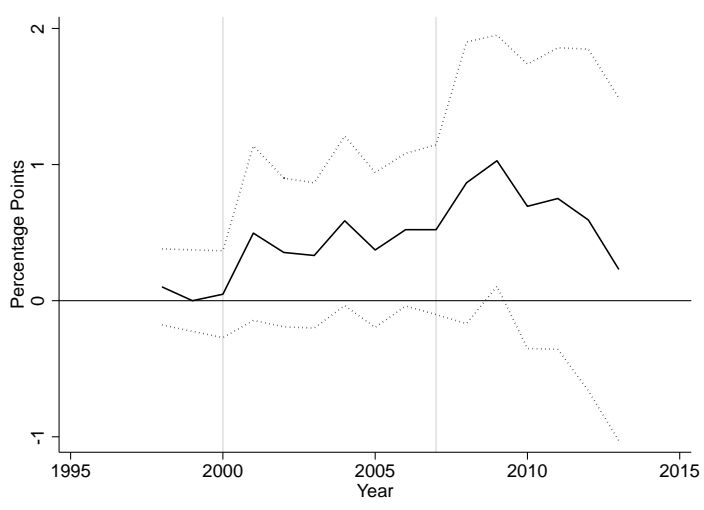

Notes: The solid line shows coefficients from the event study model (equation 1) using a continuous measure of the baseline nurse migration rate as the second difference, rather than the binary treatment variable High. The interaction with the indicator for 1999 is omitted to identify the model. 95\% confidence intervals are shown by dotted lines. All specifications include province and year fixed effects, and baseline controls interacted with year indicators as listed in Figure 2. The sample includes 74 provinces. Standard errors are clustered by province. The light grey vertical lines represent the visa expansion in 2000 and subsequent contraction in 2007.

Source: CHED, CFO, Census, and authors' calculations. 


\section{Appendix Figure 3: Effects Using Imputation Approach of Borusyak, Jaravel, and Spiess (2021)}

(a) U.S. Nurse Migration Rate

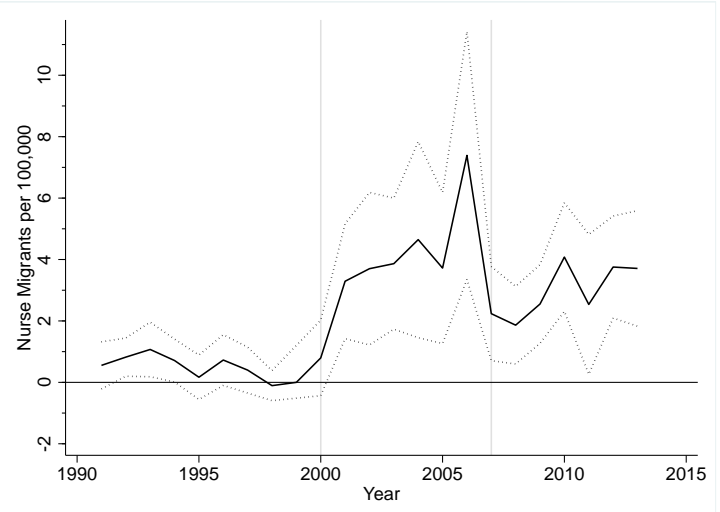

(c) Nursing Graduation Rate

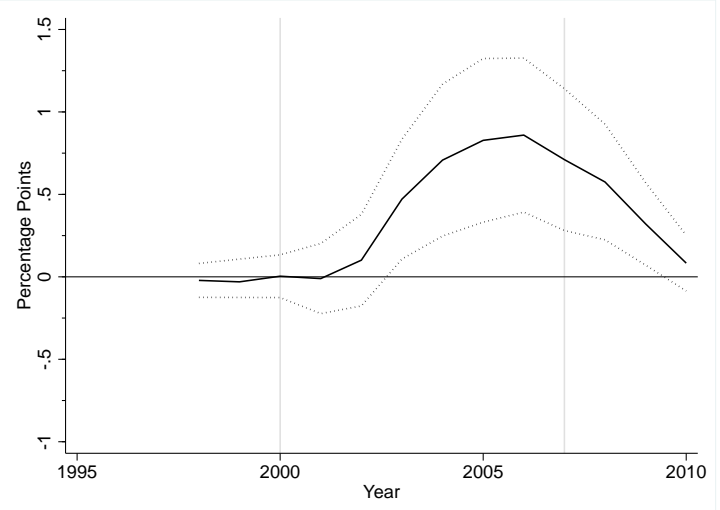

(e) Nursing Exam Pass Rate

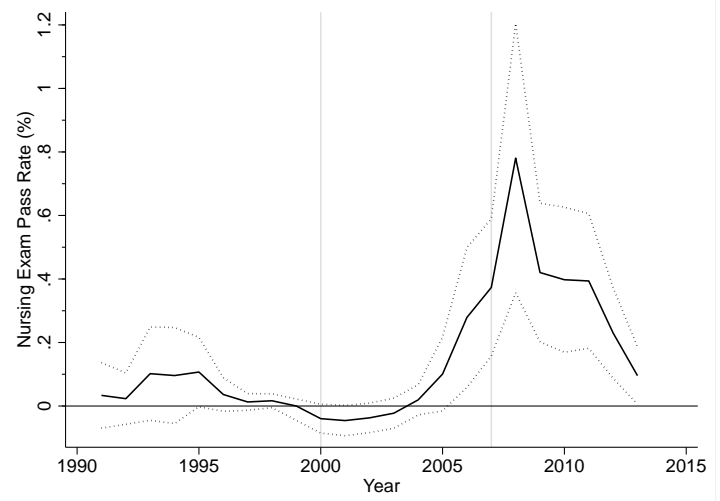

(b) Nursing Enrollment Rate

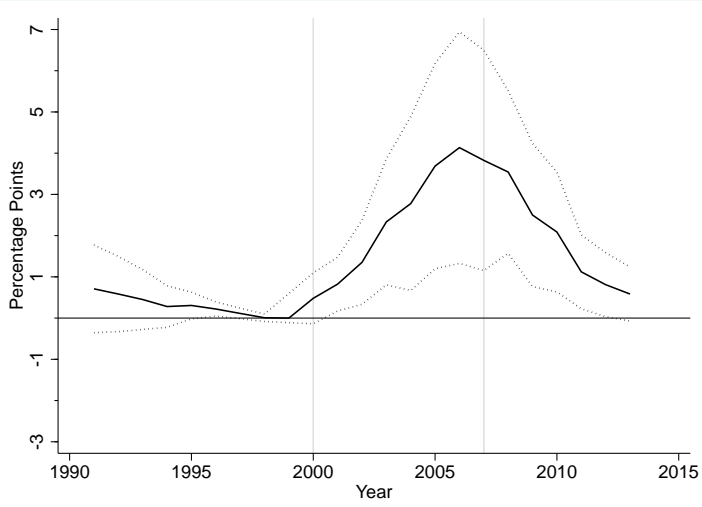

(d) Total Nursing Programs

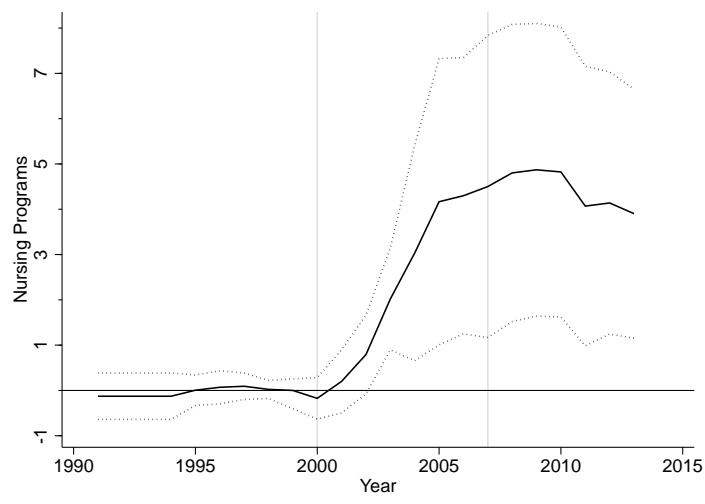

(f) Total Graduation Rate

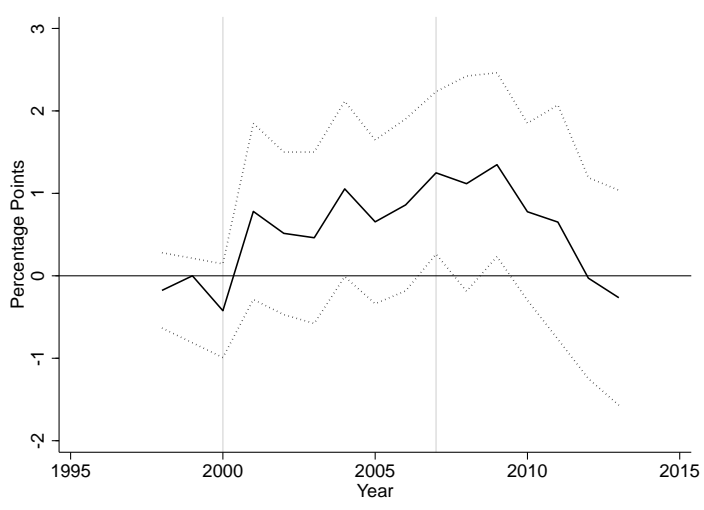

Notes: The solid line shows coefficients from the event study model (equation 1) using the imputation estimator from Borusyak et al. (2021). The interaction with the indicator for 1999 is omitted to identify the model. 95\% confidence intervals are shown by dotted lines. All specifications include province and year fixed effects, and baseline controls interacted with year indicators as listed in Figure 2. The sample includes 74 provinces. Standard errors are clustered by province. The light grey vertical lines represent the visa expansion in 2000 and subsequent contraction in 2007.

Source: CHED, CFO, Census, and authors' calculations. 


\section{Appendix Figure 4: Effect of Visa Expansion and Contraction on Nursing Enrollment and Gradu- ation Rates by Gender}

(a) Female Nursing Enrollment Rate

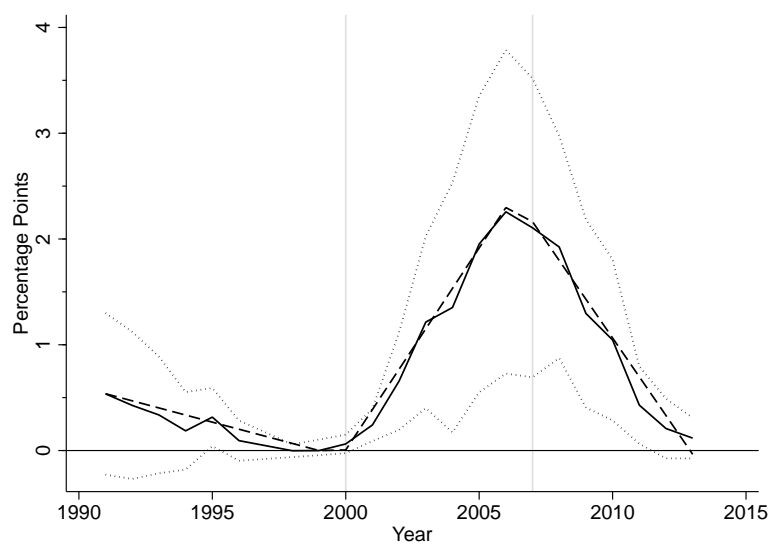

(c) Female Nursing Graduation Rate

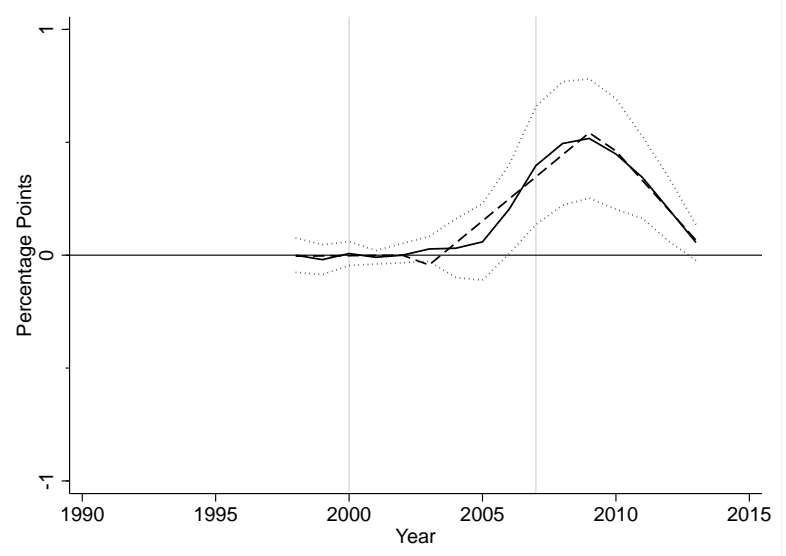

(b) Male Nursing Enrollment Rate

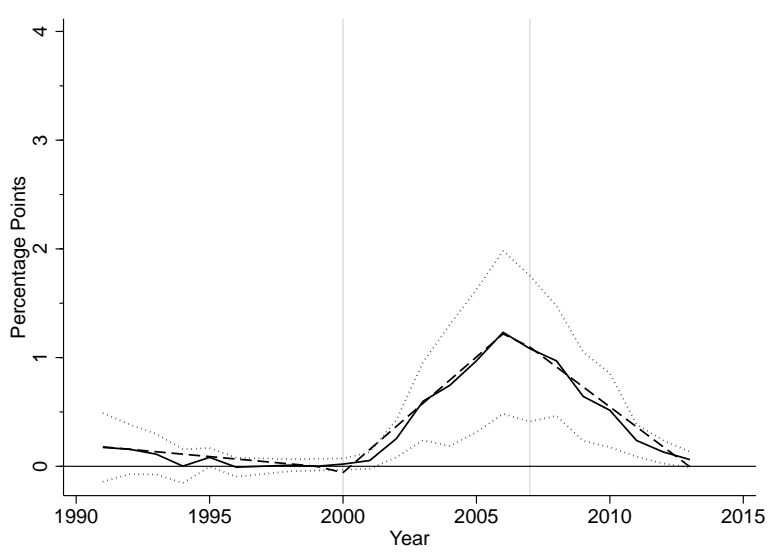

(d) Male Nursing Graduation Rate

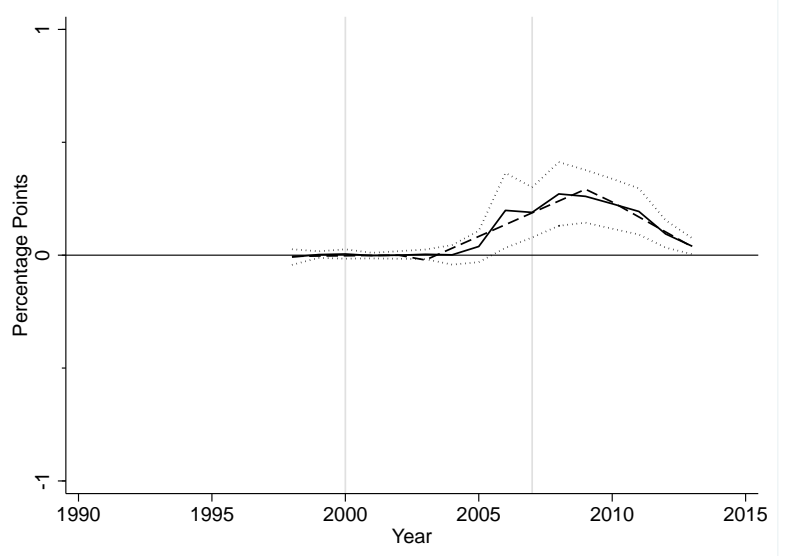

Notes: The solid line shows coefficients from the event study model (equation 1). The interaction with the indicator for 1999 is omitted to identify the model in Panels a and b and 2002 is omitted in Panels c and d since nurse graduation responds with a four-year lag. 1997 is missing in panels a and $b$ because CHED did not collect enrollment data by gender in that year. 95\% confidence intervals are shown by dotted lines. Dashed lines show the pooled model (equation 2). All specifications include province and year fixed effects, and baseline controls interacted with year indicators as listed in Figure 2. The sample includes 74 provinces. Standard errors are clustered by province. The p-value on the test of joint significance of pre-trends equals 0.17 (panel a), 0.12 (panel b), 0.88 (panel c), and 0.85 (panel d). The light grey vertical lines represent the visa expansion in 2000 and subsequent contraction in 2007.

Source: CHED, CFO, Census, and authors' calculations. 


\section{Appendix Figure 5: Effect of Visa Expansion and Contraction on Nurse Programs}

(a) Nursing Programs Added to Existing Private Institutions

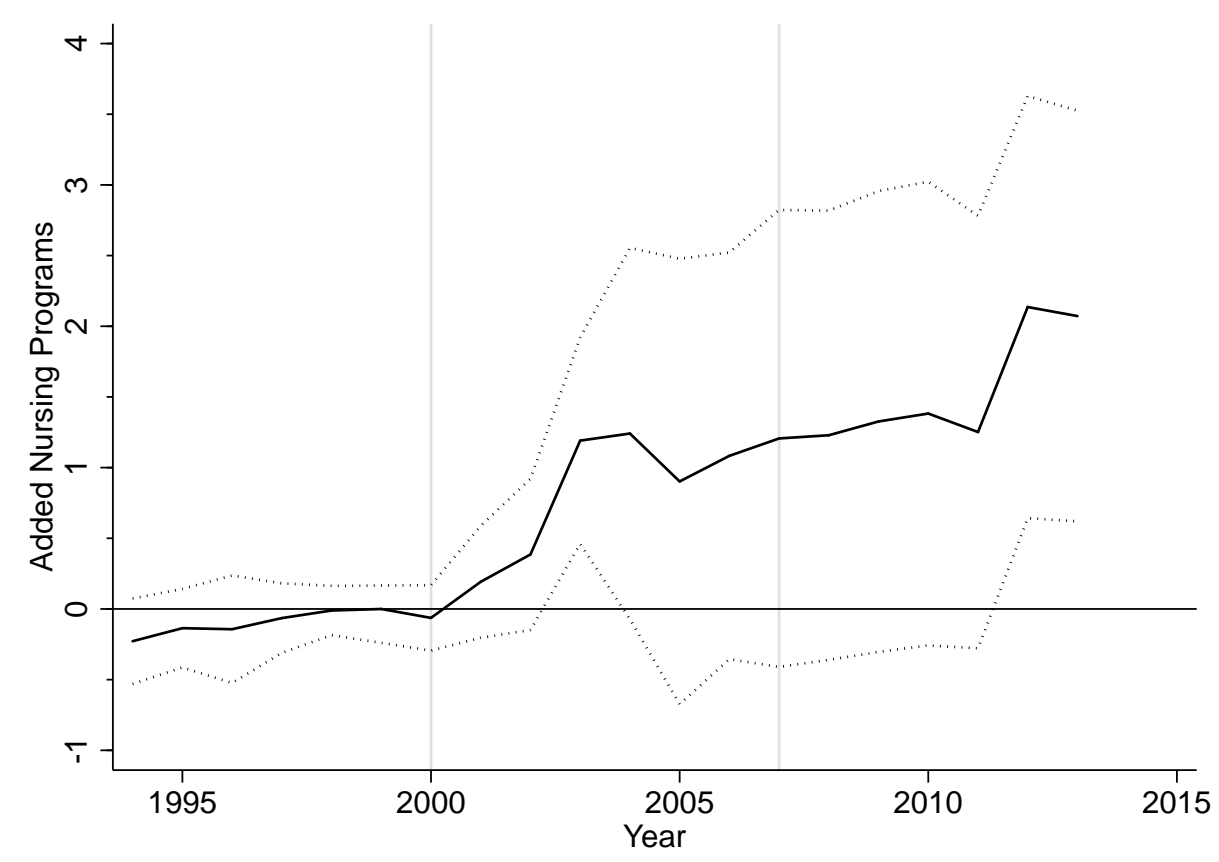

(b) New Private Nursing Institutions

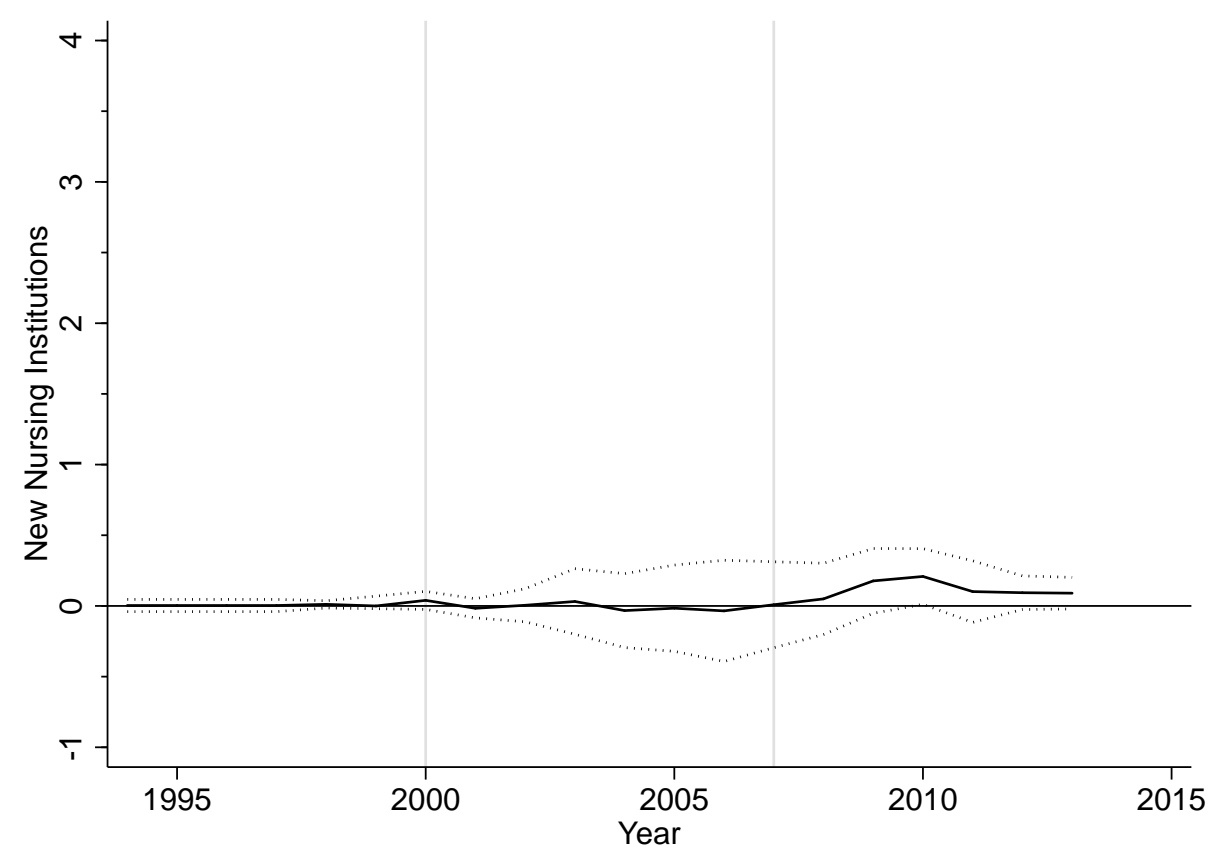

Notes: The solid line shows coefficients from the event study model (equation 1). The interaction with the indicator for 1999 is omitted to identify the model. 95\% confidence intervals are shown by dotted lines. All specifications include province and year fixed effects, and baseline controls interacted with year indicators as listed in Figure 2. The sample includes 74 provinces. Standard errors are clustered by province. The light grey vertical lines represent the visa expansion in 2000 and subsequent contraction in 2007.

Source: CHED, CFO, Census, and authors' calculations. 


\section{Appendix Figure 6: Effect of Visa Expansion and Contraction on Nursing Enrollment by Supply Elasticity of Nursing Education}

(a) More Elastic Supply

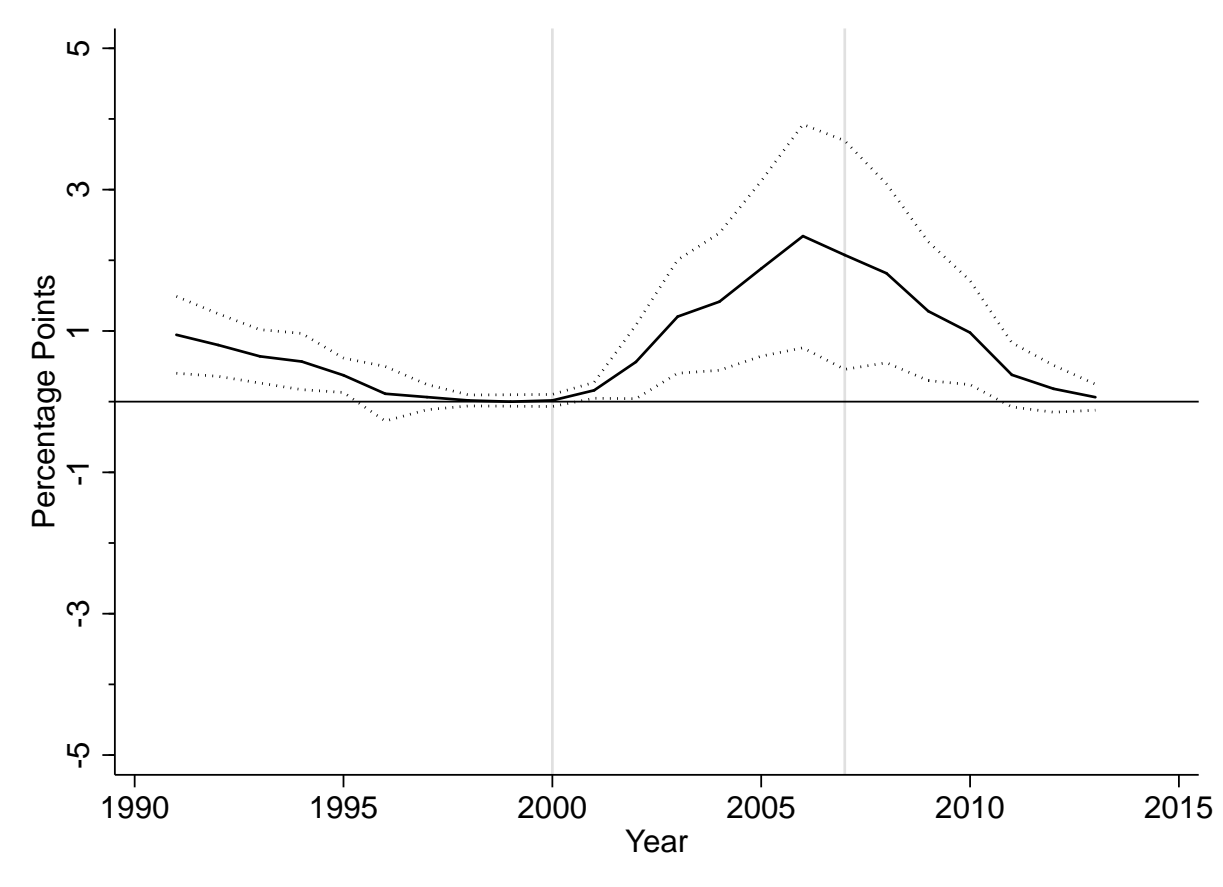

(b) Less Elastic Supply

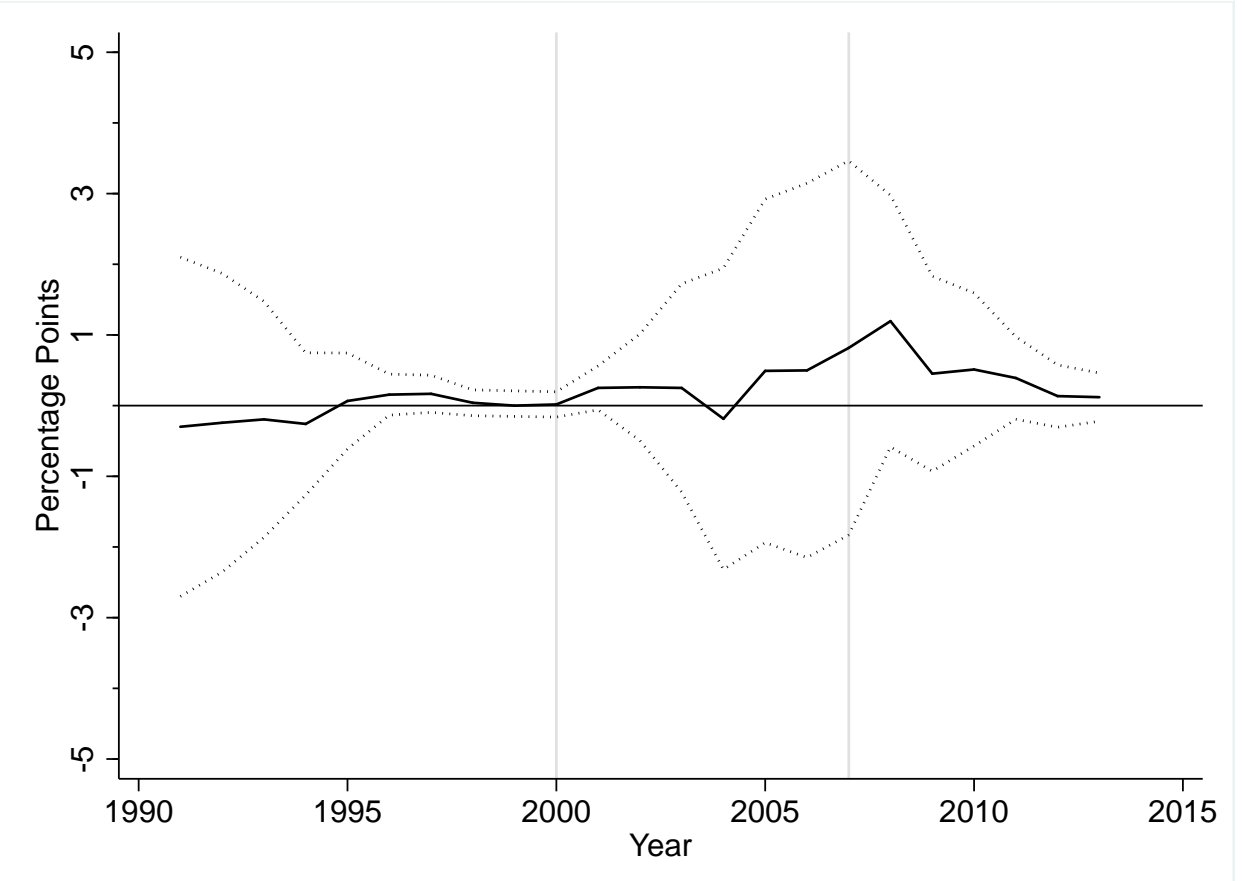

Notes: The supply elasticity is measured as the share of private institutions without nursing programs out of the total number of private institutions in the pre-period. A larger share indicates that the supply is more elastic, since there are more institutions where nursing programs can be added. Panel a includes provinces with above the median share, while panel $b$ includes provinces with below the median share. The solid line shows coefficients from the event study model (equation 1). The interaction with the indicator for 1999 is omitted to identify the model. $95 \%$ confidence intervals are shown by dotted lines. All specifications include province and year fixed effects, and baseline controls interacted with year indicators as listed in Figure 2. The sample includes 74 provinces. Standard errors are clustered by province. The light grey vertical lines represent the visa expansion in 2000 and subsequent contraction in 2007.

Source: CHED, CFO, Census, and authors' calculations. 


\section{Appendix Figure 7: Effect of Visa Expansion and Contraction on Non-U.S. Nurse Migration}

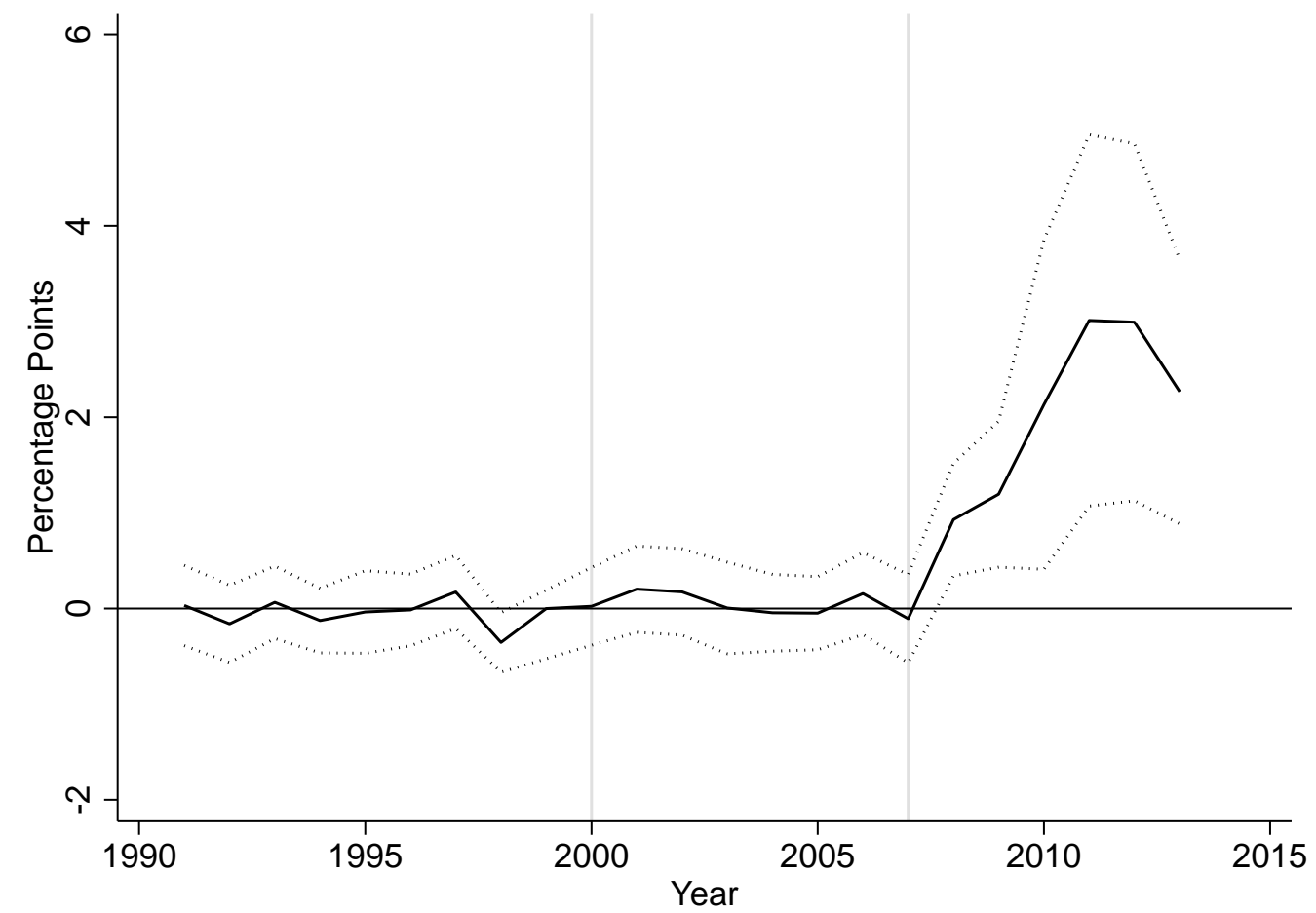

Notes: The solid line shows coefficients from the event study model (equation 1). The interaction with the indicator for 1999 is omitted to identify the model in all panels except Panel c, which omits 2002 since nurse graduation responds with a four-year lag. 95\% confidence intervals are shown by dotted lines. All specifications include province and year fixed effects, and baseline controls interacted with year indicators as listed in Figure 2. The sample includes 74 provinces. Standard errors are clustered by province. The light grey vertical lines represent the visa expansion in 2000 and subsequent contraction in 2007.

Source: CHED, CFO, Census, and authors' calculations. 


\section{Appendix Figure 8: Nurses and Midwives over Time}

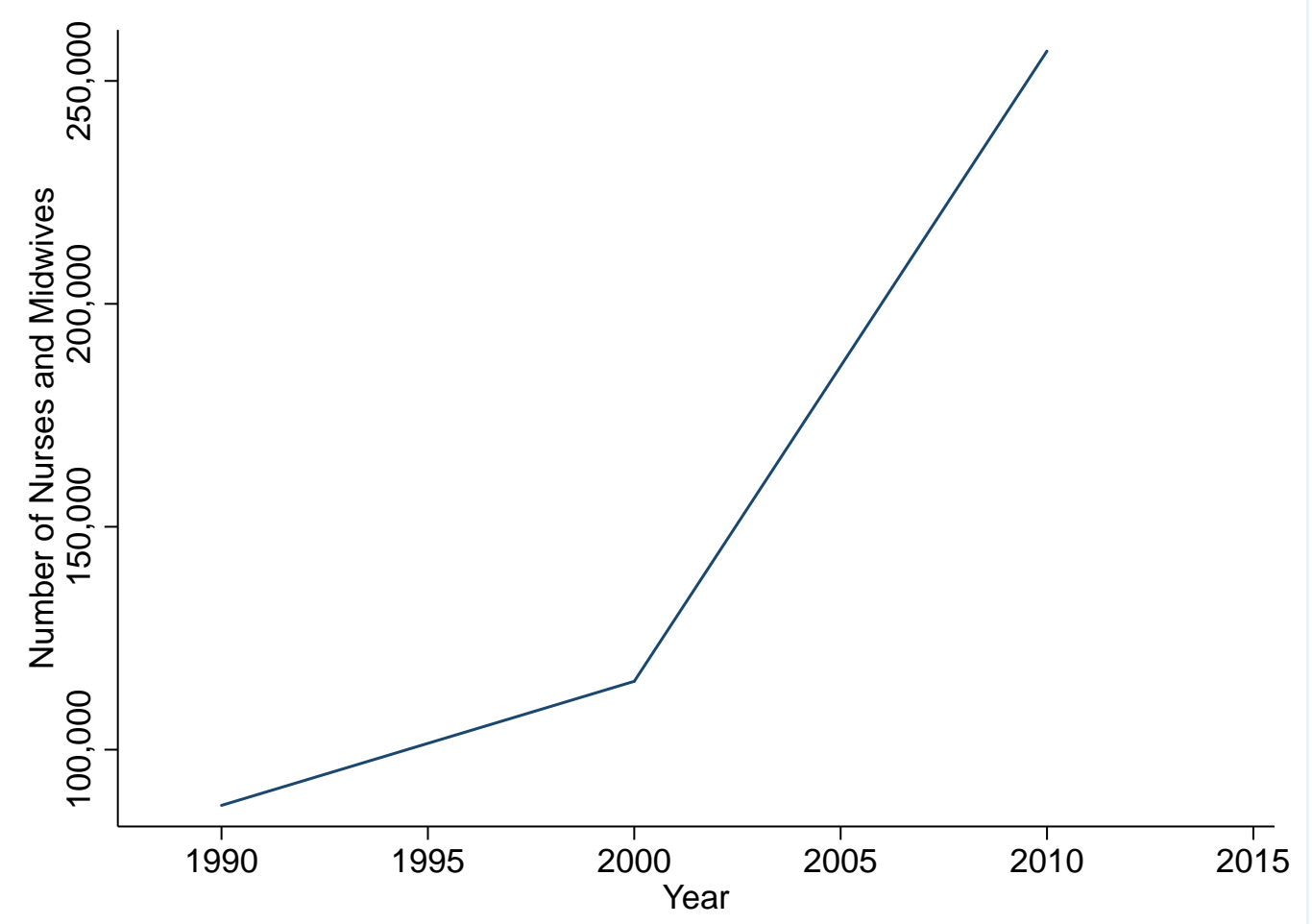

Notes: The graph shows the total number of nurses and midwives working in the Philippines based on the 1990, 2000, and 2010 Philippine Census of Population. Unfortunately, the 2000 Census does not allow us to separately identify nurses. In the 2010 Census, $85 \%$ of individuals in the nurse/midwife category were nurses.

Source: CFO and authors' calculations. 
Appendix Table 1. List of Top 20 Nurse Migration Provinces to the U.S.

Nurse Migrants to the U.S.

per 100,000 in 1990

1. Ilocos Norte

11.09

2. Zambales

10.73

3. Metro Manila

10.49

4. Benguet

9.26

5. Ilocos Sur

6.98

6. Pangasinan

6.32

7. La Union

6.07

8. Cavite

5.85

9. Iloilo

5.73

10. Pampanga

4.90

11. Tarlac

4.02

12. Nueva Vizcaya

3.98

13. Cebu

3.72

14. Bataan

3.50

15. Rizal

3.19

16. Aurora

3.02

17. Laguna

2.91

18. Nueva Ecija

2.91

19. Bohol

2.79

20. Aklan

2.72

Notes: Rates are nurse migrants to the U.S. per 100,000 residents aged $18-60$ in the province.

Source: CFO and authors' calculations. 


\begin{tabular}{|c|c|c|c|c|c|c|}
\hline & \multicolumn{2}{|c|}{ Full Sample } & \multicolumn{2}{|c|}{ High Nurse Migration Provinces } & \multicolumn{2}{|c|}{ Low Nurse Migration Provinces } \\
\hline & $\begin{array}{l}\text { Mean } \\
(1)\end{array}$ & $\begin{array}{c}\text { St. Dev. } \\
(2)\end{array}$ & $\begin{array}{c}\text { Mean } \\
\text { (3) }\end{array}$ & $\begin{array}{l}\text { St. Dev. } \\
(4)\end{array}$ & $\begin{array}{c}\text { Mean } \\
\text { (5) }\end{array}$ & $\begin{array}{l}\text { St. Dev. } \\
(6)\end{array}$ \\
\hline \multicolumn{7}{|l|}{ Panel A. All Years } \\
\hline \multicolumn{7}{|l|}{ Migrants Per 100,000 } \\
\hline Total & 75.03 & 93.83 & 123.00 & 112.29 & 27.06 & 20.11 \\
\hline U.S. Nurse & 3.89 & 5.46 & 6.17 & 6.54 & 1.61 & 2.55 \\
\hline Non-Nurse & 69.88 & 89.48 & 114.89 & 107.89 & 24.88 & 18.11 \\
\hline \multicolumn{7}{|c|}{ Postsecondary Enrollment Rates (\%) } \\
\hline Total & 25.02 & 14.70 & 29.14 & 16.88 & 20.88 & 10.64 \\
\hline Nurse & 1.80 & 3.14 & 2.73 & 3.97 & 0.87 & 1.52 \\
\hline Other & 23.21 & 12.98 & 26.41 & 14.62 & 20.01 & 10.15 \\
\hline \multicolumn{7}{|c|}{ Postsecondary Graduation Rates (\%) } \\
\hline Total & 4.43 & 2.41 & 5.21 & 2.64 & 3.66 & 1.86 \\
\hline Nurse & 0.42 & 0.67 & 0.64 & 0.82 & 0.20 & 0.35 \\
\hline Other & 4.01 & 2.08 & 4.57 & 2.21 & 3.46 & 1.78 \\
\hline \multicolumn{7}{|l|}{ Number of Nursing Programs } \\
\hline Total & 4.39 & 8.94 & 7.01 & 11.89 & 1.77 & 2.24 \\
\hline Public & 0.64 & 1.15 & 0.93 & 1.37 & 0.34 & 0.76 \\
\hline Private & 3.75 & 8.16 & 6.08 & 10.91 & 1.43 & 1.84 \\
\hline \multicolumn{7}{|l|}{ Nursing Licensure Exam (\%) } \\
\hline Examinees/Population & 0.533 & 1.048 & 0.821 & 1.303 & 0.244 & 0.579 \\
\hline Passers/Population & 0.235 & 0.439 & 0.366 & 0.552 & 0.104 & 0.214 \\
\hline \multicolumn{7}{|l|}{ Panel B. Pre-Expansion } \\
\hline \multicolumn{7}{|l|}{ Migrants Per 100,000 } \\
\hline Total & 70.71 & 107.91 & 122.52 & 133.26 & 18.90 & 13.52 \\
\hline U.S. Nurse & 1.81 & 2.50 & 3.07 & 2.93 & 0.55 & 0.87 \\
\hline Non-Nurse & 68.36 & 105.60 & 118.61 & 130.79 & 18.12 & 12.86 \\
\hline \multicolumn{7}{|c|}{ Postsecondary Enrollment Rates (\%) } \\
\hline Total & 20.34 & 14.53 & 24.85 & 16.75 & 15.78 & 10.01 \\
\hline Nurse & 0.86 & 1.46 & 1.35 & 1.63 & 0.37 & 1.06 \\
\hline Other & 19.47 & 13.62 & 23.50 & 15.72 & 15.41 & 9.54 \\
\hline \multicolumn{7}{|c|}{ Postsecondary Graduation Rates (\%) } \\
\hline Total & 3.77 & 2.56 & 4.36 & 2.55 & 3.18 & 2.44 \\
\hline Nurse & 0.12 & 0.21 & 0.18 & 0.22 & 0.06 & 0.18 \\
\hline Other & 3.65 & 2.41 & 4.18 & 2.38 & 3.12 & 2.33 \\
\hline \multicolumn{7}{|l|}{ Number of Nursing Programs } \\
\hline Total & 2.49 & 5.02 & 4.13 & 6.63 & 0.85 & 1.09 \\
\hline Public & 0.26 & 0.59 & 0.44 & 0.75 & 0.08 & 0.27 \\
\hline Private & 2.23 & 4.66 & 3.68 & 6.19 & 0.77 & 0.98 \\
\hline \multicolumn{7}{|l|}{ Nursing Licensure Exam (\%) } \\
\hline Examinees/Population & 0.245 & 0.409 & 0.380 & 0.410 & 0.109 & 0.361 \\
\hline Passers/Population & 0.139 & 0.223 & 0.216 & 0.240 & 0.063 & 0.174 \\
\hline Number of Provinces & \multicolumn{2}{|c|}{74} & \multicolumn{2}{|c|}{37} & \multicolumn{2}{|c|}{37} \\
\hline Observations (All years) & \multicolumn{2}{|c|}{1,702} & \multicolumn{2}{|c|}{851} & \multicolumn{2}{|c|}{851} \\
\hline
\end{tabular}

Notes: The sample includes all provinces in the Philippines based on 1990 geographic boundaries from 1991-2013 for the full sample and 19911999 for the pre-expansion sample. The unit of observation is the province-year. Graduation data are only available from 1998-2013. High (low) nurse migration provinces are those above or equal to (below) the median value of the U.S. nurse migration rate in 1990, as described in the text. Enrollment, graduation, and licensure rates are calculated using the population 18-22 as the denominator, while the migration rate uses the working aged population (ages 18-60).

Source: CHED, CFO, PRC, and authors' calculations. 
Appendix Table 3. Rates of Cross-Province Migration for Postsecondary Education

\begin{tabular}{cccccc}
\hline Census Year & All & Low to High & High to Low & High to High & Low to Low \\
\hline & $(1)$ & $(2)$ & $(3)$ & $(4)$ & $(5)$ \\
2000 & 8.01 & 1.70 & 0.74 & 4.80 & 0.77 \\
2007 & 7.78 & 1.14 & 0.23 & 5.56 & 0.81 \\
2010 & 7.27 & 1.73 & 0.33 & 4.33 & 0.87 \\
\hline
\end{tabular}

Notes: The rates of cross-province migration in Column 1 are calculated by dividing the nationwide number of college-aged (18-22) individuals attending college in a province other than where they reside by the nationwide number of college-aged individuals attending school overall. Columns 2 through 5 decompose this national rate into rates of cross-province migration between low nurse and high nurse migration provinces. For instance, in Column 2, the rates are calculated by dividing the number of students from low nurse migration provinces attending school in high nurse migration provinces by the total number of college-aged individuals attending school overall. Columns 3 through 5 follow a similar construction. 
Appendix Table 4. Hospitals and Barangay Health Stations Over Time

\begin{tabular}{|c|c|c|c|c|}
\hline \multirow{2}{*}{ Year } & \multicolumn{3}{|c|}{$\underline{\text { Hospitals }}$} & \multirow{2}{*}{$\begin{array}{c}\text { Barangay Health } \\
\text { Stations } \\
\end{array}$} \\
\hline & & & & \\
\hline & $(1)$ & $(2)$ & (3) & $(4)$ \\
\hline 1990 & 1,733 & 598 & 1,135 & - \\
\hline 1991 & 1,663 & 562 & 1,101 & 10,683 \\
\hline 1992 & 1,742 & 639 & 1,103 & 11,423 \\
\hline 1993 & 1,632 & 537 & 1,095 & 11,072 \\
\hline 1994 & 1,571 & 503 & 1,068 & 11,498 \\
\hline 1995 & 1,700 & 589 & 1,111 & 11,646 \\
\hline 1996 & 1,738 & 600 & 1,138 & 17,090 \\
\hline 1997 & 1,817 & 645 & 1,172 & 13,096 \\
\hline 1998 & 1,713 & 616 & 1,097 & 14,267 \\
\hline 1999 & 1,794 & 648 & 1,146 & 14,416 \\
\hline 2000 & 1,712 & 623 & 1,089 & 15,204 \\
\hline 2001 & 1,708 & 640 & 1,068 & 15,107 \\
\hline 2002 & 1,739 & 662 & 1,077 & 15,283 \\
\hline 2003 & 1,719 & 662 & 1,057 & 14,490 \\
\hline 2004 & 1,725 & 657 & 1,068 & 15,099 \\
\hline 2005 & 1,838 & 702 & 1,136 & 15,436 \\
\hline 2006 & 1,921 & 719 & 1,202 & 16,191 \\
\hline 2007 & 1,781 & 701 & 1,080 & 16,219 \\
\hline 2008 & 1,784 & 711 & 1,073 & 17,018 \\
\hline 2009 & 1,821 & 723 & 1,098 & - \\
\hline 2010 & 1,812 & 730 & 1,082 & 17,297 \\
\hline
\end{tabular}

Notes: Table lists the total number of hospitals and Barangay Health Stations in the Philippines by year. Data on the number of BHS are unavailable in 1990 and 2009. Source: Philippine Statistical Yearbook, 2012. 
Appendix Table 5. Pooled Event Study Estimates of Effect of Visa Expansion and Contraction on Nursing Education Outcomes by Gende

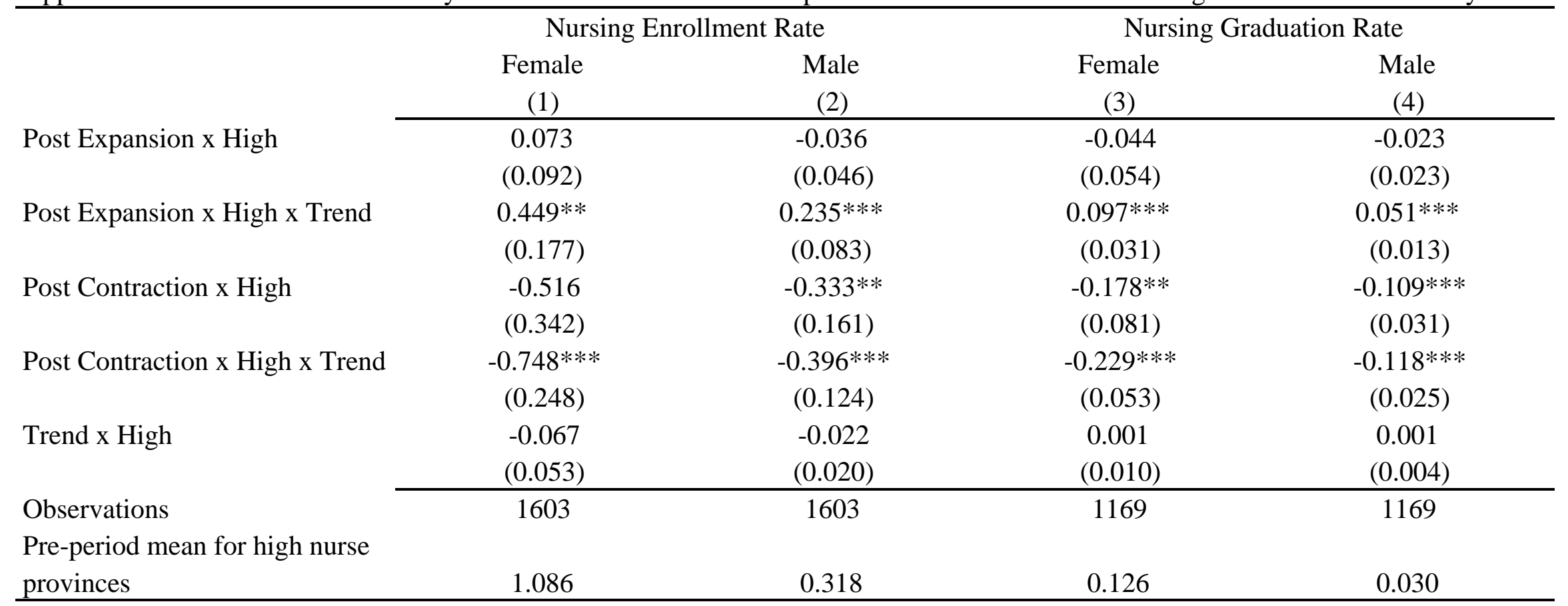

Notes: Table reports estimates of the pooled event study model (equation 2). Post Expansion is a binary variable equal to 1 if the year is 2000 or later and Post Contraction is a binary variable equal to 1 if the year is 2007 or laterfor all outcomes except graduation (Columns 1 and 2). Because it takes four years to graduate from college, for nurse graduation (Columns 3 and 4), Post Expansion is a binary variable equal to 1 if the year is 2003 or later, and Post Contraction is a binary variable equal to 1 if the year is 2010 or later. High is a binary variable for above median nurse migration to the U.S. in the base year 1990. The sample period is from 1991-2013 in columns 1 and 2, and 1997 is omitted because CHED did not college enrollment data by gender in that year. The sample period is from 1998-2013 in columns 3 and 4. Province and year fixed effects, as well as baseline controls interacted with year dummies as outlined in Figure 2 notes, are included in all specifications unless otherwise indicated. Robust standard errors are clustered at the province level. $* * * \mathrm{p}<0.01$, ${ }^{* *} \mathrm{p}<0.05,{ }^{*} \mathrm{p}<0.10$.

Sources: CFO, CHED, Census, and authors' calculations. 
Appendix Table 6. Effect of Visa Expansion and Contraction on Nursing Licensure Exam Pass Rates

\begin{tabular}{|c|c|c|c|c|}
\hline Year & $\begin{array}{c}\text { Passers out of } \\
\text { Population } \\
(1)\end{array}$ & $\begin{array}{c}\text { Examinees out of } \\
\text { Population } \\
(2) \\
\end{array}$ & $\begin{array}{c}\text { Pass Rate } \\
\text { (Column } 1 / \text { Column } \\
2 \text { ) } \\
(3) \\
\end{array}$ & $\begin{array}{c}\text { P-value, col 3=0.58 } \\
\text { (Pre-period pass } \\
\text { rate) } \\
(4)\end{array}$ \\
\hline Average Effect (2000-2013) & $\begin{array}{c}0.174 * * * \\
(0.050)\end{array}$ & $\begin{array}{c}0.453^{* * *} \\
(0.124)\end{array}$ & 0.384 & 0.000 \\
\hline 2000 & $\begin{array}{c}-0.020^{* * * *} \\
(0.006)\end{array}$ & $\begin{array}{c}-0.047 * * * \\
(0.013)\end{array}$ & 0.425 & 0.015 \\
\hline 2001 & $\begin{array}{c}-0.022^{* * *} \\
(0.008)\end{array}$ & $\begin{array}{c}-0.046 * * * \\
(0.015)\end{array}$ & 0.474 & 0.426 \\
\hline 2002 & $\begin{array}{c}-0.017^{* *} \\
(0.008)\end{array}$ & $\begin{array}{c}-0.034^{* *} \\
(0.015)\end{array}$ & 0.502 & 0.488 \\
\hline 2003 & $\begin{array}{l}-0.000 \\
(0.015)\end{array}$ & $\begin{array}{l}-0.000 \\
(0.023)\end{array}$ & 1.967 & 0.992 \\
\hline 2004 & $\begin{array}{l}0.041^{* *} \\
(0.020)\end{array}$ & $\begin{array}{l}0.084^{* *} \\
(0.040)\end{array}$ & 0.494 & 0.507 \\
\hline 2005 & $\begin{array}{c}0.122 * * \\
(0.053)\end{array}$ & $\begin{array}{l}0.225^{*} \\
(0.117)\end{array}$ & 0.541 & 0.648 \\
\hline 2006 & $\begin{array}{c}0.287 * * * \\
(0.103)\end{array}$ & $\begin{array}{c}0.657 * * \\
(0.293)\end{array}$ & 0.437 & 0.034 \\
\hline 2007 & $\begin{array}{c}0.357 * * * \\
(0.106)\end{array}$ & $\begin{array}{c}0.796 * * * \\
(0.278)\end{array}$ & 0.448 & 0.029 \\
\hline 2008 & $\begin{array}{c}0.846^{* * *} \\
(0.230)\end{array}$ & $\begin{array}{c}1.977 * * * \\
(0.599)\end{array}$ & 0.428 & 0.000 \\
\hline 2009 & $\begin{array}{c}0.415^{* * *} \\
(0.107)\end{array}$ & $\begin{array}{c}1.037 * * * \\
(0.295)\end{array}$ & 0.400 & 0.000 \\
\hline 2010 & $\begin{array}{c}0.392 * * * \\
(0.115)\end{array}$ & $\begin{array}{c}1.058^{* * *} \\
(0.325)\end{array}$ & 0.371 & 0.000 \\
\hline 2011 & $\begin{array}{c}0.370^{* * *} \\
(0.108)\end{array}$ & $\begin{array}{c}0.863 * * * \\
(0.273)\end{array}$ & 0.429 & 0.000 \\
\hline 2012 & $\begin{array}{c}0.228 * * * \\
(0.072)\end{array}$ & $\begin{array}{c}0.539 * * * \\
(0.187)\end{array}$ & 0.423 & 0.002 \\
\hline 2013 & $\begin{array}{c}0.100^{* *} \\
(0.044) \\
\end{array}$ & $\begin{array}{c}0.272^{* *} \\
(0.128) \\
\end{array}$ & 0.368 & 0.002 \\
\hline
\end{tabular}

Notes: An observation is the province-year, and the sample period is from 1991-2013. The first row of the table presents the coefficient on the interaction of the high nurse migration variable and a dummy variable equal to 1 in 2000 and later, and zero otherwise. This is the average effect of being in a high nurse migration province on the number passing the nursing licensure exam out of the college-aged population at baseline (Column 1) and on the number taking the nursing licensure exam out of the college-aged population at baseline (Column 2). The later rows show the results from the event study specification, and present the coefficients on each of the interactions of year and high from 2000 on. Column 3 calculates the implied pass rate by dividing Column 1 by Column 2 . Column 4 presents the p-value from a test of equality of Column 3 and the pre-period pass rate of 58\%. All specifications include year and province fixed effects, and baseline controls interacted with year fixed effects as specified in Figure 2 notes. Robust standard errors clustered at the province level are in parentheses. ${ }^{* * *} \mathrm{p}<0.01$, ${ }^{* *} \mathrm{p}<0.05,{ }^{*} \mathrm{p}<0.10$.

Sources: CFO, CHED, Census, PRC, and authors' calculations. 
Appendix Table 7. Effect of Visa Expansion and Contraction on Nursing Education Outcomes: Robustness Checks

\begin{tabular}{|c|c|c|c|c|c|}
\hline & $\begin{array}{c}\text { U.S. Nurse } \\
\text { Migrants Per } \\
100,000 \\
(1)\end{array}$ & $\begin{array}{l}\text { Nursing Enrollment } \\
\text { Rate } \\
(2)\end{array}$ & $\begin{array}{l}\text { Nursing Graduation } \\
\text { Rate } \\
\text { (3) }\end{array}$ & $\begin{array}{c}\text { Number of Nursing } \\
\text { Programs } \\
\text { (4) }\end{array}$ & $\begin{array}{l}\text { Total Graduation } \\
\text { Rate } \\
\text { (5) }\end{array}$ \\
\hline \multicolumn{6}{|l|}{ Panel A. Main specification } \\
\hline Post Expansion x High & $\begin{array}{l}2.632 * * \\
(1.030)\end{array}$ & $\begin{array}{l}1.380 * * * \\
(0.487)\end{array}$ & $\begin{array}{c}0.387 * * * \\
(0.114)\end{array}$ & $\begin{array}{l}1.176 * * \\
(0.552)\end{array}$ & $\begin{array}{l}0.558 * * \\
(0.278)\end{array}$ \\
\hline Post Contraction x High & $\begin{array}{l}-0.977 \\
(0.792)\end{array}$ & $\begin{array}{c}-0.127 \\
(0.159)\end{array}$ & $\begin{array}{c}0.015 \\
(0.070)\end{array}$ & $\begin{array}{l}1.246^{*} \\
(0.628)\end{array}$ & $\begin{array}{l}-0.305 \\
(0.282)\end{array}$ \\
\hline \multicolumn{6}{|c|}{ Panel B. Plus baseline non-nurse migration rate x year fixed effects } \\
\hline Post Expansion x High & $\begin{array}{l}2.722 * * * \\
(1.005)\end{array}$ & $\begin{array}{l}1.304^{* * *} \\
(0.470)\end{array}$ & $\begin{array}{c}0.365 * * * \\
(0.108)\end{array}$ & $\begin{array}{c}0.870 \\
(0.577)\end{array}$ & $\begin{array}{c}0.388 \\
(0.252)\end{array}$ \\
\hline Post Contraction x High & $\begin{array}{c}-1.792 * * \\
(0.798)\end{array}$ & $\begin{array}{l}-0.200 \\
(0.160)\end{array}$ & $\begin{array}{l}-0.089 \\
(0.072)\end{array}$ & $\begin{array}{c}0.686 \\
(0.641)\end{array}$ & $\begin{array}{l}-0.598 * \\
(0.317)\end{array}$ \\
\hline \multicolumn{6}{|l|}{ Panel C. Without Manila } \\
\hline Post Expansion x High & $\begin{array}{l}2.591 * * \\
(1.051)\end{array}$ & $\begin{array}{c}1.349 * * * \\
(0.491)\end{array}$ & $\begin{array}{c}0.380 * * * \\
(0.116)\end{array}$ & $\begin{array}{c}1.362 * * * \\
(0.372)\end{array}$ & $\begin{array}{l}0.555^{*} \\
(0.283)\end{array}$ \\
\hline Post Contraction $\mathrm{x}$ High & $\begin{array}{l}-0.968 \\
(0.792)\end{array}$ & $\begin{array}{l}-0.126 \\
(0.158)\end{array}$ & $\begin{array}{c}0.015 \\
(0.070)\end{array}$ & $\begin{array}{c}1.443^{* * *} \\
(0.438)\end{array}$ & $\begin{array}{l}-0.315 \\
(0.278)\end{array}$ \\
\hline \multicolumn{6}{|c|}{ Panel D. Plus additional controls $x$ year fixed effects } \\
\hline Post Expansion x High & $\begin{array}{c}3.137 * * \\
(1.411)\end{array}$ & $\begin{array}{l}1.501 * * \\
(0.691)\end{array}$ & $\begin{array}{l}0.340 * * \\
(0.161)\end{array}$ & $\begin{array}{c}0.509 \\
(0.801)\end{array}$ & $\begin{array}{l}0.624 * \\
(0.344)\end{array}$ \\
\hline Post Contraction x High & $\begin{array}{l}-1.789 * \\
(1.061)\end{array}$ & $\begin{array}{l}-0.110 \\
(0.183)\end{array}$ & $\begin{array}{c}0.030 \\
(0.084)\end{array}$ & $\begin{array}{c}0.346 \\
(0.815)\end{array}$ & $\begin{array}{l}-0.447 \\
(0.293)\end{array}$ \\
\hline \multicolumn{6}{|c|}{ Panel E. Plus additional controls x year fixed effects, without Manila } \\
\hline Post Expansion x High & $\begin{array}{c}3.010^{* *} \\
(1.405)\end{array}$ & $\begin{array}{l}1.399 * * \\
(0.675)\end{array}$ & $\begin{array}{l}0.315^{*} \\
(0.160)\end{array}$ & $\begin{array}{c}1.168 * * * \\
(0.387)\end{array}$ & $\begin{array}{l}0.609 * \\
(0.363)\end{array}$ \\
\hline Post Contraction $\mathrm{x}$ High & $\begin{array}{l}-1.798 * \\
(1.056)\end{array}$ & $\begin{array}{l}-0.103 \\
(0.177)\end{array}$ & $\begin{array}{c}0.032 \\
(0.086)\end{array}$ & $\begin{array}{l}1.019 * * \\
(0.419)\end{array}$ & $\begin{array}{l}-0.493 \\
(0.299)\end{array}$ \\
\hline \multicolumn{6}{|c|}{ Panel F. Plus island $x$ year fixed effects } \\
\hline Post Expansion x High & $\begin{array}{c}3.230 * * * \\
(0.912)\end{array}$ & $\begin{array}{c}1.488 * * * \\
(0.426)\end{array}$ & $\begin{array}{c}0.430 * * * \\
(0.095)\end{array}$ & $\begin{array}{c}0.892 \\
(0.669)\end{array}$ & $\begin{array}{c}0.252 \\
(0.260)\end{array}$ \\
\hline Post Contraction x High & $\begin{array}{c}-1.449 * * \\
(0.719)\end{array}$ & $\begin{array}{l}-0.194 \\
(0.162)\end{array}$ & $\begin{array}{l}-0.018 \\
(0.063)\end{array}$ & $\begin{array}{c}0.789 \\
(0.755)\end{array}$ & $\begin{array}{l}-0.313 \\
(0.273)\end{array}$ \\
\hline \multicolumn{6}{|c|}{ Panel G. Continuous Treatment Measure: Baseline Nurse Migration Rate } \\
\hline $\begin{array}{l}\text { Post Expansion x Baseline } \\
\text { Nurse Migration Rate }\end{array}$ & $\begin{array}{l}2.318^{* *} \\
(1.030)\end{array}$ & $\begin{array}{l}1.157 * * \\
(0.485)\end{array}$ & $\begin{array}{l}0.263^{* * *} \\
(0.088)\end{array}$ & $\begin{array}{c}0.814 \\
(0.651)\end{array}$ & $\begin{array}{l}0.403^{* *} \\
(0.197)\end{array}$ \\
\hline $\begin{array}{l}\text { Post Contraction x } \\
\text { Baseline Nurse Migration } \\
\text { Rate }\end{array}$ & $\begin{array}{l}-0.287 \\
(0.933)\end{array}$ & $\begin{array}{c}-0.103 \\
(0.141)\end{array}$ & $\begin{array}{c}0.101 \\
(0.080)\end{array}$ & $\begin{array}{l}1.152 * \\
(0.675)\end{array}$ & $\begin{array}{c}-0.041 \\
(0.409)\end{array}$ \\
\hline
\end{tabular}

Notes: An observation is the province-year. For Columns 1, 2, and 4, Post Expansion is a binary variable equal to 1 if the year is 2000 or later, while Post Contraction is a variable equal to 1 if the year is 2007 or later. Because it takes four years to graduate from college, for the graduation results (Columns 3 and 5), Post Expansion is a binary variable equal to 1 if the year is 2003 or later, and Post Contraction is a binary variable equal to 1 if the year is 2010 or greater. High is defined as in Table 2 . All specifications include year and province fixed effects, and baseline controls interacted with year fixed effects as specified in Figure 2 notes. Panel B adds the baseline non-nurse migration rate $\mathrm{x}$ year fixed effects to Panel A. Panel C is the specification estimated in Panel A without Manila. Panels D and E add controls to Panel A: 1) average years of schooling for 25- to 64-year-olds and 2) the share of households that are urban, each times year fixed effects. Panel F adds island x year fixed effects to Panel A. Panel G interacts the post expansion and post contraction dummy variables with a continuous measure of the baseline nurse migration rate instead of the dummy variable High. The results are scaled to represent the effect of a one standard deviation increase in baseline nurse migration. Robust standard errors clustered at the province level are in parentheses. ${ }^{* * *} \mathrm{p}<0.01,{ }^{* *} \mathrm{p}<0.05,{ }^{*} \mathrm{p}<0.10$.

Sources: CFO, CHED, Census, and authors' calculations. 
Appendix Table 8. Robustness Checks of Effect of Visa Expansion and Contraction on Nursing Education Outcomes, Pooled Estimates

\begin{tabular}{|c|c|c|c|c|c|}
\hline & $\begin{array}{c}\text { U.S. Nurse } \\
\text { Migration Rate } \\
(1) \\
\end{array}$ & $\begin{array}{c}\text { Nursing Enrollment } \\
\text { Rate } \\
(2) \\
\end{array}$ & $\begin{array}{c}\text { Nursing Graduation } \\
\text { Rate } \\
(3) \\
\end{array}$ & $\begin{array}{c}\text { Number of Nursing } \\
\text { Programs } \\
(4) \\
\end{array}$ & $\begin{array}{l}\text { Total Graduation } \\
\text { Rate } \\
(5) \\
\end{array}$ \\
\hline \multicolumn{6}{|l|}{ Panel A. Main specification } \\
\hline Post Expansion x High & $\begin{array}{l}1.211^{*} \\
(0.646)\end{array}$ & $\begin{array}{c}0.045 \\
(0.133)\end{array}$ & $\begin{array}{l}-0.067 \\
(0.074)\end{array}$ & $\begin{array}{l}-0.226 \\
(0.296)\end{array}$ & $\begin{array}{c}0.183 \\
(0.363)\end{array}$ \\
\hline Post Expansion x High x Trend & $\begin{array}{c}0.755^{* * * *} \\
(0.267)\end{array}$ & $\begin{array}{c}0.685 * * \\
(0.261)\end{array}$ & $\begin{array}{c}0.148 * * * \\
(0.043)\end{array}$ & $\begin{array}{c}0.396 * * \\
(0.187)\end{array}$ & $\begin{array}{l}-0.117 \\
(0.242)\end{array}$ \\
\hline Post Contraction x High & $\begin{array}{c}-4.200^{* *} \\
(1.760)\end{array}$ & $\begin{array}{l}-0.850 * \\
(0.497)\end{array}$ & $\begin{array}{c}-0.287 * * * \\
(0.108)\end{array}$ & $\begin{array}{l}-0.270 \\
(0.251)\end{array}$ & $\begin{array}{c}0.364 \\
(0.264)\end{array}$ \\
\hline Post Contraction x High x Trend & $\begin{array}{c}-0.441^{* *} \\
(0.218)\end{array}$ & $\begin{array}{c}-1.144^{* * *} \\
(0.371)\end{array}$ & $\begin{array}{c}-0.348 * * * \\
(0.077)\end{array}$ & $\begin{array}{l}-0.481^{*} \\
(0.250)\end{array}$ & $\begin{array}{l}-0.205^{*} \\
(0.104)\end{array}$ \\
\hline Trend x High & $\begin{array}{c}-0.105^{* * *} \\
(0.039)\end{array}$ & $\begin{array}{l}-0.091 \\
(0.073)\end{array}$ & $\begin{array}{c}0.002 \\
(0.014)\end{array}$ & $\begin{array}{c}0.027 \\
(0.038)\end{array}$ & $\begin{array}{c}0.177 \\
(0.233)\end{array}$ \\
\hline \multicolumn{6}{|c|}{ Panel B. Plus baseline non-nurse migration rate $x$ year fixed effects } \\
\hline Post Expansion x High & $\begin{array}{r}1.312^{* *} \\
(0.649)\end{array}$ & $\begin{array}{c}0.096 \\
(0.132)\end{array}$ & $\begin{array}{l}-0.005 \\
(0.074)\end{array}$ & $\begin{array}{l}-0.108 \\
(0.327)\end{array}$ & $\begin{array}{l}0.019 \\
(0.356)\end{array}$ \\
\hline Post Expansion x High x Trend & $\begin{array}{c}0.728 * * * \\
(0.253)\end{array}$ & $\begin{array}{c}0.669 * * * \\
(0.242)\end{array}$ & $\begin{array}{c}0.115^{* * *} \\
(0.040)\end{array}$ & $\begin{array}{c}0.268 \\
(0.200)\end{array}$ & $\begin{array}{l}-0.216 \\
(0.228)\end{array}$ \\
\hline Post Contraction x High & $\begin{array}{c}-4.699 * * * \\
(1.709)\end{array}$ & $\begin{array}{l}-0.895^{*} \\
(0.465)\end{array}$ & $\begin{array}{c}-0.319 * * * \\
(0.110)\end{array}$ & $\begin{array}{l}-0.317 \\
(0.255)\end{array}$ & $\begin{array}{c}0.160 \\
(0.283)\end{array}$ \\
\hline Post Contraction x High x Trend & $\begin{array}{c}-0.504 * * \\
(0.208)\end{array}$ & $\begin{array}{c}-1.093^{* * *} \\
(0.351)\end{array}$ & $\begin{array}{c}-0.283^{* * *} \\
(0.071)\end{array}$ & $\begin{array}{l}-0.341 \\
(0.267)\end{array}$ & $\begin{array}{c}-0.235^{* *} \\
(0.110)\end{array}$ \\
\hline Trend x High & $\begin{array}{c}-0.097 * * \\
(0.040)\end{array}$ & $\begin{array}{l}-0.101 \\
(0.069)\end{array}$ & $\begin{array}{c}0.005 \\
(0.013)\end{array}$ & $\begin{array}{c}0.022 \\
(0.042)\end{array}$ & $\begin{array}{c}0.267 \\
(0.220)\end{array}$ \\
\hline \multicolumn{6}{|l|}{ Panel C. Without Manila } \\
\hline Post Expansion x High & $\begin{array}{l}1.197 * \\
(0.646)\end{array}$ & $\begin{array}{c}0.042 \\
(0.134)\end{array}$ & $\begin{array}{l}-0.070 \\
(0.074)\end{array}$ & $\begin{array}{l}-0.321 \\
(0.199)\end{array}$ & $\begin{array}{c}0.174 \\
(0.368)\end{array}$ \\
\hline Post Expansion x High x Trend & $\begin{array}{c}0.755^{* * * *} \\
(0.269)\end{array}$ & $\begin{array}{c}0.679 * * \\
(0.262)\end{array}$ & $\begin{array}{c}0.146^{* * * *} \\
(0.044)\end{array}$ & $\begin{array}{c}0.461^{* * * *} \\
(0.121)\end{array}$ & $\begin{array}{l}-0.114 \\
(0.244)\end{array}$ \\
\hline Post Contraction x High & $\begin{array}{c}-4.166 * * \\
(1.786)\end{array}$ & $\begin{array}{c}-0.842 * \\
(0.494)\end{array}$ & $\begin{array}{c}-0.284^{* *} \\
(0.108)\end{array}$ & $\begin{array}{c}-0.340 \\
(0.210)\end{array}$ & $\begin{array}{c}0.361 \\
(0.264)\end{array}$ \\
\hline Post Contraction x High x Trend & $\begin{array}{c}-0.442 * * \\
(0.219)\end{array}$ & $\begin{array}{c}-1.129 * * * \\
(0.373)\end{array}$ & $\begin{array}{c}-0.344^{* * * *} \\
(0.078)\end{array}$ & $\begin{array}{c}-0.569 * * * \\
(0.155)\end{array}$ & $\begin{array}{c}-0.209 * * \\
(0.103)\end{array}$ \\
\hline Trend x High & $\begin{array}{c}-0.109 * * * \\
(0.036)\end{array}$ & $\begin{array}{l}-0.092 \\
(0.074)\end{array}$ & $\begin{array}{c}0.002 \\
(0.014)\end{array}$ & $\begin{array}{c}0.038 \\
(0.029)\end{array}$ & $\begin{array}{l}0.175 \\
(0.234)\end{array}$ \\
\hline \multicolumn{6}{|c|}{ Panel D. Plus additional controls $x$ year fixed effects } \\
\hline Post Expansion x High & $\begin{array}{l}1.381 * \\
(0.829)\end{array}$ & $\begin{array}{l}0.006 \\
(0.176)\end{array}$ & $\begin{array}{l}-0.066 \\
(0.107)\end{array}$ & $\begin{array}{c}0.392 \\
(0.373)\end{array}$ & $\begin{array}{c}0.425 \\
(0.436)\end{array}$ \\
\hline Post Expansion x High x Trend & $\begin{array}{r}0.825^{* *} \\
(0.338)\end{array}$ & $\begin{array}{l}0.613 * \\
(0.367)\end{array}$ & $\begin{array}{r}0.121^{* *} \\
(0.056)\end{array}$ & $\begin{array}{c}0.141 \\
(0.277)\end{array}$ & $\begin{array}{l}-0.030 \\
(0.289)\end{array}$ \\
\hline Post Contraction x High & $\begin{array}{c}-5.220 * * \\
(2.361)\end{array}$ & $\begin{array}{l}-0.843 \\
(0.686)\end{array}$ & $\begin{array}{l}-0.224 \\
(0.135)\end{array}$ & $\begin{array}{l}-0.065 \\
(0.355)\end{array}$ & $\begin{array}{c}0.319 \\
(0.304)\end{array}$ \\
\hline Post Contraction x High x Trend & $\begin{array}{c}-0.572 * * \\
(0.282)\end{array}$ & $\begin{array}{c}-1.080 * * \\
(0.521)\end{array}$ & $\begin{array}{c}-0.302^{* * *} \\
(0.095)\end{array}$ & $\begin{array}{l}-0.103 \\
(0.363)\end{array}$ & $\begin{array}{c}-0.235^{* *} \\
(0.113)\end{array}$ \\
\hline Trend x High & $\begin{array}{l}-0.090 * \\
(0.046)\end{array}$ & $\begin{array}{l}-0.044 \\
(0.096)\end{array}$ & $\begin{array}{c}0.007 \\
(0.018) \\
\end{array}$ & $\begin{array}{c}-0.038 \\
(0.050) \\
\end{array}$ & $\begin{array}{c}0.098 \\
(0.288)\end{array}$ \\
\hline
\end{tabular}

Continued on next page. 
Appendix Table 8. (continued)

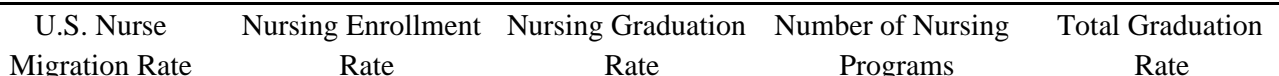

\begin{tabular}{|c|c|c|c|c|c|}
\hline & $\begin{array}{l}\text { Migration Rate } \\
\text { (1) }\end{array}$ & $\begin{array}{l}\text { Rate } \\
(2)\end{array}$ & $\begin{array}{c}\text { Rate } \\
\text { (3) }\end{array}$ & $\begin{array}{c}\text { Programs } \\
\text { (4) }\end{array}$ & $\begin{array}{l}\text { Rate } \\
(5)\end{array}$ \\
\hline \multicolumn{6}{|c|}{ Panel E. Plus additional controls $x$ year fixed effects, without Manila } \\
\hline Post Expansion x High & $\begin{array}{l}1.345^{*} \\
(0.801)\end{array}$ & $\begin{array}{l}-0.005 \\
(0.181)\end{array}$ & $\begin{array}{l}-0.072 \\
(0.110)\end{array}$ & $\begin{array}{c}0.065 \\
(0.195)\end{array}$ & $\begin{array}{c}0.394 \\
(0.442)\end{array}$ \\
\hline Post Expansion x High x Trend & $\begin{array}{r}0.827^{* *} \\
(0.348)\end{array}$ & $\begin{array}{c}0.591 \\
(0.366)\end{array}$ & $\begin{array}{r}0.116^{* *} \\
(0.056)\end{array}$ & $\begin{array}{r}0.368^{* *} \\
(0.146)\end{array}$ & $\begin{array}{l}-0.021 \\
(0.297)\end{array}$ \\
\hline Post Contraction x High & $\begin{array}{c}-5.129 * * \\
(2.394)\end{array}$ & $\begin{array}{l}-0.817 \\
(0.661)\end{array}$ & $\begin{array}{c}-0.212 \\
(0.136)\end{array}$ & $\begin{array}{l}-0.327 \\
(0.242)\end{array}$ & $\begin{array}{c}0.299 \\
(0.304)\end{array}$ \\
\hline Post Contraction x High x Trend & $\begin{array}{l}-0.582 * \\
(0.292)\end{array}$ & $\begin{array}{l}-1.027^{*} \\
(0.516)\end{array}$ & $\begin{array}{c}-0.287 * * * \\
(0.093)\end{array}$ & $\begin{array}{c}-0.409 * * \\
(0.167)\end{array}$ & $\begin{array}{c}-0.247^{* *} \\
(0.114)\end{array}$ \\
\hline Trend $\mathrm{x}$ High & $\begin{array}{c}-0.102 * * \\
(0.042)\end{array}$ & $\begin{array}{l}-0.047 \\
(0.100)\end{array}$ & $\begin{array}{c}0.007 \\
(0.019)\end{array}$ & $\begin{array}{l}-0.000 \\
(0.031)\end{array}$ & $\begin{array}{l}0.091 \\
(0.296)\end{array}$ \\
\hline \multicolumn{6}{|c|}{ Panel F. Plus island $x$ year fixed effects } \\
\hline Post Expansion x High & $\begin{array}{l}1.005^{*} \\
(0.600)\end{array}$ & $\begin{array}{c}0.165 \\
(0.106)\end{array}$ & $\begin{array}{l}-0.014 \\
(0.067)\end{array}$ & $\begin{array}{l}-0.012 \\
(0.366)\end{array}$ & $\begin{array}{l}-0.080 \\
(0.372)\end{array}$ \\
\hline Post Expansion x High x Trend & $\begin{array}{c}0.864 * * * \\
(0.226)\end{array}$ & $\begin{array}{c}0.748 * * * \\
(0.211)\end{array}$ & $\begin{array}{c}0.150 * * * \\
(0.037)\end{array}$ & $\begin{array}{l}0.267 \\
(0.235)\end{array}$ & $\begin{array}{l}-0.166 \\
(0.245)\end{array}$ \\
\hline Post Contraction x High & $\begin{array}{c}-5.475^{* * *} \\
(1.501)\end{array}$ & $\begin{array}{c}-0.888 * \\
(0.465)\end{array}$ & $\begin{array}{c}-0.308 * * * \\
(0.099)\end{array}$ & $\begin{array}{l}-0.282 \\
(0.282)\end{array}$ & $\begin{array}{l}0.306 \\
(0.321)\end{array}$ \\
\hline Post Contraction x High x Trend & $\begin{array}{c}-0.567 * * * \\
(0.185)\end{array}$ & $\begin{array}{c}-1.238 * * * \\
(0.307)\end{array}$ & $\begin{array}{c}-0.356 * * * \\
(0.065)\end{array}$ & $\begin{array}{l}-0.295 \\
(0.304)\end{array}$ & $\begin{array}{l}-0.145 \\
(0.095)\end{array}$ \\
\hline Trend $x$ High & $\begin{array}{l}-0.046 \\
(0.036)\end{array}$ & $\begin{array}{c}-0.116^{* *} \\
(0.053)\end{array}$ & $\begin{array}{l}-0.000 \\
(0.012)\end{array}$ & $\begin{array}{c}0.013 \\
(0.044)\end{array}$ & $\begin{array}{c}0.184 \\
(0.236)\end{array}$ \\
\hline \multicolumn{6}{|c|}{ Panel G. Continuous Treatment Measure: Baseline Nurse Migration Rate } \\
\hline Post Expansion x Baseline Nurse & $1.595^{*}$ & $1.331^{* *}$ & 0.076 & 0.231 & 0.517 \\
\hline Migration Rate & $(0.856)$ & $(0.563)$ & $(0.080)$ & $(0.188)$ & $(0.313)$ \\
\hline Post Expansion x Baseline Nurse & $0.416^{* * *}$ & 0.109 & $0.084^{* * *}$ & $0.135^{*}$ & 0.094 \\
\hline Migration Rate x Trend & $(0.124)$ & $(0.073)$ & $(0.023)$ & $(0.068)$ & $(0.148)$ \\
\hline Post Contraction x Baseline Nurse & -2.462 & -0.439 & $-0.281^{* *}$ & -0.389 & 0.455 \\
\hline Migration Rate & $(1.521)$ & $(0.362)$ & $(0.110)$ & $(0.285)$ & $(0.281)$ \\
\hline Post Contraction x Baseline Nurse & $0.000^{* *}$ & -0.000 & 0.000 & $-0.001 *$ & 0.000 \\
\hline Migration Rate x Trend & $(0.000)$ & $(0.000)$ & $(0.000)$ & $(0.000)$ & $(0.000)$ \\
\hline Trend x Baseline Nurse Migration & $-0.066^{*}$ & -0.063 & -0.011 & 0.022 & -0.101 \\
\hline Rate & $(0.037)$ & $(0.053)$ & $(0.010)$ & $(0.038)$ & $(0.142)$ \\
\hline
\end{tabular}

Notes: An observation is the province-year. Table reports estimates of the pooled event study model (equation 2). All variables are as defined in Table 2. All specifications include year and province fixed effects, and baseline controls interacted with year fixed effects as specified in Figure 2 notes. Panel B adds the baseline non-nurse migration rate x year fixed effects to Panel A. Panel C is the specification estimated in Panel A without Manila. Panels D and E add controls to Panel A: 1.) average years of schooling for 25-to 64-year-olds and 2.) the share of households that are urban, each times year fixed effects. Panel F adds island x year fixed effects to Panel A. Panel G uses the continuous measure of the baseline nurse migration rate instead of the binary variable $\mathrm{High}$. The results are scaled to represent the effect of a one standard deviation increase in baseline nurse migration. Robust standard errors clustered at the province level are in parentheses. ${ }^{* * *} \mathrm{p}<0.01,{ }^{* *} \mathrm{p}<0.05$, ${ }^{*} \mathrm{p}<0.10$. Sources: CFO, CHED, Census, PRC, and authors' calculations. 
Appendix Table 9. Coefficients of Relative Risk Aversion and Certainty Equivalents

\begin{tabular}{lccccc}
\hline Value of $\boldsymbol{Y}$ & 0.5 & 1.2 & 1.5 & 2 & 2.5 \\
Value of $\mathrm{w}_{\mathrm{CE}}$ & 6,205 & 5,091 & 4,844 & 4,565 & 4,374 \\
\hline
\end{tabular}

Notes: The values of the certainty equivalent $\mathrm{w}_{\mathrm{CE}}$ are calculated using equation 3 under the various values of the coefficient of relative risk aversion, $\boldsymbol{\gamma}$. 